\title{
An Evidence-Based Systematic Review of Human Knee Post-Traumatic Osteoarthritis (PTOA): Timeline of Clinical Presentation and Disease Markers, Comparison of Knee Joint PTOA Models and Early Disease Implications
}

\author{
Christine M. Khella, Rojiar Asgarian (D), Judith M. Horvath, Bernd Rolauffs (D) and Melanie L. Hart*(D)
}

Citation: Khella, C.M.; Asgarian, R.; Horvath, J.M.; Rolauffs, B.; Hart, M.L. An Evidence-Based Systematic Review of Human Knee Post-Traumatic Osteoarthritis (PTOA): Timeline of Clinical Presentation and Disease Markers, Comparison of Knee Joint PTOA Models and Early Disease Implications. Int. J. Mol. Sci. 2021, 22, 1996. https://doi.org/10.3390/ ijms22041996

Academic Editor: Walter Herzog Received: 16 December 2020

Accepted: 8 February 2021

Published: 17 February 2021

Publisher's Note: MDPI stays neutra with regard to jurisdictional claims in published maps and institutional affiliations.

Copyright: (c) 2021 by the authors. Licensee MDPI, Basel, Switzerland. This article is an open access article distributed under the terms and conditions of the Creative Commons Attribution (CC BY) license (https:// creativecommons.org/licenses/by/ $4.0 /)$.
G.E.R.N. Center for Tissue Replacement, Regeneration \& Neogenesis, Department of Orthopedics and Trauma Surgery, Faculty of Medicine, Medical Center-Albert-Ludwigs-University of Freiburg,

79085 Freiburg im Breisgau, Germany; christine.mounir86@gmail.com (C.M.K.); r0jiar.asgarian@gmail.com (R.A.); judith.m.horvath@gmail.com (J.M.H.); bernd.rolauffs@uniklinik-freiburg.de (B.R.)

* Correspondence: melanie.lynn.hart@uniklinik-freiburg.de; Tel.: +49-761-2702-6102

\begin{abstract}
Understanding the causality of the post-traumatic osteoarthritis (PTOA) disease process of the knee joint is important for diagnosing early disease and developing new and effective preventions or treatments. The aim of this review was to provide detailed clinical data on inflammatory and other biomarkers obtained from patients after acute knee trauma in order to (i) present a timeline of events that occur in the acute, subacute, and chronic post-traumatic phases and in PTOA, and (ii) to identify key factors present in the synovial fluid, serum/plasma and urine, leading to PTOA of the knee in $23-50 \%$ of individuals who had acute knee trauma. In this context, we additionally discuss methods of simulating knee trauma and inflammation in in vivo, ex vivo articular cartilage explant and in vitro chondrocyte models, and answer whether these models are representative of the clinical inflammatory stages following knee trauma. Moreover, we compare the pro-inflammatory cytokine concentrations used in such models and demonstrate that, compared to concentrations in the synovial fluid after knee trauma, they are exceedingly high. We then used the Bradford Hill Framework to present evidence that TNF- $\alpha$ and IL- 6 cytokines are causal factors, while IL- $1 \beta$ and IL-17 are credible factors in inducing knee PTOA disease progresssion. Lastly, we discuss beneficial infrastructure for future studies to dissect the role of local vs. systemic inflammation in PTOA progression with an emphasis on early disease.
\end{abstract}

Keywords: chondrocyte; articular cartilage; osteoarthritis; post-traumatic osteoarthritis; immunomodulation; acute; subacute; chronic; inflammation; early PTOA; cartilage repair; clinical; knee trauma; knee joint; injury; inflammatory cytokines; synovial fluid; in vitro models; cartilage; IL-1 $\beta$; TNF- $\alpha$; IL-6; IL-17; complement; Bradford Hill; early disease

\section{Introduction}

Osteoarthritis (OA) is the most prevalent form of joint disease and one of the leading causes of disability affecting 630 million people worldwide [1]. While OA is considered an age-related disease, it also affects younger individuals with $8 \%$ of the population aged $18-44,30 \%$ of the population aged $45-64$ and $50 \%$ of individuals over 65 years of age having OA. Joint trauma is a major cause of this degenerative disease and, astoundingly, $23 \%$ to $50 \%$ of the people that suffer a trauma to the knee joint eventually develop post-traumatic osteoarthritis (PTOA) [2-8]. Those with prior knee joint trauma are 3 to 6 times more likely to develop PTOA and were diagnosed 10 years earlier than those without any history of an injury $[1,9,10]$.

Inflammation has been shown to be play a role in the pathogenesis of OA [11-13] or PTOA [14-18] in general. While other reviews suggest a general timeline of the pathogenic response following joint injury, they do not (a) focus solely on a particular joint (i.e., acute 
knee joint injury), and/or (b) do not provide a detailed clinical inflammatory timeline and sequence of events of inflammatory and other mediators present in the synovial fluid (SF), serum, plasma and urine following knee trauma. Moreover, a detailed review that relates the available detailed knowledge derived from basic science studies, which simulate injury and induce inflammation, with data of clinically orientated studies is lacking but would be beneficial to identify types and concentrations of inflammatory mediators in post-traumatic patient tissues related to the knee joint and/or fluids. The objective of this review was, therefore, to develop a timeline of events after knee trauma from early acute inflammation to development of final end-stage clinical PTOA and to compare the clinical stages of inflammation to the in vivo and in vitro/ex vivo models of injury and/or inflammation. The aim was to identify key inflammatory inducers of knee PTOA and to determine if the models as well the concentrations of inflammatory cytokines commonly used to induce inflammation are representative of clinical knee PTOA. We also discuss beneficial infrastructure for future studies to dissect the role of local vs. systemic inflammation in PTOA progression of the knee joint with an emphasis on early disease.

\section{Methodology}

In preparing this systematic review, eligible articles were identified using PubMed, Medline, Cochrane Library, Google Scholar, Web of Science databases, and by handsearching. The following inclusion criteria were used: (1) peer-reviewed studies that were published in the English language and, unless otherwise stated, (2) clinical samples that were obtained from the knee joint or from the SF, serum, plasma or urine following acute knee trauma from patients having no history of a previous knee injury; (3) in vivo PTOA models of the knee joint that applied insult/injury and/or inflammatory cytokines (chemically induced models of injury were excluded), and (4) in vitro chondrocyte and cartilage ex vivo explant models that used cells, cartilage, SF and/or the joint capsule obtained or isolated exclusively from the knee joint.

Each clinical study was assessed for quality using the National Institute of Health (NIH) Study Quality Assessment Tool, which can be accessed at URL: www.nhlbi.nih.gov / health-topics/study-quality-assessment-tools (accessed on 14 November 2020). This tool is widely used for critically appraising cohort and cross-sectional studies and consists of 14 questions, of which most can be answered with "yes" (assigned a value of 1) or "no" (assigned a value of 0 ). Other possible answers were not reported (NR) and not applicable (NA). Based on the total score, the quality assessment was defined as 0-5 (poor), 6-9 (fair) or 10-14 (good).

The Bradford Hill Framework provides nine criteria for establishing epidemiologic evidence of a causal relationship between an exposure and an observed effect [19]. We used this framework to evaluate the relationship between the presence of inflammatory markers (IL-1 $\beta$, TNF- $\alpha$, IL- 6 or IL-17) after knee trauma and PTOA disease progression. The criteria, which are widely used in public health research and have stayed virtually unchanged since it was first published, are as follows: strength of the association, consistency of findings, specificity of the association, temporal sequence of association, biological gradient, biological plausibility, coherence, experimental evidence and analogy. Using this framework, we determined whether IL-1 $\beta$, TNF- $\alpha$, IL-6, and/or IL-17 led to a convincing, credible or probable causal PTOA disease effect, or whether the evidence was suggestive, limited, or inconclusive. The evidence collected for each viewpoint is presented with a final judgement as to whether the nine criteria were fulfilled or not.

Because we noted that each clinical assessment chose a different time range for the collection of clinical samples, in this review we defined acute inflammation as inflammation occurring directly after knee injury and lasting for up to 2 weeks, subacute inflammation as the time between acute and chronic inflammation lasting 2 to 6 weeks, and chronic inflammation, as prolonged inflammation exhibited by a significant increase in inflammatory markers, lasting for prolonged periods from greater than 6 weeks to years following knee injury [20]. 


\section{Results of the Clinical Studies That Measured Inflammatory and Other Key Biochemical Biomarkers in Patients Who Have Had Knee Trauma}

The quality assessment results of the clinical knee injury studies included in this systematic review demonstrate that all of the included studies were of good or fair quality (Table 1). The main limitations and reasons for scores of zero were due to a lack of a power calculation or justification of sample size, the absence of a blinded outcome assessment, and/or not considering possible confounding factors in the analysis. The confounding factors are listed in Table 2 along with the types of injury, the group in which injury samples were compared, the post-traumatic phase (acute, subacute, chronic, and/or PTOA), the markers measured after knee trauma, the age, cohort size, and the number of males/females that were included in the studies.

Table 1. Quality assessment results of the clinical observational cohort and cross-sectional knee injury studies included in this review. Quality was assessed using the (NIH) Study Quality Assessment Tool and guidelines. Abbreviations: Question $(\mathrm{Q})$, yes $(\mathrm{Y})$, no $(\mathrm{N})$, not applicable (NA) or not reported (NR). Yes answers are given a score of 1 and no answers a score of 0 . The study quality is defined as 0-5 (poor); 6-9 (fair): 10-14 (good).

\begin{tabular}{cccccccccccccccccc}
\hline Study & $\mathbf{Q 1}$ & $\mathbf{Q}$ & $\mathbf{Q}$ & $\mathbf{Q}$ & $\mathbf{Q}$ & $\mathbf{Q}$ & $\mathbf{Q}$ & $\mathbf{Q}$ & $\mathbf{Q}$ & $\mathbf{Q}$ & $\mathbf{Q}$ & $\mathbf{Q}$ & $\mathbf{Q}$ & $\mathbf{Q}$ & Score & Quality \\
& & $\mathbf{2}$ & $\mathbf{3}$ & $\mathbf{4}$ & $\mathbf{5}$ & $\mathbf{6}$ & $\mathbf{7}$ & $\mathbf{8}$ & $\mathbf{9}$ & $\mathbf{1 0}$ & $\mathbf{1 1}$ & $\mathbf{1 2}$ & $\mathbf{1 3}$ & $\mathbf{1 4}$ & good \\
Haller [21] & 1 & 1 & 0 & 1 & 0 & 1 & 1 & 1 & 1 & NA & 1 & 1 & 1 & 0 & 10 & good \\
Haller [22] & 1 & 1 & 0 & 1 & 0 & 1 & 1 & 1 & 1 & NA & 1 & 1 & 1 & 0 & 10 & good \\
Swärd [23] & 1 & 1 & 1 & 0 & 0 & 1 & 1 & 1 & 1 & NA & 1 & NR & 1 & 1 & 10 & good \\
Bigoni [24] & 1 & 1 & 1 & 1 & 0 & 1 & 1 & 1 & 1 & NA & 1 & NR & 1 & 0 & 10 & fair \\
Irie [25] & 1 & 1 & 1 & 1 & 0 & 1 & 1 & 1 & 1 & NA & 0 & NR & 0 & 0 & 8 & good \\
Elsaid [26] & 1 & 1 & 1 & 1 & 1 & 1 & 1 & 1 & 1 & NA & 0 & NR & 0 & 1 & 10 & fair \\
Catterall [27] & 1 & 1 & 1 & 0 & 0 & 1 & 1 & 0 & 1 & NA & 0 & NR & 1 & 0 & 7 & good \\
Watt [28] & 1 & 1 & 1 & 1 & 1 & 1 & 1 & 1 & 1 & NA & 1 & NR & 1 & 1 & 12 & fair \\
Lattermann [29] & 1 & 1 & 1 & 0 & 0 & 1 & 1 & 0 & 1 & NA & 1 & NR & U & 0 & 7 & good \\
Dahlberg [30] & 1 & 1 & 1 & 1 & 0 & 1 & 1 & 1 & 1 & NA & 1 & NR & 1 & 0 & 10 & fair \\
Higuchi [31] & 1 & 1 & 1 & 0 & 0 & 1 & 1 & 1 & 1 & NA & 1 & NR & 1 & 0 & 9 & fair \\
Struglics [32] & 1 & 1 & 1 & 0 & $\mathrm{U}$ & 1 & 1 & 1 & 1 & NA & 0 & U & 1 & 1 & 9 & fair \\
Sarafan [33] & 1 & 0 & 1 & $\mathrm{U}$ & 0 & 1 & 1 & 0 & 1 & NA & 1 & NR & 1 & 0 & 7 & fair \\
Lohmander [34] & 1 & 1 & 0 & 0 & 0 & 1 & 1 & 1 & 1 & NA & 1 & NR & NA & 1 & 8 & fair \\
Lohmander [35] & 1 & 1 & 0 & 0 & 0 & 1 & 1 & 1 & 1 & NA & 1 & NR & NA & 1 & 8 & good \\
Struglics [36] & 1 & 1 & 1 & 0 & 0 & 1 & 1 & 1 & 1 & NA & 1 & NR & 1 & 1 & 10 & good \\
Struglics [37] & 1 & 1 & 0 & 1 & 1 & 1 & 1 & 1 & 1 & NA & 1 & NR & 0 & 1 & 10 & good \\
Larsson [38] & 1 & 1 & NA & 1 & 0 & 1 & 1 & 1 & 1 & NA & 1 & 1 & 1 & 0 & 10 & fair \\
Panina [39] & 1 & 1 & 1 & 1 & 0 & 1 & 1 & 1 & 1 & NA & 0 & NR & 1 & 1 & 10 & \\
\hline
\end{tabular}

Table 2. Details of the clinical observational cohort and cross-sectional knee injury studies included in this review. The phase after injury refers to acute (A), subacute (S), chronic (C) inflammation or clinically diagnosed PTOA. For the remaining abbreviations we refer the readers to the list of abbreviations. The age, cohort size and sex are of the injured group only. Data not reported (NR) indicate that the information was not described in the study.

\begin{tabular}{|c|c|c|c|c|c|c|c|c|}
\hline Study & Type of Injuries & $\begin{array}{l}\text { Comparison } \\
\text { Group }\end{array}$ & $\begin{array}{l}\text { Phase } \\
\text { after } \\
\text { Injury }\end{array}$ & $\begin{array}{l}\text { Markers } \\
\text { Measured }\end{array}$ & $\begin{array}{c}\text { Age } \\
\text { Mean } \\
\text { Median } \\
\text { (Range) }\end{array}$ & $\begin{array}{l}\text { Cohort } \\
\text { Size }\end{array}$ & Sex & $\begin{array}{c}\text { Confounding } \\
\text { Factor }\end{array}$ \\
\hline $\begin{array}{c}\text { Haller } \\
{[21]}\end{array}$ & $\begin{array}{c}24 \text { patients had low and } \\
21 \text { high energy acute } \\
\text { tibial plateau fracture }\end{array}$ & $\begin{array}{l}\text { Contralateral } \\
\text { uninjured } \\
\text { knee }\end{array}$ & A & $\begin{array}{c}\text { IFN- } \gamma, \text { IL-1 } \beta \text {, } \\
\text { IL-1RA, IL-2, } \\
\text { IL-4, IL-6, IL-7, } \\
\text { IL-8, IL-10, } \\
\text { IL-12(p70), IL-13, } \\
\text { IL-17A, TNF- } \alpha, \\
\text { MCP-1, MIP-1 } \beta\end{array}$ & $\begin{array}{c}42 \\
(20-60)\end{array}$ & 45 & $\begin{array}{l}31 \text { males } \\
14 \\
\text { females }\end{array}$ & \\
\hline $\begin{array}{c}\text { Haller } \\
\text { [22] }\end{array}$ & $\begin{array}{c}24 \text { patients had low and } \\
21 \text { high energy acute } \\
\text { tibial plateau fracture }\end{array}$ & $\begin{array}{l}\text { Contralateral } \\
\text { uninjured } \\
\text { knee }\end{array}$ & A & $\begin{array}{c}\text { MMP-1, }-2,-3,-7 \\
-9,-10,-12,-13\end{array}$ & $\begin{array}{c}42 \\
(20-60)\end{array}$ & 45 & $\begin{array}{l}31 \text { males } \\
14 \\
\text { females }\end{array}$ & \\
\hline
\end{tabular}


Table 2. Cont.

\begin{tabular}{|c|c|c|c|c|c|c|c|c|}
\hline Study & Type of Injuries & $\begin{array}{l}\text { Comparison } \\
\text { Group }\end{array}$ & $\begin{array}{l}\text { Phase } \\
\text { after } \\
\text { Injury }\end{array}$ & $\begin{array}{l}\text { Markers } \\
\text { Measured }\end{array}$ & $\begin{array}{c}\text { Age } \\
\text { Mean } \\
\text { Median } \\
\text { (Range) }\end{array}$ & $\begin{array}{l}\text { Cohort } \\
\text { Size }\end{array}$ & Sex & $\begin{array}{l}\text { Confounding } \\
\text { Factor }\end{array}$ \\
\hline $\begin{array}{c}\text { Swärd } \\
{[23]}\end{array}$ & $\begin{array}{c}\text { 100\% had hemarthrosis; } \\
57 \text { ACL tear, } 3 \text { medial } \\
\text { meniscus injuries, } 1 \\
\text { posterior cruciate } \\
\text { ligament tear, } 5 \text { patellar } \\
\text { dislocations; } 1 \\
\text { suspected tibial } \\
\text { fracture; } 3 \text { MCL tear, } 2 \\
\text { lateral collateral } \\
\text { ligament tears, } 35 \\
\text { rotational knee } \\
\text { traumas; } 3 \text { knee } \\
\text { contusions; } 1 \text { knee } \\
\text { hyperextension. } 15 \text { of } \\
\text { these had associated } \\
\text { MCLT }\end{array}$ & $\begin{array}{l}\text { Age- and } \\
\text { gender- } \\
\text { matched } \\
\text { healthy } \\
\text { uninjured } \\
\text { controls }\end{array}$ & $A, S$ & $\begin{array}{c}\text { sGAG, } \\
\text { ARGS aggrecan } \\
\text { fragments, OCL, } \\
\text { SPARC, OPN, } \\
\text { IL-1 } \beta, \text { IL-6, IL-8, } \\
\text { TNF- } \alpha\end{array}$ & $\begin{array}{c}25 \\
(13-64)\end{array}$ & 111 & $\begin{array}{c}83 \text { males } \\
28 \\
\text { females }\end{array}$ & $\begin{array}{l}16 \text { patients had a } \\
\text { previous injury } \\
\text { (mean } 5 \text { years } \\
\text { prior to injury) } \\
\text { and } 7 \text { had } \\
\text { previous knee } \\
\text { surgery }\end{array}$ \\
\hline $\begin{array}{c}\text { Bigoni } \\
{[24]}\end{array}$ & $\begin{array}{c}18 \text { patients had } \mathrm{ACL} \\
\text { tear, } 30 \mathrm{ACL} \text { tear } \\
\text { associated }+ \\
\text { meniscal injury }\end{array}$ & $\begin{array}{l}\text { Healthy } \\
\text { uninjured } \\
\text { controls }\end{array}$ & A, S, C & $\begin{array}{l}\text { IL-1, IL-1ra, IL-6, } \\
\text { IL-8, IL-10, } \\
\text { TNF- } \alpha\end{array}$ & $\begin{array}{c}30 \\
(14-55)\end{array}$ & 48 & 48 males & $\begin{array}{l}\text { Unequal } \\
\text { distribution of } \\
\text { the number of } \\
\text { patients at the } \\
\text { different time } \\
\text { points measured; } \\
\text { Did not include } \\
\text { any female } \\
\text { subjects }\end{array}$ \\
\hline $\begin{array}{l}\text { Irie } \\
{[25]}\end{array}$ & ACL tear & $\begin{array}{l}\text { OA \& post- } \\
\text { meniscec- } \\
\text { tomy } \\
\text { including } \\
\text { hydrarthro- } \\
\text { sis }\end{array}$ & A, S & $\begin{array}{c}\text { TNF- } \alpha, \text { IL-1 } \beta \text {, } \\
\text { IL-6, IL-8, IL-1ra, } \\
\text { IL-10 }\end{array}$ & $\begin{array}{c}27 \\
(13-55)\end{array}$ & 34 & $\begin{array}{c}20 \text { males } \\
14 \\
\text { females }\end{array}$ & $\begin{array}{l}\text { Unequal } \\
\text { distribution of } \\
\text { the number of } \\
\text { patients at the } \\
\text { different time } \\
\text { points measured }\end{array}$ \\
\hline $\begin{array}{c}\text { Elsaid } \\
{[26]}\end{array}$ & ACL tear & $\begin{array}{c}\text { Contralateral } \\
\text { uninjured } \\
\text { knee }\end{array}$ & $S, C$ & $\begin{array}{c}\text { Lubricin, IL-1 } \beta \text {, } \\
\text { TNF- } \alpha, \text { IL-6, } \\
\text { Procathepsin B, } \\
\text { Neutrophil } \\
\text { elastase, sGAG }\end{array}$ & $\begin{array}{c}24 \\
(15-47)\end{array}$ & 30 & $\begin{array}{c}19 \text { males } \\
11 \\
\text { females }\end{array}$ & $\begin{array}{c}\text { Unequal } \\
\text { distribution of } \\
\text { patients at } \\
\text { different time } \\
\text { points; No } \\
\text { sub-stratification } \\
\text { of the injured } \\
\text { groups based on } \\
\text { time after injury }\end{array}$ \\
\hline $\begin{array}{c}\text { Catterall } \\
{[27]}\end{array}$ & $\begin{array}{l}\text { ACL tear + other knee } \\
\text { joint tissue damage } \\
\text { including bone } \\
\text { contusions, medial } \\
\text { collateral ligament } \\
\text { tears, meniscal tears } \\
\text { and chondral defects }\end{array}$ & $\begin{array}{l}\text { None } \\
\text { (samples } \\
\text { were } \\
\text { measured } \\
\text { over time) }\end{array}$ & $A, S$ & $\begin{array}{c}\text { IL-1 } \beta, \text { CRP, } \\
\text { sGAG, } \\
\text { ARGS-aggrecan, } \\
\text { FA846, CS846, } \\
\text { C2C, CTxII, } \\
\text { C1,2C, CTxI, } \\
\text { NTX, CPII, } \\
\text { Osteocalcin, } \\
\beta-\text { Aspartate, } \\
\text { D-Asx, D-Serine, } \\
\text { sCD44, COMP, } \\
\text { Tenascin C, } \\
\text { Lubricin, MMP-3 }\end{array}$ & $\begin{array}{c}23 \\
(19-26)\end{array}$ & 11 & $\begin{array}{c}6 \text { males } \\
5 \\
\text { females }\end{array}$ & $\begin{array}{l}\text { Half of the } \\
\text { patients at } 2^{\text {nd }} \\
\text { time point were } \\
\text { given i.a. IL-1ra } \\
\text { but authors } \\
\text { reported no } \\
\text { statistical } \\
\text { differences } \\
\text { between IL-1ra } \\
\text { vs. placebo arms } \\
\text { for all measured } \\
\text { biomarkers }\end{array}$ \\
\hline
\end{tabular}


Table 2. Cont.

\begin{tabular}{|c|c|c|c|c|c|c|c|c|}
\hline Study & Type of Injuries & $\begin{array}{l}\text { Comparison } \\
\text { Group }\end{array}$ & $\begin{array}{l}\text { Phase } \\
\text { after } \\
\text { Injury }\end{array}$ & $\begin{array}{l}\text { Markers } \\
\text { Measured }\end{array}$ & $\begin{array}{c}\text { Age } \\
\text { Mean } \\
\text { Median } \\
\text { (Range) }\end{array}$ & $\begin{array}{l}\text { Cohort } \\
\text { Size }\end{array}$ & Sex & $\begin{array}{l}\text { Confounding } \\
\text { Factor }\end{array}$ \\
\hline $\begin{array}{l}\text { Watt } \\
{[28]}\end{array}$ & $\begin{array}{c}74 \% \text { had hemarthrosis; } \\
61 \text { combined } \\
\text { ACL + meniscal tear, } 34 \\
\text { severe trauma (1 or } \\
\text { more injuries including } \\
\text { meniscal tear, cruciate } \\
\text { ligament rupture, } \\
\text { collateral ligament tear, } \\
\text { posterolateral corner } \\
\text { injury, traumatic } \\
\text { chondral defects, } \\
\text { articular or } \\
\text { periarticular fracture, } \\
\text { or patellofemoral or } \\
\text { tibiofemoral } \\
\text { dislocation with severe } \\
\text { knee trauma defined as } \\
\text { combined ( }>1) \\
\text { ligament rupture, } \\
\text { fracture or dislocation); } \\
28 \text { a single ACL or } \\
\text { MCL rupture, } 27 \\
\text { meniscal tears }\end{array}$ & $\begin{array}{l}\text { Macroscopically } \\
\text { intact } \\
\text { cartilage } \\
\text { from lower } \\
\text { limb tumor } \\
\text { amputation } \\
\text { or transplant } \\
\text { donations }\end{array}$ & A, S, C & $\begin{array}{c}\text { Activin A, CRP, } \\
\text { IL-1 } \beta \text {, IL-6, } \\
\text { MCP-1, MMP-3, } \\
\text { TIMP-1, TSG-6 }\end{array}$ & $\begin{array}{c}25 \\
(16-50)\end{array}$ & 150 & $\begin{array}{c}121 \\
\text { males } 29 \\
\text { females }\end{array}$ & $\begin{array}{l}\text { Wide time range } \\
\text { for baseline visit } \\
\quad(0-8 \text { weeks })\end{array}$ \\
\hline $\begin{array}{l}\text { Lattermann } \\
\text { [29] }\end{array}$ & $\begin{array}{c}\text { Isolated ACL injury (no } \\
\text { more than a grade } 1 \\
\text { MCL injury defined } \\
\text { clinically) }\end{array}$ & $\begin{array}{l}\text { None } \\
\text { (samples } \\
\text { were } \\
\text { measured } \\
\text { over time) }\end{array}$ & $\mathrm{A}, \mathrm{S}$ & $\begin{array}{c}\text { IL-1 } \alpha, \text { IL-1 } \beta, \\
\text { IL-1ra, COMP } \\
\text { fragments, } \\
\text { CTX-II, sGAG, } \\
\text { MMP-1, MMP-3, } \\
\text { MMP-9, NTX-I, } \\
\text { TSG-6 }\end{array}$ & $\begin{array}{c}\text { NR } \\
(18-32)\end{array}$ & 41 & NR & $\begin{array}{l}\text { Controls were } \\
\text { not included }\end{array}$ \\
\hline $\begin{array}{c}\text { Dahlberg } \\
\text { [30] }\end{array}$ & $\begin{array}{l}31 \text { patients had a } \\
\text { combination of cruciate } \\
\text { ligament, collateral } \\
\text { ligament and meniscus } \\
\text { injuries, } 15 \text { isolated } \\
\text { meniscus injuries, } 8 \\
\text { cartilage lesions } \\
\text { without ligament } \\
\text { injuries; remaining had } \\
\text { fibrillations + occa- } \\
\text { sional clefts in the joint } \\
\text { cartilage surface in one } \\
\text { knee compartment }\end{array}$ & $\begin{array}{l}\text { Contralateral } \\
\text { uninjured } \\
\text { knee or } \\
\text { healthy } \\
\text { uninjured } \\
\text { controls }\end{array}$ & $A, S, C$ & $\begin{array}{l}\text { Aggrecan } \\
\text { fragments, } \\
\text { COMP, MMP-3, } \\
\text { TIMP-1 }\end{array}$ & $\begin{array}{c}28 \\
(18-40)\end{array}$ & 54 & NR & $\begin{array}{l}4 \text { patients had } \\
\text { undergone } \\
\text { ligament } \\
\text { reconstruction } \\
\text { more than } 3 \\
\text { years before }\end{array}$ \\
\hline $\begin{array}{l}\text { Higuchi } \\
\text { [31] }\end{array}$ & Complete ACL rupture & $\begin{array}{l}\text { Age- } \\
\text { matched } \\
\text { healthy } \\
\text { uninjured } \\
\text { controls }\end{array}$ & A, S, C & $\begin{array}{c}\text { IL-1 } \beta, \text { TNF- } \alpha, \\
\text { IL-6, MMP-3, } \\
\text { TIMP-1 }\end{array}$ & $\begin{array}{c}26 \\
(17-42)\end{array}$ & 32 & $\begin{array}{c}20 \text { males } \\
12 \\
\text { females }\end{array}$ & $\begin{array}{l}\text { Wide time range } \\
\text { for injury group } \\
\text { (2-134 weeks) } \\
\text { and with no } \\
\text { sub-stratification } \\
\text { of the injured } \\
\text { groups for most } \\
\text { of the markers } \\
\text { measured; } \\
\text { Performed } \\
\text { mostly } \\
\text { correlations }\end{array}$ \\
\hline
\end{tabular}


Table 2. Cont.

\begin{tabular}{|c|c|c|c|c|c|c|c|c|}
\hline Study & Type of Injuries & $\begin{array}{l}\text { Comparison } \\
\text { Group }\end{array}$ & $\begin{array}{l}\text { Phase } \\
\text { after } \\
\text { Injury }\end{array}$ & $\begin{array}{l}\text { Markers } \\
\text { Measured }\end{array}$ & $\begin{array}{c}\text { Age } \\
\text { Mean } \\
\text { Median } \\
\text { (Range) }\end{array}$ & $\begin{array}{l}\text { Cohort } \\
\text { Size }\end{array}$ & Sex & $\begin{array}{l}\text { Confounding } \\
\text { Factor }\end{array}$ \\
\hline $\begin{array}{c}\text { Struglics } \\
{[32]}\end{array}$ & Acute ruptured ACL & $\begin{array}{l}\text { Healthy } \\
\text { uninjured } \\
\text { controls }\end{array}$ & A, S, C & $\begin{array}{l}\text { TNF- } \alpha, \text { IL-6, IL-8, } \\
\text { IL-10, IFN- } \gamma, \\
\text { ARGS, CTX-II, } \\
\text { NTX-I }\end{array}$ & $\begin{array}{c}\text { NR } \\
(21-31)\end{array}$ & 121 & $\begin{array}{c}152 \\
\text { males } \\
31 \\
\text { females }\end{array}$ & $\begin{array}{l}\text { Wide time range } \\
\text { for baseline visit } \\
\quad(0-6 \text { weeks })\end{array}$ \\
\hline $\begin{array}{c}\text { Sarafan } \\
\text { [33] }\end{array}$ & Intra-articular fractures & $\begin{array}{l}\text { Healthy } \\
\text { uninjured } \\
\text { controls }\end{array}$ & C & IL-17, CRP & $\begin{array}{c}\text { NR } \\
(28-42)\end{array}$ & 20 & $\begin{array}{c}9 \text { males } \\
11 \\
\text { females }\end{array}$ & $\begin{array}{l}\text { Confusing inclu- } \\
\text { sion/exclusion } \\
\text { criteria; While } \\
\text { the authors } \\
\text { report that } \\
\text { fracture patients } \\
\text { endured pain for } \\
\text { at least } 3 \text { months } \\
\text { and samples } \\
\text { were taken at the } \\
\text { time of knee joint } \\
\text { surgery, it was } \\
\text { not clear when } \\
\text { the samples were } \\
\text { collected }\end{array}$ \\
\hline $\begin{array}{l}\text { Lohmander } \\
\text { [34] }\end{array}$ & $\begin{array}{l}\text { ACL rupture isolated } \\
\text { or combined with } \\
\text { another ligament or } \\
\text { meniscus tear or an } \\
\text { isolated meniscus tear }\end{array}$ & $\begin{array}{l}\text { Healthy } \\
\text { uninjured } \\
\text { controls }\end{array}$ & A, S, C & $\begin{array}{l}\text { CTX-II, Aggrecan } \\
\text { fragments, } \\
\text { MMP-1, MMP-3, } \\
\text { TIMP-1 }\end{array}$ & $\begin{array}{c}37 \\
(14-70)\end{array}$ & & $\begin{array}{c}247 \\
\text { males } 82 \\
\text { females }\end{array}$ & \\
\hline $\begin{array}{c}\text { Lohmander } \\
\text { [35] }\end{array}$ & $\begin{array}{l}159 \text { patients had ACL } \\
\text { rupture + / - injury to } \\
\text { meniscus; } 129 \text { medial } \\
\text { or lateral meniscus tear }\end{array}$ & $\begin{array}{l}\text { Healthy } \\
\text { uninjured } \\
\text { controls }\end{array}$ & A, S, C & $\begin{array}{l}\text { Aggrecan and } \\
\text { COMP } \\
\text { fragments, CPII, } \\
\text { MMP-1, MMP-3, } \\
\text { TIMP-1, BSP }\end{array}$ & $\begin{array}{c}33 \\
(14-70)\end{array}$ & & $\begin{array}{c}221 \\
\text { males } \\
67 \\
\text { females }\end{array}$ & \\
\hline
\end{tabular}

Patients were recently injured (0-12 weeks after injury; $98 \%$ had hemarthrosis) or had an old injury (1-37 years after injury): 39

had ACL, 4 PCL, 69

ACL injury + meniscal tear, $37 \mathrm{ACL}$

injury + meniscal

tear + other ligament injuries, $47 \mathrm{ACL}$

Struglics injury + other ligament

[36] injuries, 58 isolated

meniscal tear, 7 meniscal tear + non-ACL

ligament injuries, 13

patellar dislocation

$+/$ - soft tissue injuries, 7 other

injuries + medial or

lateral collateral

ligament tears;

$2+$ give-way), 10 no

signs of soft tissue injury
Only $8 \%$ of the old injury group were diagnosed with PTOA;
$\mathrm{C} 4 \mathrm{~d}, \mathrm{C} 3 \mathrm{bBbP}$

sTCC, sGAG,

IL-1 $\beta$, IL-6, IL-8,

Healthy

uninjured controls, OA, PTOA

RA or PPA

TNF- $\alpha$, ARGS

neoepitope of

aggrecan,

Osteocalcin

SPARC, COMP,

$\mathrm{C} 2 \mathrm{C}$

Osteopontin
Recently

injury

(13-64)

Old

injury

32

(18-65)
164

males

55

females

50 males

25

females
Sub-stratification

of the group was only divided into two groups: 1-3 years (median of

2.0 years) and

3.01-36.9 years

(median of 5.1

years) with the

latter group

having a wide range of time after injury 
Table 2. Cont.

\begin{tabular}{|c|c|c|c|c|c|c|c|c|}
\hline Study & Type of Injuries & $\begin{array}{l}\text { Comparison } \\
\text { Group }\end{array}$ & $\begin{array}{l}\text { Phase } \\
\text { after } \\
\text { Injury }\end{array}$ & $\begin{array}{l}\text { Markers } \\
\text { Measured }\end{array}$ & $\begin{array}{c}\text { Age } \\
\text { Mean } \\
\text { Median } \\
\text { (Range) }\end{array}$ & $\begin{array}{l}\text { Cohort } \\
\text { Size }\end{array}$ & Sex & $\begin{array}{l}\text { Confounding } \\
\text { Factor }\end{array}$ \\
\hline $\begin{array}{c}\text { Struglics } \\
{[37]}\end{array}$ & ACL injury & $\begin{array}{l}\text { Healthy } \\
\text { uninjured } \\
\text { controls }\end{array}$ & $\mathrm{A}, \mathrm{S}, \mathrm{C}$ & COMP & $\begin{array}{c}26 \\
(21-31)\end{array}$ & 121 & $\begin{array}{l}90 \text { males } \\
31 \\
\text { females }\end{array}$ & \\
\hline $\begin{array}{c}\text { Larsson } \\
{[38]}\end{array}$ & $\begin{array}{l}\text { ACL rupture + } /- \\
\text { meniscus tear }\end{array}$ & $\begin{array}{l}\text { Healthy } \\
\text { uninjured } \\
\text { controls }\end{array}$ & $\begin{array}{l}\text { A, S, C, } \\
\text { PTOA }\end{array}$ & $\begin{array}{c}\text { Aggrecan, ARGS } \\
\text { aggrecan } \\
\text { fragments, sGAG }\end{array}$ & $\begin{array}{c}\text { Acute knee } \\
\text { injury } \\
27 \\
(16-59) \\
\text { Chronic knee } \\
\text { injury } \\
40 \\
(16-70)\end{array}$ & 192 & $\begin{array}{c}56 \text { males } \\
13 \\
\text { females } \\
95 \text { males } \\
28 \\
\text { females }\end{array}$ & $\begin{array}{l}\text { Chronic knee } \\
\text { injury group had } \\
\text { a wide range of } \\
\text { time from } 3 \\
\text { months-36 years } \\
\text { (mean of } 1 \text { year) } \\
\text { after injury and } \\
97 \% \text { had PTOA }\end{array}$ \\
\hline $\begin{array}{c}\text { Panina } \\
{[39]}\end{array}$ & $\begin{array}{l}\text { All patients suffered a } \\
\text { knee injury } \leq 1 \text { year } \\
\text { following a meniscus } \\
\text { injury and were } \\
\text { diagnosed with early- } \\
\text { (Kellgren-Lawrence } \\
\text { grade 1-2) or late-stage } \\
\text { (grade 3-4) PTOA }\end{array}$ & $\begin{array}{l}\text { Healthy } \\
\text { uninjured } \\
\text { controls }\end{array}$ & PTOA & $\begin{array}{c}\text { IL-1 } \beta \text {, IL-6, IL-18, } \\
\text { TNF- } \alpha \text {, Leptin, } \\
\text { NO }\end{array}$ & $\begin{array}{c}\text { NR } \\
(26-65)\end{array}$ & 134 & $\begin{array}{c}60 \text { males } \\
74 \\
\text { females }\end{array}$ & $\begin{array}{l}77 \% \text { of patients } \\
\text { were in the } \\
\text { early-stage } \\
\text { PTOA group; } \\
\text { Control data was } \\
\text { only included for } \\
\text { plasma samples; } \\
\text { not for SF }\end{array}$ \\
\hline
\end{tabular}

Samples were measured in the synovial fluid, serum/plasma and/or urine within $24 \mathrm{~h}$ and up to many years following knee trauma and ranged from the acute, subacute, and chronic phases of inflammation after knee trauma to clinical PTOA of the knee joint. Most studies were cross-sectional studies in which only one sample was taken from each patient. The type of reported knee trauma was mostly caused by anterior cruciate ligament (ACL) and medial collateral ligament injuries [23-32,34-38] or intraarticular fracture $[21-23,28,33,36]$. Fewer injuries were due to patellar dislocation, rotational knee trauma, knee contusion, medial meniscus injury, or posterior cruciate ligament injury $[23,27,28,36,39]$. Some studies included controls and others did not (Table 2). A few studies also investigated the contralateral uninjured knee joints or included OA, postmeniscectomy, hydrarthrosis, or chronic arthritis samples for comparisons. Most of the studies consisted of a larger percentage of males (range 59-100\%) [21-28,31,32,34-38] rather than female subjects, with only a few studies having a majority of females in their cohort that reached up to $55 \%[33,39]$. The age of patients having a knee injury varied from 13 to 70 years old [21-26,28-39] and had a mean age of 29 years [21-26,28,30,31,34-38].

Although differences in the timescale and the choice of markers may make comparisons across clinical studies difficult, we simplified the resulting data by (a) including such information in the text and (b) by dividing the clinical studies into different sections to create a timeline of events that occur after knee trauma (Figure 1). We first present studies representative of localized knee joint inflammation, followed by studies that measured proteolytic enzymes and tissue injury markers. We then present studies that demonstrate the systemic effects of injury, and finally discuss the inflammatory factors that were measured in clinically diagnosed cases of PTOA due to knee joint trauma. 


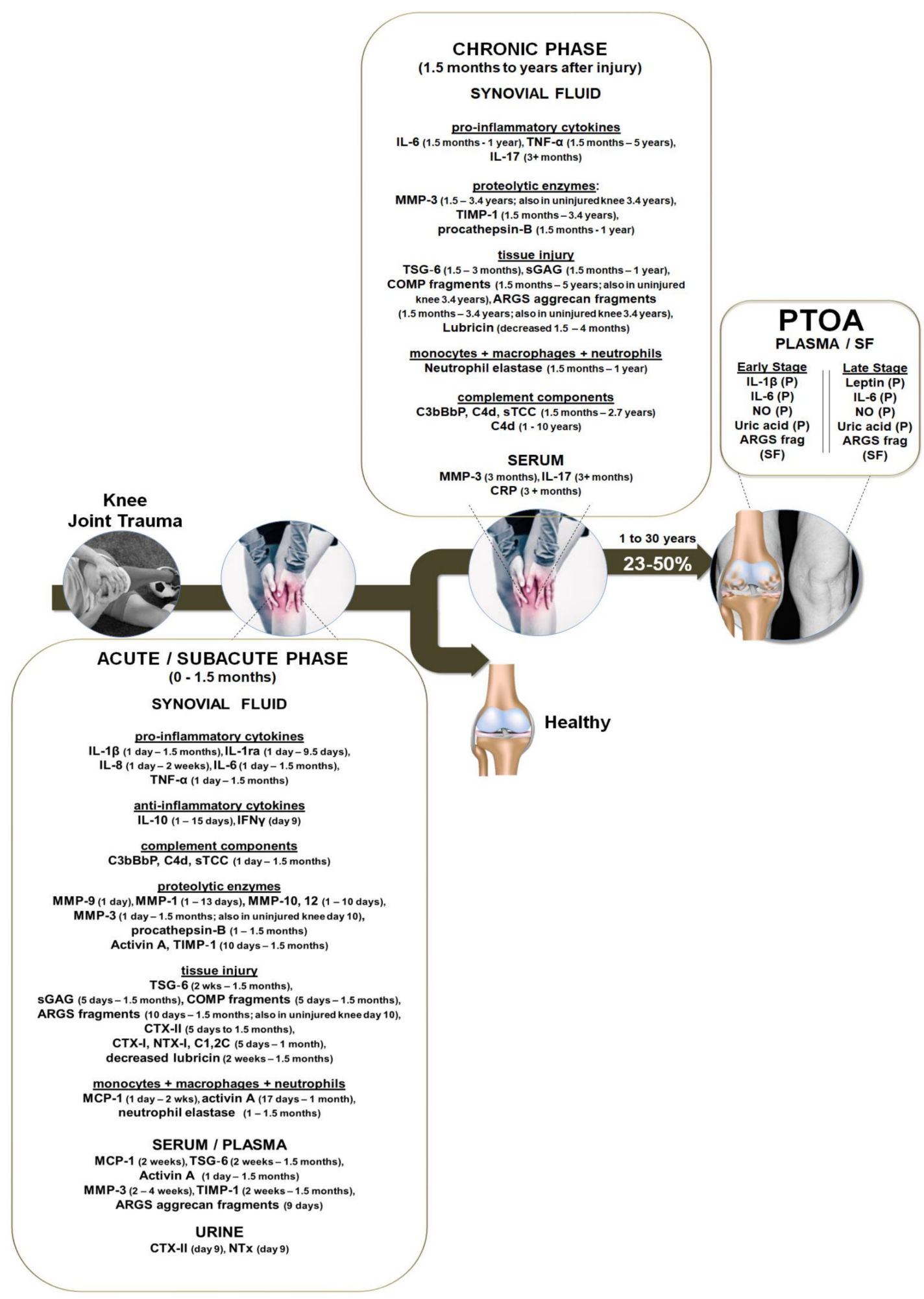

Figure 1. PTOA development after knee joint injury. Following knee joint injury, an immediate acute phase of inflammation occurs which continues for up to 2 weeks and is typically followed by a subacute phase, lasting up to 1.5 months, exhibited by a primary high wave of inflammatory cytokines that decrease over time but remain higher than uninjured controls. Likewise, other mediators, including complement components, neutrophil and macrophage-associated factors, MMPs, degradative proteolytic enzymes and ECM fragments increase in the synovial fluid, while lubricin decreases, all indicative 
of early, and possibly irreversible, damage to the cartilage tissue. When inflammation is not resolved, cartilage degradation continues to be associated with a low-grade chronic phase of inflammation characterized by decreased, but higher than normal, levels of pro-inflammatory cytokines IL-6, TNF- $\alpha$ and IL-17. Although these inflammatory mediators are lower than what may be observed in OA or RA patients, this sustained low-grade inflammation is still clearly present, significantly higher than healthy controls, and correlates with degenerative effects, all of which promote joint pathology. A long-term inflammatory status persists, leading to a systemic effect (presence of biomarkers in the blood and/or uninjured knee) accompanied with alterations in joint function leading to PTOA. This figure was composed based on all of the clinical data discussed in this review that measured the concentrations of these markers at the (mean) time or range of times (using the data of multiple studies) post-injury showing, with the exception of lubricin which was decreased, significantly high levels of these markers at the indicated time points.

\subsection{Continuous Localized Inflammation from Months to Years after Knee Trauma}

As pro-inflammatory and anti-inflammatory cytokines are the major immunoregulatory molecules that control the immune response and could dictate the direction towards or against PTOA progression, we first focused on studies that measured these cytokines after knee trauma. Haller et al. showed that, compared to uninjured knees, the SF collected $24 \mathrm{~h}$ after acute tibial plateau fracture contained significantly higher levels of IL-1 $\beta$, IL-6 and IL-8, as well as monocyte chemoattractant protein-1 (MCP-1), also known as CCL2, which regulates the migration and infiltration of monocytes and macrophages [21]. While anti-inflammatory cytokines IL- 4 and IL- 13 were not detectable at any time point, anti-inflammatory and immunoregulators IL-10 and IL-1 receptor antagonist (IL-1ra), the natural inhibitor or regulator of IL-1 $\beta$, were locally and significantly increased $24 \mathrm{~h}$ after knee injury. Approximately half of those patients that were reassessed at a mean of 9.5 days after injury, which showed that the concentrations of IL-6, IL-8, MCP-1, IL-10 and IL-1ra concentrations continued to remain elevated in the injured vs. uninjured knees. Interestingly, they did not detect any differences in SF cytokine concentrations between low vs. high energy injuries $24 \mathrm{~h}$ after fracture, suggesting a similar immediate immune response in tibial plateau fractures despite the level of impact energy. Similar to the aforementioned study, Watt et al. also showed that MCP-1 was significantly elevated in both the SF and serum in samples taken within 8 weeks (median 17 days) of knee injury vs. controls [28] suggesting acute phase infiltration of monocytes and macrophages into the knee joint. This group also showed that, IL-6, Activin A (a member of the TGF- $\beta$ superfamily that is closely related to TGF- $\beta 1$ and controlled by fibroblast growth factor 2 and NF-kB [40]), and TSG-6 (a product of TNF- $\alpha$ gene 6 ) that binds to complement proteins, hyaluronic acid and CXC and CC chemokines [41]) were all significantly elevated in the SF vs. controls and, while the concentrations decreased over time, the majority of patients still had IL-6, Activin A, and TSG-6 present 1.5 months after injury with levels higher than control values [28]. Activin A and TSG-6 have both been strongly associated with rapid knee OA progression [42,43]. In this study, IL-1 $\beta$ was below the limit of detection for all but one individual. Higher levels of SF IL-6 associated with worse clinical symptoms and loss of function, based on the Knee Injury and Osteoarthritis Outcome Score $4\left(\mathrm{KOOS}_{4}\right)$. Even though the levels of IL-6 increased with the severity of injury, the inflammatory response in all types of knee injuries was similar, suggesting that the inflammatory response is comparable across different types of injuries. Higuchi et al. similarly showed that IL-6 was significantly elevated compared to controls at a mean of 6 months (range of 2-140 weeks) after injury [31]. Moreover, SF matrix metalloproteinase-3 (MMP-3) concentration significantly correlated with the IL-6 concentration among the various cytokines, but did not correlate with IL- $1 \beta$ or TNF- $\alpha$.

Similar to the aforementioned study [21], Swärd et al. showed that injured patients with hemarthrosis, which is bleeding into the joint cavity, exhibited an increase in IL- $1 \beta$, TNF- $\alpha$, IL- 6 and IL- 8 in the SF $24 \mathrm{~h}$ after injury, followed by a time-dependent decrease thereafter, with IL-8 remaining significantly higher than age- and gender-matched healthy controls up to 15 days and IL- $1 \beta$, TNF- $\alpha$ and IL- 6 up to 23 days after injury [23]. Catterall et al. demonstrated the presence of IL- $1 \beta$ at both time points measured (i.e., 15 to 47 days post-injury) [27]. Bigoni et al. screened SF collected after various time points, including 
within $48 \mathrm{~h}$ after injury, between 3 and 15 days, 15 days and 3 months, or more than 3 months following knee injury [24]. Within $48 \mathrm{~h}$ of injury, the SF concentrations of IL-1 $\beta$, IL-6, and IL-8 were significantly increased vs. healthy controls. IL- $1 \beta$ steadily decreased after $48 \mathrm{~h}$ and between days 3 to 15 days post-injury, and from that point on it was comparable to control values. IL-8 also gradually decreased and was comparable to controls in the 15 day to 3 months post-injury group. IL-6 remained high up to 15 days post injury and, although it decreased, it continued to be present in patients with chronic symptoms (defined as 3 months or more post injury) and was significantly higher than controls. TNF- $\alpha$ progressively and significantly increased with time after injury and was still elevated up to 3 or more months post injury. While IL-10 was not compared to controls in this study, at all time points it was comparable to healthy controls reported in another study [25]. Interestingly, in the $0-48 \mathrm{~h}$ post-injury group, IL-1ra was significantly lower than the control group and did not increase at any of the time points. While the study of Lattermann et al. did not have a control group, they also showed that IL-1ra significantly decreased from day 5 (range 2-8 days) to day 13 (range 9-20 days) post injury and continued to decrease 28 days (range $15-45$ days) post injury [29].

Irie et al. measured the concentration of SF cytokines at several different time points (within 24 h, 2-3 days, 4-6 days, 7-9 days, 10-14 days, 15-21 days) after injury, and determined whether cytokine concentrations were comparable or higher than patients already with chronic arthritis in the knee [25]. In line with the aforementioned studies, this study demonstrated a comparable immediate inflammatory response in which the levels of cytokines TNF- $\alpha$, IL-1 $\beta$, IL-6, IL-8, IL-1ra, and IL-10 were significantly elevated within $24 \mathrm{~h}$ and then steadily decreased thereafter. Notably, despite a decrease in cytokines over time, concentrations were higher than in chronic arthritis patients with IL-1ra elevated up to 6 days and IL-10 up to 9 days post-trauma. With the exception of the 10-14-day injury group, IL-1 $\beta$ was significantly higher than in chronic arthritis patients at all of the other days and remained significantly higher up to 21 days post-injury. TNF- $\alpha$ was also significantly higher than in chronic arthritis patients and at all time points up to 3 weeks post-injury. While IL-6 concentration values were exceedingly high compared to the other cytokines measured in this study, the concentrations of IL- 6 only exceeded those of chronic arthritis patients during the first 3 days following knee trauma.

Other studies have also shown that local inflammation persists and develops into chronic inflammation [26,30-36]. Thus, IL-17 concentrations were significantly higher in the SF for 3 or more months after injury compared to healthy controls [26]. Elsaid et al. showed that, when SF aspirations were taken at a mean of 3 months (range of 32-364 days) after injury, patients had elevated levels of IL- $1 \beta$, IL- 6 and TNF- $\alpha$, compared to uninjured knees [26]. The concentrations of individual cytokines were also assessed in the injured knee and plotted against the time of collection after injury, which showed that IL- $1 \beta$ was present 1 to 3 months post-injury in 50\% of the patients andTNF- $\alpha$ in $60 \%$ of the patients 1 to 6 months after injury. Interestingly, IL- 6 and the catabolic enzymes procathepsin-B and neutrophil elastase were detectable from 1 month up to 1 year post injury in the injured knees in $95 \%, 100 \%$ and $80 \%$ of patients, respectively.There were no detectable levels of these markers in SF samples taken from the contralateral joints. Struglics et al. showed that the concentrations of cytokines IL-6, IL-8, IL-10, IFN- $\gamma$, TNF- $\alpha$ and and Alanine-ArginineGlycine-Serine (ARGS) aggrecan fragments fragment in SF collected from the injured patients at the initial 0-6 weeks (mean of 9 days) time point were significantly higher than those of healthy subjects but their levels steadily decreased over time, with SF TNF- $\alpha$ remaining elevated for up to 5 years after injury [32]. Moreover, over the 5-year period, ARGS aggrecan fragments concentrations in SF correlated with all of the SF cytokines measured. Using a mixed variance components model with values adjusted for differences in age, sex, and body mass index (BMI), this group estimated that TNF- $\alpha$ has a half-life of 3.6 years in the SF, while IL-6 has a half-life of 0.9 years in the SF and, astonishingly, a half-life of 45 years in the serum. 
Hence, all of the studies discussed here point to continued subacute and chronic inflammation in the knee joint after knee trauma with multiple studies confirming that TNF- $\alpha$ and IL- 6 remain significantly elevated months to years after knee trauma and at comparable concentrations to chronic arthritis patients.

\subsection{Activation of the Complement System Correlates with Inflammation Months to Years after Knee Trauma}

Since it is believed that the crucial and driving event in the development of PTOA is a sustained early inflammatory reaction after trauma or acute injury [14-16,18] (this review), it is also important to explore a possible contribution of the complement system to knee PTOA. The 3 distinct but overlapping complement pathways, referred to as the classical, alternative and lectin complement pathways, are activated through various mechanisms that result in a proteolytic cascade of events that generates potent pro-inflammatory molecules and leukocyte chemoattractants, which (i) recruits inflammatory cells such as neutrophils, monocytes, macrophages and T lymphocytes, and (ii) leads to the production and assembly of the terminal membrane attack complex (MAC), sometimes referred to as the terminal complement complex (TCC), a cytolytic protein complex that activates destroys cells. While this complex network of activating, and its regulating proteins, is needed for clearance of pathogens and dead or dying cells, and thereby helps support repair of injured tissues, it can also lead to detrimental effects on the host by exerting pathological mechanisms that promote tissue damage and chronic inflammation [36,44-46].

One study has highlighted complement's role in chronic inflammation and the possible progression of PTOA in the knee [36]. This group measured the SF levels of C4d, C3bBbP, and soluble TCC (sTCC) from those with a recent knee injury (defined as 1-83 days after injury) or an old injury (defined as 1-37 years after injury) with $8 \%$ of those patients diagnosed with PTOA, as well as from healthy controls from another cohort and OA, RA and pyrophosphate arthritis (PPA) patients. Patients with a recent knee injury or OA displayed similar increased levels of $\mathrm{C} 4 \mathrm{~d}, \mathrm{C} 3 \mathrm{bBbP}$ and sTCC in the SF which were significantly higher than those of healthy controls. Moreover, $98 \%$ of patients with recent knee injuries had hemarthrosis, suggesting that complement components present in the SF after initial knee trauma may stem from intra-articular bleeding. The concentrations of pro-inflammatory cytokines TNF- $\alpha$, IL- 6 and IL-1 $\beta$ positively correlated with the levels of complement factors in patients with a recent injury, with the strongest correlation between SF TNF- $\alpha$ and C4d levels. While complement components decreased over time, C4d remained elevated in SF that was aspirated up to 10 years after knee injury, demonstrating the continuous chronic activation of the complement system following trauma to the knee.

In addition to a potential role in PTOA development, several groups have also shown that the complement cascade is involved in the pathogenesis of both early and late-stage OA in the knee [36,47-52]. C3a and sTCC were significantly higher in the SF from patients with early-stage knee OA (having symptoms less than 1 year) compared to healthy individuals $[49,51]$ and complement transcripts and/or activation components C3/C3a, C4a, C4d, $\mathrm{C} 3 \mathrm{bBbP}$, factor $\mathrm{B}$, and sTCC have been detected at high levels in the SF, synovial membrane and in the cartilage of patients with OA in the knee joint $[36,47-49,53]$. Recent evidence suggests that all three complement pathways are capable of being activated within the knee joint in both early and late knee OA and that the synovial membrane is the main source of complement activation rather than the articular cartilage tissue [50]. Patients with OA also exhibited high concentrations of lectin complement pathway components, including mannose bindin lectin (MBL), H-ficolin, M-ficolin, mannan-binding lectin serine protease2 (MASP-2), and MASP-3, which were higher in the plasma than the SF [54], and while the levels were significantly lower than patients with RA, this data suggests a possible role of the lectin pathway in promoting chronic disease in knee OA. Moreover, inhibitors of the complement system, including factor $\mathrm{H}, \mathrm{C} 4$-binding protein, $\mathrm{C} 1$ inhibitor and clusterin, were significantly decreased in both early- and end-stage OA vs. healthy synovial membranes [51], suggesting a lack of complement system regulation. Thus, complement 
could be a major contributor to not only injury-related acute inflammation but also chronic inflammation and possibly PTOA pathogenesis.

3.3. Release of MMPs, ECM Components and Damage to the Cartilage Collagen Network Months to Years after Knee Trauma

In addition to increased levels of inflammatory cytokines after knee joint injury, the expression of MMPs, the release of ECM components, and the degradation of type II collagen in articular cartilage tissue is increased compared to the controls. In the same set of patients from [21], Haller et al. showed that MMP-1, 3, 9, 10, 12 were initially elevated in the acute samples (within $24 \mathrm{~h}$ after injury) with MMP-1, 3, 10, 12 remaining elevated at the second aspiration a mean of 9.5 days (range of 3-21 days) after injury [22]. Lattermann et al. also showed that MMP-1 significantly increased from day 1 to day 13 after injury [29]. Watt et al. demonstrated that, compared to controls, MMP-3 and TIMP-1 were significantly elevated in the SF samples that were obtained within 8 weeks (median 17 days) of knee injury and, while the concentrations decreased over time, the majority of patients still had higher than control concentrations of MMP-3 and TIMP-1 1.5 months after injury [28]. Higher levels of SF MMP-3 and TIMP-1 also associated with the presence of hemarthrosis (moderate or severely blood-stained SF) and the severity of injury. In line with the aforementioned studies, Higuchi et al. similarly showed that MMP-3 and TIMP-1 remained highly elevated in the SF at a mean of 6 months (range of 2-140 weeks) after injury compared to healthy controls [31].

Lubricin, a glycoprotein secreted by synoviocytes as well as superficial zone chondrocytes found in the SF that covers the superficial layer of articular cartilage and provides boundary lubrication in articular joints, is also affected by knee injury. Catterall et al. showed that SF lubricin levels were significantly decreased in injured knees when comparing levels at baseline (mean $15.2 \pm 7.2$ days) to the follow-up (mean $47.6 \pm 12.4$ days) [27]. Similarly, Elsaid et al. showed that the levels of lubricin significantly decreased in the injured knee 2-4 months, compared to the contralateral uninjured knee joint [26]. While lubricin returned to normal levels within 1 year, there was a significant inverse correlation between high SF TNF- $\alpha$ and low SF lubricin concentrations and between low SF lubricin and the high release of sulfated glycosaminoglycan (sGAG), which also remained significantly elevated from 1 month to 1 year after injury in injured vs. uninjured knee joints.

In addition to synovial inflammatory biomarkers and MMPs, major ECM cartilage degradative products increased rapidly upon injury, and while they decreased in the subacute to chronic phases, their levels remain significantly higher than healthy controls. Whereas the following two studies did not include controls, Lattermann et al. showed that sGAG and the non-collagenous ECM cartilage oligomeric matrix protein (COMP) fragments were highest in the SF during the first two weeks of injury but started to decrease at a mean of 28 days post-injury, while C-telopeptide fragments of collagen type II (CTX-II) increased over time from the acute (day 5 and day 14) to the subacute (day 28) phase [29]. Catterall et al. similarly showed that the concentrations of sGAG and ARGS aggrecan fragments decreased from $15.2 \pm 7.2$ days to $47.6 \pm 12.4$ days after injury, while CTX-II, as well other collagen I and II collagen fragments, including C-terminal crosslinked telopeptide type I collagen (CTX-I), N-terminal telopeptides of type I collagen (NTX-I) and $\mathrm{C} 1,2 \mathrm{C}$ significantly increased [27]. In line with these studies, Lohmander et al. showed that CTX-II peaked hours after injury and, while concentrations gradually decreased over time, CTX-II remained present and significantly higher in the SF vs. healthy uninjured controls 1 week, 2.5 months, 1 year and even up to 2.7 years after injury [34]. Similarly, Struglics et al. demonstrated that SF COMP fragments were significantly higher than controls at all time points investigated (i.e., 9.1 days, 3.6 and 7 months, and 1, 2, and 5 years after injury), which positively correlated with SF IL-6, IL-8, TNF- $\alpha$, IFN $\gamma$ and IL-10, with SF and serum ARGS aggrecan fragments and urine CTX-II and NTX-I levels [37].

In another study, Struglics et al. showed that the ARGS neoepitope was increased in the SF 4-7 months after injury compared to the controls [32], whereas Lohmander 
et al. demonstrated that the concentration of the ARGS aggrecan fragments in the SF peaked hours after injury, significantly increased from 2 weeks to 10 weeks after injury, and then decreased gradually during the first year after injury, but then leveled off with concentrations remaining significantly elevated vs. healthy controls 1 week, 2.5 months, 1 year and up to 2.7 years after injury [35]. Dahlberg et al. demonstrated that the SF concentrations of ARGS and COMP fragments as well as MMP-3 and TIMP-1 were greater than healthy controls at 10 days post-injury and, while the concentrations of markers in the injured knee decreased with increased time after injury, the concentrations of COMP fragments, MMP-3 and TIMP-1 were still higher than healthy controls 3.4 years after injury [30].

These studies indicate that the injured knee joint continues to be exposed to the degradative action of catabolic enzymes during the early acute, to subacute and chronic phases following injury, and that this exposure correlates with measurable inflammation. While the above studies demonstrate a temporal decrease in tissue injury markers, they point to a sustained post-traumatic inflammation, which is associated with a long-term, continuing degradation of the cartilage matrix after knee joint injury, suggesting a lasting role in progression to PTOA.

\subsection{Systemic Measurable Effects after Knee Trauma}

While the inflammatory response following joint injury may in part be localized to the knee joint, studies investigating inflammatory components in the blood (serum/plasma), contralateral uninjured knee and urine have also demonstrated the presence of systemic subacute and chronic inflammation following knee trauma. Sarafan et al. showed that IL-17 was present in the serum (and SF as already discussed) three or more months after knee trauma. OA patients had significantly higher serum IL-17 concentrations than patients with intra-articular knee joint fractures, with the healthy control group exhibiting the lowest IL-17 values [33]. Other studies have similarly shown both circulating and SF IL-17 in patients diagnosed with early- or late-stage knee OA compared to healthy controls and that synovia IL-17 levels correlate with knee OA severity [35,55-60].

Multiple studies showed that CRP concentrations in the serum significantly exceeded the levels in SF, beginning 2 to 3 months following knee injury $[27,28,33]$. CRP levels were equally present in the serum and SF of patients having either OA or an intra-articular fracture with associated pain for at least three months and, in both cases, CRP levels were significantly higher than in the controls [33]. Catterall et al. showed that, while CRP levels decreased over time in both the serum and SF from $15.2 \pm 7.2$ days to $47.6 \pm 12.4$ days after injury, there was a significant correlation between SF and serum CRP [27]. Watt et al. demonstrated a similar correlation between serum and SF CRP up to 3 months compared to the baseline samples obtained within 2 months after injury [28].

Struglics et al. showed that the urine concentrations of the collagen fragments CTX-II and NTX-I were initially increased at the baseline point (mean 9 days after injury; range 0-6 weeks) in the patients having knee injury, but levels decreased with time after injury [32]. Catterall et al. found significant correlations between the serum and SF concentrations of CTX-I and NTX-I and MMP-3 1.5 months after injury [27]. Watt et al. showed that at the baseline visit (taken within 8 weeks of knee injury; median 17 days), like the concentrations found in the SF, serum/plasma concentrations of MMP-3, TIMP-1, TSG-6, MCP-1, and Activin A were also significantly elevated compared to controls [28]. In fact, TSG-6 levels remained constant in the serum, while MMP-3 continued to increase in the serum up to 3 months after baseline taken within 2 months of injury, suggesting that MMP-3 was still systemically present up to 5 months post-injury. Dahlberg et al.'s data demonstrated that the contralateral uninjured also had significantly higher concentrations of MMP-3 as well as ARGS and COMP fragments compared to healthy controls at 10 days and 3.4 years after injury [30]. Moreover, the SF concentrations of MMP-3 and COMP fragments were similar in the injured and the contralateral uninjured knee 3 months and 3.4 years after knee injury, further emphasizing systemic long-term effects of knee injury. 
Struglics et al. also showed a correlation between the concentrations of the ARGS neoepitope in the SF and serum [32]. These studies highlight the systemic long-term effects of knee trauma.

Pengas et al. showed that, even up to forty years after open total meniscectomy (an outdated surgical method of repairing meniscal tears), SF MMP-3 levels remained high and, while sGAG levels were low, both correlated with the radiographic OA score. Moreover, serum MMP-3 correlated with MMP-3 SF levels in the operated knee. Interestingly, they showed that the quality of life could be predicted 40 years after surgery using the pre- and post-surgery concentrations of MMP-3 and sGAG and patient age [61]. Together, these studies [22,27-31,61] indicate the importance of MMP-3 as a reflective systemic biomarker of degradative activity after knee trauma that is measurable in both injured and uninjured knee joints and even in serum.

Importantly, these data suggest that, whereas the inflammation caused by injury originated from a single knee injury, the inflammatory effects lead to a systematic response, suggesting that certain serum markers could potentially be assessed along with other clinical assessments of joint inflammation and injury in the subacute to chronic phases to post-traumatically monitor systemic knee injury and possible progression to PTOA.

\subsection{Local and Circulating Inflammatory Cytokines and Other Biochemical Biomarkers Once PTOA Is Diagnosed}

Two studies showed that progression to clinical PTOA can occur as early as 1 year or less following ACL and/or meniscus injury [38,39]. Larsson et al. demonstrated that while SF sGAG, ARGS aggrecan fragments and aggrecan levels were significantly elevated at a mean of 10 days post-injury, only the ARGS aggrecan fragments remained significantly higher in the SF of patients diagnosed with early to late PTOA (mean 1 of year post-injury; range of 3 months to 36 years post-injury) vs. healthy controls [38]. Panina et al. showed that, compared to healthy controls, progression to clinical PTOA can occur as early as 1 year or less following meniscus injury [39]. Patients diagnosed with either early- (KellgrenLawrence grade 1-2) or late-stage (grade 3-4) PTOA had significantly higher levels of IL-6, $\mathrm{NO}$ and uric acid in the plasma, while plasma IL-1 $\beta$ was significantly increased only in the early-stage PTOA group. Leptin, a hormone associated with obesity that is known to play a catabolic role in articular cartilage, especially in women [62], was significantly increased in the late-stage PTOA group compared to the control group. Cytokines in the SF were not vs. controls and no significant differences between early-stage vs. late-stage PTOA were detected. However, correlation analyses showed that the levels of NO, IL-6, and IL-18 in the plasma significantly correlated with those in SF. SF and plasma leptin levels and SF IL-18 significantly correlated with PTOA severity and PTOA progression. Moreover, there was a 1000-fold increase in IL-6 in the SF compared to the plasma and the plasma IL-6 concentrations were significantly higher than healthy controls, interestingly, there was not a significant increase in SF or plasma TNF- $\alpha$ levels compared to controls or between patients with early and late PTOA. Other studies have shown similar results in patients diagnosed with knee OA. Thus, TNF- $\alpha$ was not increased in the SF $[55,63]$ or the serum of patients diagnosed with knee OA [64]. However, the data suggest that both IL-6 and TNF- $\alpha$ chronically persist years after knee trauma (Figure 1 ).

Similar to the results from Ersoy et al. [39], another study showed that the serum nitrate and nitrite levels, measured by the same assay, in 36 OA patients were significantly higher than in 30 healthy controls [65]. Other OA studies have corroborated increased uric acid levels in subjects with knee OA. Serum uric acid levels predicted future joint space narrowing in knee OA patients [66] and, while the mean serum uric acid concentrations were significantly higher than their paired SF uric acid concentrations, SF uric acid strongly correlated with SF inflammatory cytokines IL-1 $\beta$ and IL-18 [67].

\subsection{The Role of Inflammation in the Pathogenesis of Knee PTOA-Summary of Clinical Proof}

Compiling the available clinical data, we developed a chronological representation of specific inflammatory and other biochemical biomarkers that significantly increase fol- 
lowing knee joint trauma (Figure 1). It is clear from the clinical studies discussed above that knee joint injuries lead to a normal acute inflammatory response following the initial trauma and, importantly, this is followed by a continuous phase of inflammation lasting from months to years following knee trauma, indicating the importance of the early regulation of the immune response for potential clinical benefit. Load-bearing macromolecules of the articular cartilage ECM (notably, ARGS aggrecan and COMP fragments and sGAG), followed by collagen cleavage products, become clinically measurable in the SF early after knee joint injury and continue to be present, signifying early and possibly even irreversible damage to articular cartilage. Not surprisingly, there is a high patient variability between individual, but local joint inflammation often persists in what we defined as the chronic phase of inflammation characterized by higher-than-normal levels of inflammatory cytokines IL-6, TNF- $\alpha$ and IL-17 in the SF. Evidence suggests a systemic response from 1 weeks to 5 years after knee injury, as specific markers are detectable in the contralateral uninjured knee, serum and urine. Once PTOA is clinically diagnosed, there is a systemic inflammatory response with patients exhibiting higher than normal levels of IL-6, IL-1 $\beta$, leptin, NO, uric acid, ARGS aggercan fragments and possibly complement pathway activation products in the SF and/or plasma.

\section{Results of the In Vivo, Ex Vivo and In Vitro Models That Simulate Inflammation and/or Injury of the Knee Joint}

\subsection{In Vivo Knee Joint Inflammatory, Injury and PTOA Animal Models}

In vivo models are useful for mimicking clinically relevant injury conditions and help us to understand the factors that contribute to knee PTOA disease onset and progression. The majority of knee injuries included in the clinical part of this review were ACL/MCL injuries or articular fractures (Table 2). Several clinical studies also reported rapidly developing hemarthrosis in the acutely injured knee $[23,36,68]$. We will briefly discuss selected models that mimic these clinical scenarios and show that they induce, to various degrees, subsequent structural damage, inflammation, and/or biomechanical changes that eventually lead to the degeneration of articular cartilage and knee PTOA.

Several studies have shown that intra-articular injection of the cytokines TNF- $\alpha$, IL- $1 \beta$, or IL-17 alone (i.e., without applying injury) [69-71] are capable of producing some of the injurious effects observed in the different acute, subacute and chronic phases after clinical trauma. Sixteen hours after the intra-articular injection of $10 \mu \mathrm{g}$ of TNF- $\alpha$ into rat knee joints, a maximal aggrecan loss was observed that was followed by gradual recovery of the proteoglycans in the articular cartilage after $72 \mathrm{~h}$ [71]. Likewise, the levels of sGAG in the SF significantly increased vs. control between 8 and 16 hours after TNF- $\alpha$ treatment, but returned to normal levels within $24-48$ h suggesting that TNF- $\alpha$ alone may not induce a profound effect on ECM degradation. A single intra-articular injection of IL-17 caused NO release into the SF in rats, similar to IL-1 $\beta$, IL-17 also dose-dependently inhibited proteoglycan synthesis, but to a lesser extent than IL-1 $\beta[69,70]$. IL-17 also upregulated the expression of IL-1 $\beta$. Moreover, three intra-articular injections of IL-17 (1, 10 and $50 \mathrm{ng} / \mathrm{mL})$ for up to 6 days in New Zealand rabbits led to an early significant increase, at $72 \mathrm{~h}$ after the last injection, in the expression of MMP-1, -3 , and -13 , as well as ADAMTS-4 and -5 and COMP, along with the chondrogenic markers COL10A1 and COL1A2; and, concomitantly, a significant decrease in COL2A1 expression [70]. With the exception of MMP-13, which decreased at 12 weeks post-injury, the expression of these markers increased over time until 12 weeks after injection. Furthermore, at the later time points (3,6 and 12 weeks) the intra-articular injection of the higher doses of IL-17 progressively caused cartilage defects and an increase in the synovial thickness and synovium cell number. Interestingly, the same study showed that the intra-articular injection of IL-17 was capable of inducing PTOA similar to rabbits having their anterior and posterior cruciate ligaments transected and the medial meniscus excised. Likewise, the levels of sGAG in synovial fluid significantly increased vs. control between 8 and $16 \mathrm{~h}$ but returned to normal levels within 24-48 h. Interestingly, in antigen-induced experimental arthritis, IL-6 has been shown to function upstream of IL-17, but has also been shown to be a downstream target of IL-17A, and 
the combination of IL- 6 and IL-17A synergistically generated a positive IL-6 expression feedback loop that resulted in excessive IL-6 signaling through the soluble IL-6 receptor (IL-6R) signaling pathway [72]. These data collectively suggest that, while trauma is the initiating factor of inflammation in the clinical setting, pro-inflammatory cytokines alone, and particularly IL-17, can replicate injurious effects.

Joint bleeding is very common after acute knee injury and occurs in up to $98 \%$ of knee injuries $[23,28,36,68,73]$. The blood entering the joint generally reaches up to $100 \%$ volume/volume $(v / v)$ and is cleared within a week if the bleeding stops [73]. When joint bleeding is prevented during surgery, the severity of synovitis and the infiltration of mononuclear cells significantly decreases [74]. Only one study has mimicked acute joint bleeds of the knee joint in animals by injecting $(20 \% v / v)$ of coagulated blood for up to 4 days. This canine blood-induced injury model increased synovial inflammation (OARSI score) and decreased sGAG content for up to 4 weeks [73]. The exposure of healthy cartilage tissue to a minimal amount of blood (only $10 \% v / v$ blood) for two days was capable of increasing general MMP activity and long-term articular cartilage damage measured by decreased proteoglycan synthesis and content [75]. In other studies, exposure of healthy human cartilage to $50 \% v / v$ blood similarly decreased proteoglycan synthesis, increased sGAG and resulted in temporal release of IL- $\beta$, TNF- $\alpha$, and IL-6 for up to 10 days [76-78]. Traumatized (i.e., bluntly injured) OA articular cartilage explants exposed to (20-30\% $v / v$ ) human serum and also cartilage homogenate caused significantly more deposition of complement C5b-9 (i.e., TCC), increased the expression of several injury/inflammatory genes, including MMP-13, IL-8, and CXCL1, and increased chondrocyte cell death vs. trauma alone [52]. Moreover, the inactivation of complement by heat inactivation of the serum prevented most of the effects, suggesting that the exposure of cartilage tissue to blood potentiates injurious effects through complement system activation. In the human arthritic joint, complement proteins are produced by synoviocytes, chondrocytes, macrophages and osteoblasts in the subchondral bone and the activation of complement increases in response to IL-1 $\beta$, TNF- $\alpha$ or blunt mechanical injury in the presence of serum [52,79-86]. While the evidence to date is inconclusive on whether this could account for the increased complement components in the SF in the acute stage of inflammation after knee trauma (Figure 1), it suggests that such models may be useful for understanding the early acute to subacute blood-induced injurious mechanistic effects of knee trauma.

Furman et al., in 2007, were the first to report a non-invasive intra-articular tibial plateau fracture PTOA model [87]. This intra-articular high energy fracture model uses a blunt impact to the proximal tibia and has been generally performed in C57BL/ 6 mice. It is capable of producing a fracture to the articular cartilage and subchondral bone, as well as the release of blood and bone marrow into the synovium, which is accompanied by subsequent synovial inflammation and articular cartilage degeneration 2 to 52 weeks after impact [87-90]. Tibial plateau fracture mouse models using either low or high energies since then have shown similar outcomes with the loss of articular cartilage and sGAG depletion, reduced chondrocyte viability, synovitis, and the presence of circulating IL- $1 \alpha$, IL- $\beta$, TNF- $\alpha$, and IL-6 [89-91] demonstrating that such fracture models mirror all stages of clinical PTOA. Moreover, it has a very high (87-95\%) success rate in creating a fracture [92]. Similar to articular cartilage injury models that show that mechanical force cause various types of damage ranging from single cartilage ECM fracture to full intra-articular fractures [93-95], this type of intra-articular fracture injury model is capable of resulting in both simple and complex fractures of the tibia and, thus, resembles sports and accident-induced high impact joint injuries.

It has been shown that injuries of the ACL and menisci result in PTOA $\leq 1$ year $[38,39]$ or up to 10 to 20 years after initial injury [3]. Commonly used models for ACL injury include non-invasive and invasive models. A non-invasive ACL rupture single tibial compression overload model applies a single load of 8-12 $\mathrm{N}$ at both high $(500 \mathrm{~mm} / \mathrm{s})$ [96] and low speeds $(1 \mathrm{~mm} / \mathrm{s})$ in C57BL/ 6 mice $[96,97]$. While the two injury models did not significantly differ from one another with respect to long-term changes in bone structure, 
joint laxity, and articular cartilage degeneration, the models were able to induce moderate to severe PTOA 8-10 weeks post injury. Low speed injury also caused synovial hyperplasia (days 3-15), synovial inflammation (days 3-28) as well as sGAG loss (8 weeks) and fibrosis (24 h-8 weeks). Using an in vivo fluorescence reflectance imaging (FRI) quantification method, this same group demonstrated that the high speed injury model increased the activity of cathepsin proteases produced by activated macrophages and neutrophils, as well as the activity of MMPs and cathepsin $\mathrm{K}$, which is involved in bone resorption and aggrecan degradation and, interestingly, while the levels peaked 1-7 days post-injury, their activity remained present up to 8 weeks post-injury [97], further confirming the chronic presence of activated macrophages and neutrophils after knee trauma. Another study showed that three different compression forces $(3,6$, and $9 \mathrm{~N})$ applied for 60 cycles with $10 \mathrm{~s}$ of rest between each cycle similarly increased the apoptosis of chondrocytes, COL1 expression (day 14), cartilage matrix degradation, and the disruption of the cartilage collagen fibril arrangement and decreased the pericellular aggrecan intensity in the injured region, while the high energy injury caused faster and more substantial post-traumatic synovitis and fibrotic scores, cell death in the deeper zone cartilage, and loss of proteoglycans compared to moderate and low energy injuries [98]. All of the compressive (low to high) forces also mimicked the systemic effects of injury as a similar, albeit lower, concentration of these markers was present in the uninjured contralateral limb and COMP fragments were present in the serum. Trabecular bone loss also occurred in the uninjured contralateral limb. Because this model ruptures the ACL by mechanical forces that are externally applied to the joint, this may also result in injury to other joint structures (i.e., cartilage, menisci, and subchondral bone), depending on the amount of force applied. This model is easy to perform, highly reproducible, and avoids confounding factors, such as infection, that may be associated with invasive injury models and is representative of the clinical phases of PTOA. However, it needs to be taken into consideration that the murine model is better for investigating the acute to subacute phases of injury, as it results in severe posterior bone erosion on the medial side of the tibial plateau, which is reportedly atypical of ACL injuryinduced PTOA in other animal species or in humans [96]. It also often causes extreme erosion of both bone and cartilage 10 or more weeks after injury.

Other animal studies included invasive injury models by applying ACL surgical transection (ACLT) with or without additional partial medial meniscectomy (MMX) to investigate the impact on articular cartilage and the expression profile of various inflammatory and chondrogenic markers. Bajpayee et al. performed unilateral ACLT on 3-month-old mature female New Zealand rabbits and found that, compared to the contralateral uninjured knee, the levels of IL-1 $\beta$, MMP-1, 3 and 13 significantly increased in cartilage explants 3 weeks after surgery, while ACAN expression levels significantly decreased and stayed significantly low at 9 weeks after surgery. While the expressed levels of MMP-3 and -13 remained elevated in the cartilage samples at week 9 after injury, IL-1 $\beta$ levels significantly decreased [99]. This is in line with the clinical data (Figure 1) showing an initial increase of IL-1 $\beta$ in the acute and subacute phase (up to 1.5 months) after injury which disappears in the chronic phase. In another study, Pickarski et al. compared the effects proceeding two different PTOA models using ACLT and ACLT + MMX in 10-week-old male rats. They demonstrated that, in both models, the expression of MMP-13, as well as aggrecanase-1, significantly increased in the articular cartilage samples at the first time point 1 week after surgery, where MMP-13 continued to increase, reaching the peak at 10 weeks, while aggrecanase- 1 levels remained steady but high vs. the contralateral uninjured knee [100]. The gene expression of SOX9 and COL2A, which are chondrogenic phenotype markers of the chondrocytes, increased in the first week but then returned to normal levels by the tenth week after injury and, unexpectedly, the levels of expressed SOX9 and COL2A were lower in the ACLT + MMX model, compared to the ACLT model. However, both ACLT and ACLT + MMX models lead to degradation of the articular cartilage. It is notable that this invasive ACLT model may lead to unintended outcomes due to the disruption of the natural joint environment, e.g., incomplete retinaculum repair with patella maltrack- 
ing, which may increase the rate of subsequent joint degeneration [101]. This procedure may also irritate the fat pad that could additionally increase intra-articular inflammation. Therefore, it has been suggested that this model is not entirely representative of human ACL injury.

When considering the use of animal models, it is important to note genetic and/or anatomical differences in animals compared to humans [102-106]. The injury models discussed here have been performed on mice, rats and rabbits. Each of these animal species has their advantages and disadvantages $[102,103]$. While naturally occurring OA is common in rabbits, they have a much higher chondrocyte density than other species, and the thickness and cellularity of the transitional and radial zones of chondrocytes is highly variable. Moreover, rabbit articular cartilage spontaneous heals and regenerates, especially in young animals up to 5 months of age. Rodent models have a significantly smaller joint size and thinner articular cartilage than humans, but they serve as the most cost-effective models for feasibility, preclinical studies and mechanistic studies. Mice do not exhibit distinct chondrocyte zonal depth arrangements as humans do in the superficial, transitional, and radial zones of the cartilage. Additionally, the radial zone makes up nearly two-thirds of the rat articular cartilage thickness. Another microstructural difference is that human articular cartilage displays joint surface-specific cell arrangements in the large joints termed "superficial chondrocyte spatial organization", which other species do not display [107-110]. In the context of inflammation and articular cartilage regeneration, it is important to point out that certain mouse strains (e.g., MRL/MpJ, LG/J, and LGXSM-6 mouse strains) have shown a superior regenerative and healing response of the articular cartilage, as well as other tissues, compared to other mouse strains (e.g., C57BL/6, LGXSM-33) [104,105,111,112]. In fact, in a closed articular tibial plateau fracture, the PTOA model MRL/MpJ mice had lower systemic IL-1 $\alpha$ and higher anti-inflammatory cytokines IL-4 and IL-10 present than C57BL/ 6 mice. When comparing the injured to the uninjured knee, in contrast to C57BL/ 6 mice, MRL/MpJ mice showed no differences in the histologic grading of articular cartilage degeneration, bone density, or subchondral bone thickness [111]. This suggests that, e.g., C57BL/6 may be more beneficial for knee PTOA studies. Moreover, unlike rats, mice have naturally occurring OA as well as a rapid disease onset. Importantly, the availability of genetically modified mouse strains provides the opportunity to study the molecular mechanisms contributing to PTOA development.

\subsection{Considerations in Using In Vitro Chondrocyte and Ex Vivo Articular Cartilage Models}

While the experimental environment of cell-based or articular cartilage explant models may not fully simulate the joint tissues post-trauma, such models decrease the overall complexity and allow application of injury and/or inflammatory cytokines in controlled, defined microenvironments. Ex vivo tissue articular cartilage explant studies permit the preservation of the cells in their natural three-dimensional environment and the maintenance of cell-matrix interactions and cartilage zonal cell arrangements. Moreover, mechanical injury, e.g., through single vs. repetitive impact, can simulate different types of trauma or ranges of trauma extent and, thus, apply different forces to the tissue and the cells within their native ECM. Such studies allow us to probe input-output behavior and bridge gaps in mechanisms of post-injurious inflammation, helping to identify the specific mechanisms that contribute to post-injurious perpetuation of inflammation and subsequent PTOA. These studies also allow for linking the observed effects to both cell and tissue behavior, helping us to understand cytokine and/or cell-cell crosstalk, and will one day help in explaining the presence of differing responses between patient groups and the progression to PTOA in many, but not all, patients.

Before we discuss these models, we will discuss the source of articular cartilage tissue used in in vitro and ex vivo models. The majority of cell-based in vitro studies have used primary chondrocytes of human origin. Others have used primary bovine chondrocytes or cell lines, such as the chondrosarcoma SW-1353 human cell line, the murine chondroprogenitor ATDC5 cell line derived from AT805 teratocarcinoma cells or 
immortalized human juvenile costal-derived chondrocyte T/C-28a2 cells. Obviously, there are pros and cons for each source. Cell lines are convenient, but they do not fully represent a primary cell. For example, T/C-28a2 and SW-1353 human cell lines are not suitable for studying NO release and iNOS expression because, in comparison to ATDC- 5 cells, these cells are incapable of producing NO and expressing iNOS in response to LPS, IL- $1 \alpha$, or IL-1 $\beta$ treatment [113]. ATDC5 cells are an acceptable alternative as they imitate the articular chondrocyte phenotype and they have been successfully used in inflammatory in vitro models of OA [113-117]. However, an important question remains; namely, how the accumulated data translate to the clinical outcome.

Articular cartilage explant studies tend use bovine or human tissues. The advantage of using bovine tissue is that it is easily accessible and a healthy source of young and adult tissue that could be used to better understand disease progression in different age groups, especially if both injury and inflammatory factors are applied. Another advantage of bovine cartilage explant is the development of naturally occurring $\mathrm{OA}$ in multiple bovine joints that very closely mimic the onset and progression in aging humans [103]. Therefore, bovine tissue is useful for investigating the early disease onset or in preclinical assessments aimed at prevention of early disease. One disadvantage of bovine cartilage is its decreased thickness and higher cellularity compared to human cartilage [100]. However, access to healthy human cartilage is difficult and, for this reason, most of the human injury and/or inflammatory studies have been performed on tissue explants or on chondrocytes isolated from human patient OA articular cartilage. While some studies grade their tissue and use "healthier" parts, e.g., macroscopically intact-appearing areas, the tissue cannot be considered truly healthy due to disease presence and exposure to inflammatory cytokines and degradative enzymes present in the joint. However, the use of different grades of diseased OA tissue may be beneficial for simulating chronic inflammation, especially if the media is supplemented with the chronic inflammatory cytokines present in the diseased joint (Figure 1). This suggests that, in some settings, human tissue-based models may be more relevant due to the morphological, physiological and biochemical tissue properties, whereas basic science studies can very well address mechanistic questions in cells and tissues other than human. Because cells and tissues are derived from patients with differences in, e.g., age, genetics, or co-morbidities, it is often unavoidable to investigate a larger number of patient tissue explants or use stratification strategies to better understand outcomes and treatment effects.

An important consideration of inflammatory or other in vitro studies is the arising dedifferentiation of chondrocytes that stem from culturing cells on conventional tissue culture plastic [118]. It is well known that chondrocytes in monolayer culture undergo in vitro dedifferentiation exhibited by a change in their cell morphology, transitioning from a spherical morphology to a flat spindle-like morphology, with a corresponding change in the cell gene expression profile exhibited by an increase in type I collagen (COLIA2) and decrease in type II collagen (COL2A1) expression that results in lower quality cartilage ECM. This process occurs early after the expansion of primary chondrocytes in cell culture and increases with increasing passage $[119,120]$. For example, previous studies have used alginate bead and pellet culture [121,122], serum or growth factors combined with subsequent alginate bead cultures [123], pellet cultures combined with low oxygen concentrations [124], co-cultures with mesenchymal stromal cells (MSCs) on a porous surface [125], agarose hydrogels with varying RGD adhesion site densities and mechanical properties [126], single-component photo-crosslinkable hydrogels [127], and chimeric Activin A/BMP2 ligand AB235 [128] to attempt re-differentiation of passaged chondrocytes. These studies generated valuable insight by inducing the re-differentiation of human OA chondrocytes obtained during joint replacement procedures $[121,123,124,127,128]$ and of porcine and bovine chondrocytes [125,126]. In one of our own studies, we cultured patient- and joint surface-matched human OA chondrocytes vs. OA chondrons, which are OA chondrocytes within their retained pericellular matrix, in a self-assembling peptide hydrogel. Interestingly, human OA chondrons displayed a significant long-term survival 
advantage over chondrocytes in hydrogel culture [129]. Thus, retaining a native cartilage structure presented a significant advantage in stabilizing the chondrocyte phenotype. In another study, we evaluated human chondrocytes isolated from articular cartilage lesion sites vs. knee joint notch sites and showed that, after monolayer expansion, redifferentiating lesion chondrocytes cultured in alginate beads resulted in a pool of cells with a greater chondrogenic potential compared to expanded and de-differentiated notch chondrocytes, indicating that ex vivo re-differentiated lesion chondrocytes may hold nonutilized clinical potential for tissue engineering articular cartilage [130]. On a side note, such location-based investigations are important because chondrocyte metabolic characteristics differ across joints [131-135], whereas other characteristics such as the abovementioned chondrocyte arrangements within the tissue differ, even between individual joint surfaces within the same joint $[107,110]$ and between different stages of OA $[108,109,136]$. Thus, while there are various methods to delay chondrocyte dedifferentiation, current methods have not achieved complete success in preventing this process. However, because relatively few chondrocytes are present in the tissue, the expansion of chondrocytes is essential to achieve experimentally (and clinically) relevant cell numbers. Therefore, although these studies are essential, these points need to be considered.

A study by Tsuchida et al. elucidated the effect of culturing chondrocytes on the production of various inflammatory mediators [137]. This study showed that most of the concentrations of inflammatory cytokines, such as IL- $1 \alpha$, IL-6, and TNF- $\alpha$ in the cartilage from tissues with grade III and IV focal defects or from OA tissue were 10- to 100 -fold higher than those measured in the SF. Remarkably, the cytokine production by chondrocytes in cell culture was much higher for many inflammatory mediators, compared to articular cartilage. This is in contrast with the general belief that synovial cells are the main source of inflammatory mediators in articular joints and, instead, indicate that the chondrocytes within their native tissue can act as a primary source of the production of many cytokines. Moreover, there were large variations in the concentrations of these inflammatory mediators after 7 days of culture of chondrocytes, which were seeded onto collagen-coated plates directly after isolation vs. those that were seeded at passage 2 . In addition, some cytokines, such the pro-inflammatory IL- $1 \alpha$ and IL- 8 cytokines and antiinflammatory IL-4, IL-10 and IL-13 cytokines, were absent in protein extracts from healthy native tissue, whereas they were produced in healthy chondrocyte cultures. This suggests a response to culture, although a head-to-head comparison of directly isolated chondrocytes and cultured chondrocytes vs. isolated cartilage explants, as well as cultured cartilage explants would be needed to fully conclude this. These results and the resuls of another study [138] show that chondrocytes are clearly capable of contributing to inflammation, and this process may represent a normal healing or regenerative response to cell culture. These findings should be considered in future in vitro studies using chondrocytes as a representative model by clearly stating and discussing the cell source and culture details to avoid misleading data and/or inaccurate interpretations. This also further supports performing combined studies at multiple levels when assessing inflammation or antiinflammatory treatment strategies for a better representation of the full narrative.

\subsection{In Vitro Chondrocyte and Ex Vivo Articular Cartilage Explant Injury and/or Inflammatory Models}

Other reviews $[139,140]$ have well described how articular cartilage explant models have used various types of injurious compression protocols to simulate mechanical injury and have demonstrated that, despite differences in protocols, these models show that they similarly and successfully induce the clinically observed pathologies following trauma to the knee joint. Hence, the mechanically-induced injury of articular cartilage leads to a significant increase in chondrocyte death, ECM loss, expression of matrix-degrading enzymes and a decrease in the COL2 gene and, to some extent, an increase in inflammatory cytokines even in the absence of inflammatory cells, such as macrophages [141-153]. Some studies have used a combination of mechanical injury and inflammatory cytokine treatment, typically using IL- $1 \alpha$, IL- $1 \beta$, TNF- $\alpha$, IL-17, or the combi- 
nation of TNF- $\alpha /$ IL-6/sIL-6R [143-146,148,152,154] to mirror trauma and the presence of cytokines that are significantly present with the injured knee.

Articular cartilage explant and in vitro chondrocyte studies, using cells or tissue derived from either OA or healthy sources have shown that IL- $1 \alpha$ treatment alone is capable of increasing production of MMP-1, 3, 9 and -13 and ADAMTS- 4 and -5 , decreasing proteoglycan synthesis and increasing the loss of sGAG [144,148,149,155-157], while IL-1 $\beta$ alone is capable of enhancing NO production, collagenase activity, IL-6, IL-8, LIF, MMPs (MMP-1, -3, -13, -7, -9, -12), complement components, chemokines as well as aggrecan release; and inhibiting type II collagen, NF-kB binding activation and phosphorSmad2/3 [69,147,152,158-164]. These studies, as well as animal models, showed that IL-1 $\beta$ is involved in inflammation and cartilage degradation. However, Bougault et al. demonstrated that IL-1 $\beta$ was not produced by OA articular cartilage itself but rather by synovial tissue [165]; therefore, the source of IL-1 $\beta$ could be synovial fibroblasts or other cells such as macrophages.

TNF- $\alpha$ alone similarly increased IL-6, IL-8 and LIF, MMPs (MMP-1, -3, -9 and -13), ADAMTS-5 and -4, complement components, chemokines as well as aggrecan fragment and SGAG release and decreased COL2 expression of isolated chondrocytes but only increased NO production when used at high concentrations [143-147,157,160,161,166-169]. In addition, TNF- $\alpha$ induced the expression of IL-1 $\beta$ in healthy human chondrocytes [166]. Moreover, Patwari et al. showed that the combination of injury and TNF- $\alpha$ caused higher loss of sGAG compared to either alone [144].

IL-17 alone dose-dependently increased MMP-1, $-3,-13$, and MCP-1 and decreased TIMP, COL2A1, and SOX9 mRNA expression in human OA chondrocytes [170]. When IL-17 was combined with low concentrations of IL- $1 \beta$, the combination increased NO production and decreased GAG synthesis in a rat patellar articular cartilage explant model greater than either cytokine treatment alone. This study, like other studies on articular cartilage explants, chondrocytes and/or synoviocytes suggest that IL-17 acts synergistically with IL-1 $\beta$ or TNF- $\alpha[152,153,169,171-178]$, potentiates inflammatory gene expression (e.g., IL-6, IL-8, TNF- $\alpha$ ) and MMP expression, and causes catabolic effects, such as ECM component loss and a decrease in the mRNA expression of chondrogenic markers, such as SOX9, XYLT1, COL2A1, and ACAN. IL-17A also caused the release of MMP-2, and -9, sGAG, the ADAMTS-mediated aggrecan degradation fragment (exAGNx1) and MMP-mediated type II collagen (C2M) in a bovine full-depth articular cartilage [150]. Moreover, this study showed that the proteomic analysis of conditioned media from IL-17A treated articular cartilage revealed an upregulation of IL-6, MMP-3, ADAMTS-4, neutrophil/macrophage chemoattractants CXCL6 and CCL20 (also known as macrophage inflammatory protein-3 alpha, MIP-3 $\alpha$ ), complement factor B, latent TGF- $\beta$-binding protein 2 and chitinase 3 -like 1 (CHI3L1 or YKL-40), a secreted glycoprotein linked to OA, compared to control-treated tissue. This study and another study suggest that the exposure of chondrocytes and synoviocytes to IL-17, which led to the increased expression of granulocyte-attracting regulating genes and release of chemokines, could further drive inflammation by inducing the influx of mononuclear cell influx, such as macrophages [173,174].

IL-17 also inhibited TGF- $\beta 3$-induced the chondrogenic differentiation of human MSCs [179], which may be locally present after knee trauma, or at least after surgical procedures, such as microfracture [180] or combined microfracture and autologous chondrocyte implantation (ACI) $[181,182]$. Therefore, theoretically, TGF- $\beta$ would also be subjected to IL-17 modulation. For other effects of TGF- $\beta$ on chondrocytes and/or MSCs, we refer the interested reader to our recent reviews $[13,183]$.

Many IL-17 effects can be reversed by the removal of e.g., IL1- $\beta$ and IL-17A from the media [152] or by pre-treatment with an IL-17 receptor antibody [175], dexamethasone, or kinase inhibitors $[172,176]$. Secukinumab, a human monoclonal antibody that binds to IL-17A, is already used clinically to treat arthritis-associated symptoms and joint disease damage in ankylosing spondylitis and psoriatic arthritis, further supporting the antagonistic role of IL-17A in joint disease [184]. These studies demonstrate that, like TNF- $\alpha$ or 
IL- $\beta$, IL-17 is strongly capable of enhancing inflammation and causing catabolic effects that lead to degeneration of articular cartilage; and that potentiating effects of cytokine combinations with IL-17 surpass those of individual cytokines. This review, in the context of PTOA of the knee, as well as others reviews, suggest that IL-17 is a crucial pathogenic molecule in local and systemic disease pathogenesis in many types of disease tissues and that IL-17 signaling may promote chronic disease development [185-189] emphasizing the need for further mechanistic IL-17 studies in various contexts.

Whereas most studies generally focus on the use of one cytokine, a few studies have used a combination of TNF- $\alpha$, IL- 6 and soluble IL- 6 receptor (sIL-6R) to better simulate the inflammatory environment existing after knee trauma. Before proceeding to their effects on articular cartilage, we first briefly discuss the two mechanisms, by which IL-6 interacts with target cells $[190,191]$. IL-6 is capable of binding to the membrane-bound IL-6 receptor (IL-6R), a receptor that alone lacks signaling capacity because it does not contain a signal transduction domain. When the complex of IL-6/IL-6R binds to a second membrane receptor called glycol-protein 130 (gp130), the dimerization of gp130 occurs, which initiates intracellular signaling. This "classical" form of IL-6 signaling is important in the acute phase of inflammation. Interestingly, while gp130 is found in all cell types, the membrane-bound IL-6R is expressed in only a few cell types, such as neutrophils, monocytes, and macrophages as well as in naive and memory T cells. IL-6 can also exert its effects through a second mechanism by interacting with the soluble form of the IL-6 receptor (i.e., sIL-6R) that is generated through proteolytic actions (e.g., by protease disintegrin and ADAM enzymes). The sIL-6R binds to IL- 6 with a similar binding affinity as the membrane-bound IL-6R and rather than competing with the membrane-bound IL-6R, the complex of sIL-6R/IL-6 bind to gp130-expressing cells and, thereby, induce intracellular "trans-signaling". This mechanism of signaling leads to a more robust activation of the IL-6 intracellular signaling pathway that promotes the chronification of disease [191].

In healthy bovine articular cartilage, the addition of IL- 6 and sIL-6R alone was able to increase the latent form of MMP-3 (pro-MMP-3), with increases in proMMP-3 being more prominent with the addition of TNF $\alpha$ [146]. However, the application of mechanical injury and TNF- $\alpha / \mathrm{IL}-6 /$ sIL-6R to articular cartilage markedly increased MMP-1, 3, and -10 and aggrecanase-mediated, rather than MMP-mediated, aggrecan catabolism and produced a more pronounced loss of sGAG and COMP and COMP Ser ${ }^{77}$ neoepitopes $[143,145,146,192,193]$. The exposure of non-injured articular cartilage to TNF- $\alpha /$ IL-6/ sIL-6R alone for up to 3 weeks resulted in a similar release of both intact COMP and COMP $\mathrm{Ser}^{77}$ neoepitopes into the surrounding media of articular cartilage explants to levels found in the SF of patients suffering from acute knee pain with or even without acute trauma [192]. Therefore, such combinations may be more suitable for understanding the complex, not yet understood chronic effects after injury.

\subsection{Co-Culture Studies}

Even though chondrocytes are a strong source of pro-inflammatory cytokines, as discussed above, the elevated levels of inflammatory cytokines in both articular cartilage and SF suggest the role of other cells, in addition to chondrocytes, in governing inflammation. Therefore, co-culture studies can aid in understanding the role of specific cell types, such as macrophages or synovial fibroblasts, in the development and progression of PTOA.

Several studies demonstrated the importance of synovial fibroblasts as well as macrophages in clinical knee OA [174,194-197]. Synovial membrane biopsies from untreated PTOA knee joints contain a high number of macrophages and fibroblasts as well as thicker collagen bundles in the sublining and subsynovial regions of the synovium [194]. Wood et al. detected the presence of two types of macrophages in patients, with knee OA having distinct functional gene signatures, which were defined as articular cartilage remodeling and inflammatory macrophages, respectively [196]. The presence of soluble macrophage CD163 and CD14 markers in the SF and plasma were shown to correlate with pain and with OA structural damage progression, i.e., joint space narrowing and osteophyte severity, in the knee joint [195]. After 
fracture of the tibia plateau MRL/MpJ mice, which are known to generally heal and regenerate tissues faster [104,105,111], had a lower intra-articular and systemic inflammatory response compared to wildtype CD7BL/6 mice which may be attributable to reduced synovial macrophages present after joint injury, as macrophage chemoattractants were also reduced in these mice [112]. Together, these studies suggest that macrophage-related inflammation help drive and may predict PTOA progression.

To resemble the in vivo joint, some studies have used co-cultures of bovine articular cartilage explants combined with the joint capsule containing the synovial membrane [198-200], as it is responsible for producing the SF and contains synovial fibroblasts, as well as lymphocytes and monocytes that could affect the inflammatory environment. In these studies, the proteolytic activity of both MMPs and aggreganases were elevated when the synovial joint capsule was added to mechanically injured cartilage, and, consequently, the concentration of released aggrecan fragments, e.g., ARGS, was higher in the medium, while GAG synthesis was significantly decreased, demonstrating the direct contribution of the synovial joint capsule in post-injurious articular cartilage damage. Interestingly, this same group showed that the human and bovine joint capsule from a normal knee joint released a 20-25 kDa heat-labile factor that was capable of causing a 40 to $60 \%$ decrease in cartilage proteoglycan synthesis and the inhibition of IL-1 and/or TNF- $\alpha$ was unable to prevent sGAG loss, suggesting that the joint capsule is capable of releasing an IL-1 or TNF-independent pathway cytokine or other factor, which strongly inhibits cartilage biosynthetic activity [200]. IL-17 could be a candidate for this factor, as it is within this molecular weight range.

Similarly, Beekhuizen et al. used a human in vitro single vs. co-culture model comprised of articular cartilage explants and synovial tissue to study the contribution of both in OA tissues [201]. Whereas mono-cultured cartilage released IL-1 $\beta$, IL-4, IL-7, IL-10, and IL-13, the synovial tissue culture released IL-6, IL-8 and IL-1ra. Most of the cytokines detected in the co-cultured articular cartilage/synovial explants matched with cytokines measured in OA SF, suggesting that both tissues are capable of contributing to an inflammatory environment, but with a differential response. Another study demonstrated that the inflammatory milieu of OA SF inhibited the cell viability of chondrocytes, altered their cell morphology by producing smaller and more globular-like cells that had reduced cell-cell contacts and significantly increased the concentrations of IL-6, IL-8, MCP-1 as well as vascular endothelial growth factor (VEGF) [202]. These studies highlight the use of in vitro co-culture studies in gaining insights into post-traumatic mechanisms as well as their contribution in promoting post-injurious effects and inflammation.

In vitro models have further assessed the role of macrophages to understand how these pro-inflammatory or anti-inflammatory cells could enhance the inflammatory environment and OA progression. In a 3D co-culture model containing either healthy chondrocytes or OA chondrocytes and pro-inflammatory M1 macrophages, there was a simultaneous increase in both matrix degradative enzymes, including MMP-1 and -3 and pro-inflammatory cytokines IL-1 $\beta$, TNF- $\alpha$, IL-8, MCP-1 and IFN- $\gamma$ [203], demonstrating that (lipopolysaccharide (LPS)-stimulated) M1 macrophages are capable of initiating inflammation and inducing cartilage degradation at both an early stage (i.e., prior to OA) in healthy cells, as well as during later stages of OA. In line with this study, another study showed that conditioned media from (IFN- $\gamma+$ TNF- $\alpha$ stimulated) M1 macrophages upregulated IL- $1 \beta$, IL-6, MMP-13 and ADAMTS5 and inhibited ACAN and COL2A1 expression in human articular cartilage explants, further endorsing the role of M1 macrophages in disease progression [204]. Together, these results manifest a remarkable effect of the synovial inflammatory environment in the progression of inflammation, articular cartilage destruction and disease progression. All of these studies reinforce the validity of co-culture systems as relevant and helpful PTOA models. 


\section{Clinical Findings vs. Experimental Evidence}

5.1. Comparing the Concentrations of Inflammatory Cytokines Used in Laboratory Models vs. the Clinical Presentation

While the results of the models discussed in this review match the profile of the clinical presentation of patients after knee joint trauma and, therefore, are useful models for investigating the post-injurious effects and mechanisms of inflammation, it is important to note that most of the laboratory studies applied markedly higher concentrations of IL- $1 \beta$, TNF- $\alpha$, IL- 6 and IL-17 than those measured in the SF of the knee joint after knee trauma (Table 3), especially IL-1 $\beta$ or TNF- $\alpha$. While the IL- 6 and IL-17 concentrations used in laboratory models were not as exceedingly high, they were still higher than physiological concentrations found after knee joint trauma. Importantly, although this problem in the study design has been raised in the context of OA [185,205], the present review concludes that a comparable problem affects studies pertaining to PTOA. Therefore, future study designs may consider investigating cytokine concentrations that are similar to the range found in the SF of joints after trauma or PTOA. By doing so, one may discover new facets of articular cartilage biology, which is especially important in pre-clinical assessments of acute anti-inflammatory and/or regenerative PTOA treatments aiming to reduce inflammation and early articular cartilage damage.

Table 3. Concentrations of pro-inflammatory cytokines measured in the synovial fluid after knee trauma or in clinically diagnosed cases of knee OA vs. those used in in vitro chondrocyte and ex vivo cartilage explant models.

\begin{tabular}{ccccc}
\hline Cytokine & $\begin{array}{c}\text { Concentration in } \\
\text { Synovial Fluid }\end{array}$ & $\begin{array}{c}\text { Phase Present after } \\
\text { Knee Trauma }\end{array}$ & $\begin{array}{c}\text { Concentration Used in } \\
\text { Laboratory Models }\end{array}$ & Fold Change \\
\hline IL-1 $\beta$ & $\begin{array}{c}0-25 \\
\mathrm{pg} / \mathrm{mL}\end{array}$ & Acute, Subacute, PTOA & $25-1 \times 10^{5} \mathrm{pg} / \mathrm{mL}$ & $50-400 \times$ \\
\hline TNF- $\alpha$ & $\begin{array}{c}7-20 \\
\mathrm{pg} / \mathrm{mL}\end{array}$ & $\begin{array}{c}\text { Acute, Subacute, } \\
\text { Chronic }\end{array}$ & $100-1 \times 10^{6} \mathrm{pg} / \mathrm{mL}$ & $77-5000 \times$ \\
\hline IL-6 & $1-66,099 \mathrm{pg} / \mathrm{mL}$ & $\begin{array}{c}\text { Acute, Subacute, } \\
\text { Chronic, PTOA }\end{array}$ & $100-2 \times 10^{6} \mathrm{pg} / \mathrm{mL}$ & $3-5 \times$ \\
\hline IL-17 & $\begin{array}{c}2-8 \\
\mathrm{pg} / \mathrm{mL}\end{array}$ & Chronic, PTOA & $100-1 \times 10^{6} \mathrm{pg} / \mathrm{mL}$ & $12-52 \times$ \\
\hline
\end{tabular}

\subsection{Comparing the Results of In Vivo, Ex Vivo and In Vitro Laboratory Models vs. the Clinical Presentation}

One of the questions that we address in this review is whether the various in vivo, in vitro and ex vivo models of inflammation and/or injury simulate the clinical scenario and adequately replicate the different stages of post-injurious inflammation that occur after acute clinical trauma in the human knee joint. To address this question, much like the clinical studies that generally excluded patients with prior joint pathology, we focused on the animal models (Figure 2A) discussed in this review as well as articular cartilage (Figure 2B) and chondrocytes (Figure 2C) obtained from healthy (i.e., non-OA) tissue. 


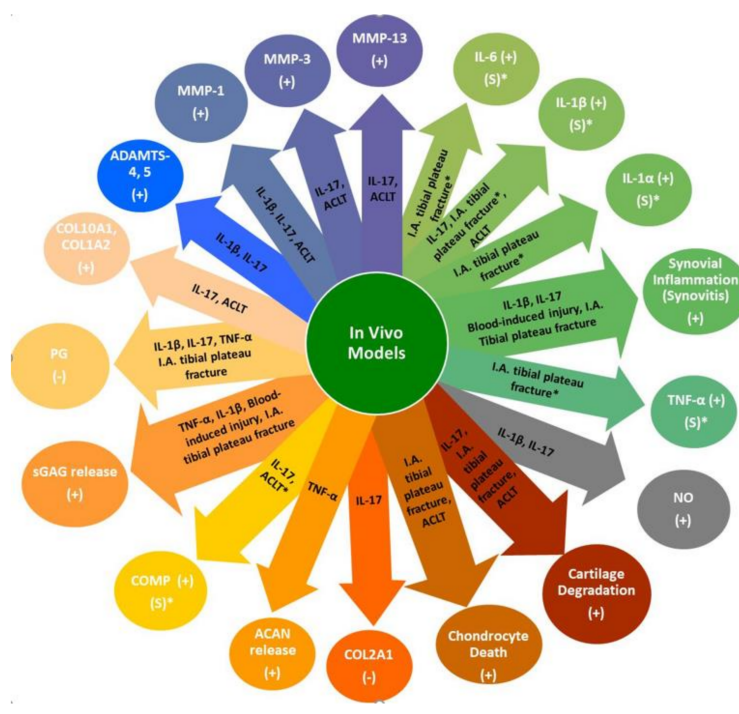

(a)
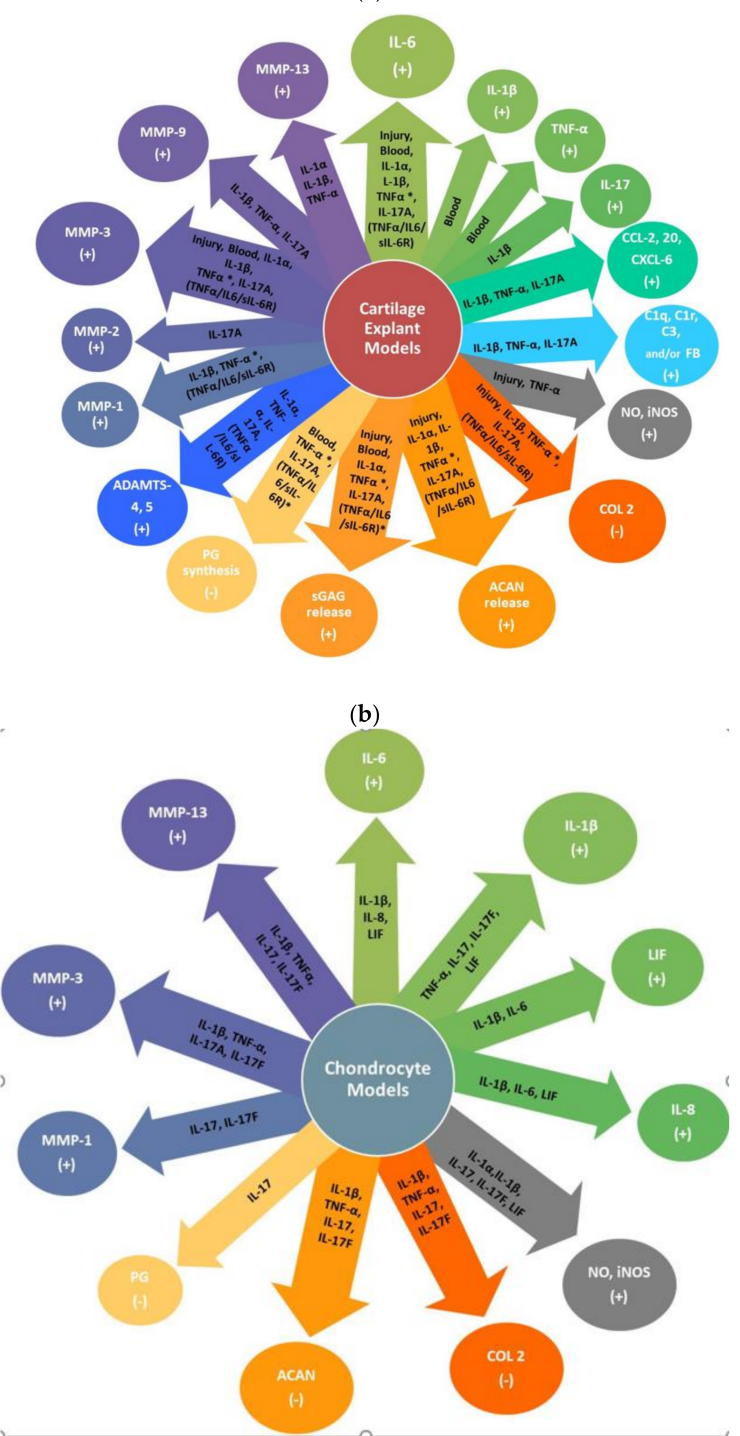

(c)

Figure 2. The effects of injury and/or inflammatory cytokines in in vivo models and ex vivo and 
in vitro models using tissue and chondrocytes from non-0A (healthy) articular cartilage. A (-) sign indicates a decrease and a (+) sign an increase. (a) In vivo models effects showing the effects of intra-articular injection of IL-1 $\beta[69,70]$, TNF- $\alpha$ [71], or IL-17 [69,70] alone, blood-induced injury [73], intra-articular (I.A.) acute tibial plateau fracture [87-92], or ACLT which includes data from the non-invasive ACL rupture single tibial compression overload model and invasive ACLT model [96-101]. The * indicates the corresponding model that showed an increase of that marker in the serum (S). (b) Ex vivo cartilage explant models using non-0A (healthy) tissue showing the effects of blood-induced injury [76-78], mechanical injury using a single injurious compression without the addition of any pro-inflammatory cytokines [93,141,143,144,206,207], inflammatory cytokines IL- $1 \alpha$ alone $[144,149,155,156]$ or combined with injury* $[144,148]$, IL-1 $\beta$ alone $[147,152]$, TNF- $\alpha$ alone [144-147] or combined with injury* [143-146], IL-17A alone [150], and TNF- $\alpha /$ IL-6/sIL-6R alone $[143,146,154]$ or combined with injury* $[144,148,154]$. (c) In vitro chondrocyte models using cells isolated from non-OA (healthy) cartilage tissue showing the effects of IL-1 $\alpha$ [157], IL-1 $\beta$ [159,160], TNF- $\alpha$ [166,167], IL-17 or IL-17F [172,175], IL-6 or IL-8 [160], and LIF [160,175].

As shown in Figure 2B,C, the application of blood, mechanical injury, pro-inflammatory cytokines, or their combination in the various in vitro models on healthy chondrocytes and ex vivo models of healthy articular cartilage explants showed similar results to the clinical post-injury data. IL-6, one of the distinctive markers detected in all phases following clinical injury (Figure 1), was significantly increased in these models on the mRNA and protein expression level in response to blood and multiple pro-inflammatory cytokine stimuli (IL-1 $\alpha$, IL-1 $\beta$, TNF- $\alpha$, IL-17, IL-8, LIF and the combination of TNF- $\alpha /$ IL-6/sIL-6R) alone. Similarly, as with the increased MMP-3 noted in clinical studies, MMP-3 was increased in vitro and ex vivo in response to injury or to the presence of pro-inflammatory cytokines (IL-1 $\beta$, TNF- $\alpha$, IL-17, or the combination of TNF- $\alpha$, IL-6 and sIL-6R). The breakdown of ECM components (release of aggrecan and sGAG fragments and decreased proteoglycan and COL2 synthesis) was also apparent in response to injury or IL- $1 \alpha$, IL-1 $\beta$, TNF- $\alpha$, IL-17, or the combination of TNF- $\alpha /$ IL-6/sIL-6R. Although TNF- $\alpha$ was not measured in articular cartilage/chondrocyte injury and/or inflammatory studies, blood-induced injury models on articular cartilage explants showed that the presence of blood was capable of increasing TNF- $\alpha$. These data together, with the continued presence of TNF- $\alpha$ in the chronic stage of inflammation after knee joint trauma (Figure 1), suggest that TNF- $\alpha$ is produced by other cell types, such as synovial macrophages, synovial fibroblasts or T helper 17 (Th17) cells.

These data demonstrate that ex vivo/in vitro models using healthy tissue sources are capable of replicating the various clinical phases after knee trauma. When explant models combine injury with the application of pro-inflammatory cytokines, they can simulate the mechanisms and phases of inflammation that are associated with PTOA of the human knee joint. Moreover, Figure 2C confirms that the in vivo models of intra-articular injection of Il-1 $\beta$ or IL-17 or intra-articular tibial plateau fracture or ACL injury recreate PTOA disease progression. Interestingly, the intra-articular tibial plateau fracture model and ACLT models showed that injury resulted in high levels of IL-1 $\beta$ and/or IL-6 in the serum, indicating that both models also successfully mimicked the systemic effect observed in the clinical early and late PTOA stages. Therefore, these models are capable of fully simulating the acute, subacute, and chronic phases of injury and the PTOA of the knee joint.

\subsection{Assessing Clinical and Experimental Results to Determine if IL-1 $\beta, T N F-\alpha, I L-6$ and IL-17} Are Possible Causal Factors in Inducing Progression towards Knee PTOA

As in vivo (Figure 2A) and ex vivo articular cartilage (Figure 2B) and chondrocyte (Figure 2C) studies illustrated that the presence of one or more inflammatory cytokines alone (i.e., without application of injury) is equally capable of producing the same effects of those induced by injury, these data confirm that inflammatory cytokines lead to prolonged post-traumatic inflammatory and catabolic effects and function in a damage-perpetuating way similar to injury alone. Because IL-1 $\beta$, TNF- $\alpha$, IL-6, and IL-17 were the leading proinflammatory cytokines that led to these effects (Figure 2) and predominated in the clinical setting as well (Figure 1), we used the Bradford Hill Framework [19] to establish whether 
the presence of these factors may lead to a causal PTOA disease effect. As shown in Table 4, nine out of nine criteria were met for TNF- $\alpha$ and IL-6, indicating that there is convincing evidence that the presence of these pro-inflammatory cytokines is causal in PTOA of the knee. Seven out of nine criteria were met for IL- $1 \beta$ and IL-17, indicating that it is credible that these cytokines are causal in PTOA disease progression. The reasons for this credible effect, as opposed to a causal effect, stated for IL-1 $\beta$ and IL-17 will be discussed.

Table 4. Use of the Bradford Hill criteria as evidence of causation between the presence of IL-1 $\beta$, TNF- $\alpha$, IL-6 or IL-17 after knee trauma and a PTOA disease progressive effect. We used this as a framework to evaluate the relationship between the presence of inflammatory markers (IL-1 $\beta$, TNF- $\alpha$, IL-6, or IL-17) at different stages of inflammation after knee trauma to determine whether these markers led to a convincing, credible or probable causal PTOA disease progressive effect or whether the evidence was suggestive, limited, or inconclusive.

\begin{tabular}{|c|c|c|c|c|c|}
\hline & & IL-1 $\beta$ & TNF- $\alpha$ & IL-6 & IL-17 \\
\hline $\begin{array}{l}\text { STRENGTH OF } \\
\text { ASSOCIATION }\end{array}$ & $\begin{array}{l}\text { Association } \\
\text { between risk factor } \\
\text { and outcome }\end{array}$ & $\begin{array}{c}\text { Convincing } \\
{[21,23-27,29,31,39,208]}\end{array}$ & $\begin{array}{c}\text { Convincing } \\
{[23-26,28,32,36,37]}\end{array}$ & $\begin{array}{c}\text { Convincing } \\
{[21,23-26,28,31,32,36,} \\
37,39,208,209]\end{array}$ & $\begin{array}{l}\text { Convincing } \\
{[21,33,55-60]}\end{array}$ \\
\hline $\begin{array}{l}\text { CONSISTENCY OF } \\
\text { FINDINGS }\end{array}$ & $\begin{array}{l}\text { The same findings } \\
\text { are observed } \\
\text { among different } \\
\text { locations, } \\
\text { populations or in } \\
\text { different study } \\
\text { designs including } \\
\text { different types of } \\
\text { injuries }\end{array}$ & $\begin{array}{c}\text { Convincing } \\
\text { While some studies } \\
\text { showed that IL-1 } \beta \text { was } \\
\text { significantly increased } \\
\text { vs. }[21,23-27,29,31,39] \text {, } \\
\text { some studies showed } \\
\text { that it was below the } \\
\text { detection for some } \\
\text { patients }[24,26,28,29,31]\end{array}$ & $\begin{array}{c}\text { Convincing } \\
{[23-26,28,32,36,37]}\end{array}$ & $\begin{array}{c}\text { Convincing } \\
{[21,23-} \\
26,28,31,32,36,37,39]\end{array}$ & $\begin{array}{c}\text { Convincing } \\
{[21,33]}\end{array}$ \\
\hline $\begin{array}{l}\text { SPECIFICITY OF } \\
\text { ASSOCIATION }\end{array}$ & $\begin{array}{c}\text { The factor } \\
\text { influences the } \\
\text { outcome }\end{array}$ & $\begin{array}{c}\text { Credible } \\
\text { Clinically present from } \\
24 \text { h to } 1.5 \text { months in A, } \\
\text { S phases } \\
\text { [21,23-27,29,31] and in } \\
\text { early PTOA [39] } \\
\text { indicating that it } \\
\text { influences disease } \\
\text { progression } \\
\text { Conflicting data: Some } \\
\text { studies showed that } \\
\text { IL-1 } \beta \text { was not present } \\
\text { [28] or only present in } \\
\text { some patients } \\
\text { [24,26,29,31] } \\
\text { Application of IL-1 } \beta \\
\text { in vivo, ex vivo \& } \\
\text { in vitro mirrors clinical } \\
\text { symptoms } \\
\text { (Figure } 2 A-C)\end{array}$ & $\begin{array}{c} \\
\text { Convincing } \\
\text { Clinically present } \\
\text { from } 24 \text { h to } 5 \text { years } \\
\text { in A, S, C phases } \\
{[23-26,28,32,36,37]} \\
\text { Application of TNF- } \alpha \\
\text { in vivo, ex vivo and } \\
\text { in vitro mirrors } \\
\text { clinical symptoms } \\
\text { (Figure } 2 \text { A-C) }\end{array}$ & $\begin{array}{c}\text { Convincing } \\
\text { Clinically present } \\
\text { from } 24 \mathrm{~h} \text { to } 1 \text { year in } \\
\text { A, S, C phases and in } \\
\text { early \& late PTOA } \\
{[21,23-} \\
\text { 26,28,31,32,36,37,39] } \\
\text { IL-6 KO mice } \\
\text { develop more } \\
\text { advanced knee OA } \\
\text { [210] and application } \\
\text { of IL-6 ex vivo and } \\
\text { in vitro mirrors } \\
\text { clinical symptoms } \\
\text { (Figure 2A-C) }\end{array}$ & $\begin{array}{c}\text { Credible } \\
\text { There are only } 2 \\
\text { clinical studies } \\
\text { showing that IL-17 is } \\
\text { present from } 24 \mathrm{~h} \text { to } \\
9.5 \text { days in the A } \\
\text { phase [21] and C } \\
\text { phase (3 or more } \\
\text { months) after injury } \\
\text { [33] } \\
\text { Application of IL-17 } \\
\text { in vivo, ex vivo and } \\
\text { in vitro mirrors } \\
\text { clinical symptoms } \\
\text { (Figure 2A-C) }\end{array}$ \\
\hline $\begin{array}{c}\text { TEMPORAL } \\
\text { SEQUENCE OF } \\
\text { ASSOCIATION }\end{array}$ & $\begin{array}{l}\text { The factor } \\
\text { precedes the } \\
\text { outcome }\end{array}$ & $\begin{array}{c}\text { Convincing } \\
\text { A, S, Early PTOA } \\
{[21,23-27,29,31,39]}\end{array}$ & $\begin{array}{c}\text { Convincing } \\
\text { A, S, C Phases } \\
{[23-26,28,32,36]}\end{array}$ & $\begin{array}{c}\text { Convincing } \\
\text { A, S, C, Early \& Late } \\
\text { PTOA } \\
{[21,23-} \\
26,28,31,32,36,39]\end{array}$ & $\begin{array}{c}\text { Convincing } \\
\text { A, C Phases } \\
{[21,33]}\end{array}$ \\
\hline $\begin{array}{l}\text { BIOLOGICAL } \\
\text { GRADIENT }\end{array}$ & $\begin{array}{l}\text { Dose-response } \\
\text { relationship, where } \\
\text { longer or higher } \\
\text { exposure leads to } \\
\text { an increased risk of } \\
\text { disease }\end{array}$ & $\begin{array}{c}\text { Convincing } \\
\text { Early PTOA was } \\
\text { associated with a } \\
\text { highIL-1 } \beta \text { plasma } \\
\text { concentration [39] }\end{array}$ & $\begin{array}{c}\text { Convincing } \\
\text { Correlationbetween } \\
\text { TNF- } \alpha \\
\text { concentrations and } \\
\text { ARGS fragments in } \\
\text { the SF up to } 5 \text { years } \\
\text { after knee trauma } \\
\text { [32] suggesting that } \\
\text { long exposure to } \\
\text { TNF- } \alpha \text { increases the } \\
\text { risk of disease }\end{array}$ & $\begin{array}{c}\text { Convincing } \\
\text { Early and late PTOA } \\
\text { were associated with } \\
\text { high IL-6 } \\
\text { concentrations PTOA } \\
\text { [39] }\end{array}$ & $\begin{array}{c}\text { Convincing } \\
\text { Levels of IL-17 in the } \\
\text { SF correlate with } \\
\text { severity of knee OA } \\
\text { [58] } \\
\text { Presence of IL-17 in } \\
\text { synovial fluid } \\
\text { identifies a subset of } \\
\text { patients with } \\
\text { end-stage knee OA } \\
\text { [60] }\end{array}$ \\
\hline $\begin{array}{l}\text { BIOLOGICAL } \\
\text { PLAUSIBILITY }\end{array}$ & $\begin{array}{c}\text { Presence of a } \\
\text { potential biological } \\
\text { mechanism }\end{array}$ & $\begin{array}{c}\text { Convincing } \\
{[12,211]}\end{array}$ & $\begin{array}{c}\text { Convincing } \\
{[12,212]}\end{array}$ & $\begin{array}{c}\text { Convincing } \\
{[191,213]}\end{array}$ & $\begin{array}{l}\text { Convincing } \\
{[187,189]}\end{array}$ \\
\hline
\end{tabular}


Table 4. Cont.

\begin{tabular}{|c|c|c|c|c|c|}
\hline & & IL-1 $\beta$ & TNF- $\alpha$ & IL-6 & IL-17 \\
\hline COHERENCE & $\begin{array}{l}\text { The current studies } \\
\text { agree and do not } \\
\text { conflict with } \\
\text { previously } \\
\text { reported evidence } \\
\text { and the biology of } \\
\text { disease }\end{array}$ & $\begin{array}{c}\text { Credible } \\
\text { Clarification is needed } \\
\text { on why some patients } \\
\text { have high } \\
\text { concentrations of IL-1 } \beta \\
\text { present, while others } \\
\text { do not }\end{array}$ & Convincing & Convincing & $\begin{array}{l}\text { Credible } \\
\text { More clinical studies } \\
\text { need to measure } \\
\text { IL-17 in the SF and } \\
\text { serum at the various } \\
\text { phases after knee } \\
\text { trauma and in } \\
\text { clinical PTOA }\end{array}$ \\
\hline $\begin{array}{l}\text { EXPERIMENTAL } \\
\text { EVIDENCE }\end{array}$ & $\begin{array}{l}\text { Evidence drawn } \\
\text { from experimental } \\
\text { models agree with } \\
\text { clinical data }\end{array}$ & Convincing & Convincing & Convincing & Convincing \\
\hline ANALOGY & $\begin{array}{c}\text { Analogous } \\
\text { examples that lead } \\
\text { to the same } \\
\text { outcome }\end{array}$ & $\begin{array}{c}\text { Convincing } \\
\text { RA, periodontitis } \\
{[214,215]}\end{array}$ & $\begin{array}{c}\text { Convincing } \\
\text { RA, psoriatic arthritis } \\
\text { ankylosing } \\
\text { spondylitis, Crohn's } \\
\text { disease }[216,217]\end{array}$ & $\begin{array}{l}\text { Convincing } \\
\text { RA, psoriatic arthritis, } \\
\text { periodontitis } \\
{[216,218,219]}\end{array}$ & $\begin{array}{c}\text { Convincing } \\
\text { RA, psoriatic } \\
\text { arthritis, ankylosing } \\
\text { spondylitis, } \\
\text { periodontitis } \\
{[184,216,220,221]}\end{array}$ \\
\hline CAUSAL EFFECT & & $\begin{array}{c}7 / 9 \\
\text { EVIDENCE MET }\end{array}$ & $\begin{array}{c}9 / 9 \\
\text { EVIDENCE MET }\end{array}$ & $\begin{array}{c}9 / 9 \\
\text { EVIDENCE MET }\end{array}$ & $\begin{array}{c}7 / 9 \\
\text { EVIDENCE MET }\end{array}$ \\
\hline
\end{tabular}

While most of the clinical studies showed that IL-1 $\beta$ was significantly increased vs. healthy controls $[21,23-27,29,31,39]$, some studies demonstrated that IL-1 $\beta$ was not present [28] or that it was only present in a certain percentage of the patients $[24,26,29,31]$. Evidence from the laboratory models clearly demonstrated that IL- $1 \beta$ leads to posttraumatic PTOA-like effects (Figure 2). There could be several explanations for the lack of detectable IL- $1 \beta$ in some patients, such as common polymorphisms of IL- $1 \beta$ genes that may cause alterations in the transcription of IL- $1 \beta$ that subsequently affects its circulating levels, causing increased the susceptibility to PTOA [208] or, alternatively, a lack of immunoregulators such as IL-1ra or anti-inflammatory IL-10, IL-13 and IL-4 cytokines. Il-1ra was present in the SF after knee trauma in three out of four clinical studies discussed in this review, while one group showed that IL-1ra was significantly lower than the control group 0-48 $\mathrm{h}$ after injury and did not increase up to 21 days post-injury [25]. Another study provided insight on this and showed that commonly occurring IL-1ra gene variants, which can posttranscriptionally influence IL-1ra levels [222], associates with radiographic progression of knee OA [223], suggesting that an imbalance of IL-1 may cause disease progression in certain OA cohorts due to a lack of IL-1 control. Moreover, IL-10 [21,24,32,137] was present in the knee joint during acute inflammation, but significantly decreased thereafter. Other anti-inflammatory cytokines, such as IL-4 and IL-13, were also absent [21]. Notably, inflammatory and blood-induced injury models showed that maintaining concentrations of anti-inflammatory cytokines [12,76,77,114,141,142,224,225] or IL-1ra [226-228] not only modulated the inflammatory response by reducing inflammation, but additionally stimulated chondro- and cartilage-protective effects. Moreover, IL-10 promoted the regeneration of cartilage tissue [142]. Therefore, while it is not clear whether IL-1 $\beta$ polymorphisms, an imbalance between IL-1 and IL-1ra, or a lack of control of anti-inflammatory cytokines in the early stages after knee trauma, or even other reasons beyond the scope of this review, are responsible for why some patients have excessively high IL- $1 \beta$ while others do not; how this relates to clinical PTOA of the knee remains unclear.

Whereas levels of IL-1 $\beta$, TNF- $\alpha$ and IL- 6 were frequently measured after knee trauma, IL-17 was not. There are two clinical studies that measured IL-17 and demonstrated that IL-17 was present in the acute [21] and chronic phase (3+ months) after injury [33]. However, in [21], IL-17 correlated with macrophage inflammatory protein-1 beta (MIP-1 $\beta$, also known as CCL4) $24 \mathrm{~h}$ after injury and IFN- $\gamma$, TNF- $\alpha$, IL-12, and IL-1ra $24 \mathrm{~h}$ and 9.5 days post-injury, whereas IL-17A was not significantly elevated in the injured knees, compared to the controls. Strong correlations were also shown, at both time points, between IL- 8 and 
IL-6 and between IL-1 $\beta$ and IL-2, which negatively regulates Th17 cells, suggesting that Th17 cells could partake in the inflammatory processes associated with injury. In [33], IL-17 was significantly increased in both the serum and SF compared to controls. However, it was not clear exactly how long IL-17 was chronically present, as the authors only reported that fracture patients endured pain for at least 3 months. Therefore, longitudinal studies are needed to relate the IL-17 changes in the SF and serum to the development of PTOA of the knee.

\section{Summary, Outlook and Early Disease Considerations}

The objective of this review was to focus on the current state of the research findings of one joint, the post-traumatic knee joint, after severe acute knee trauma in order to show how inflammation plays a central role not only in the initial post-traumatic pathology, but also in chronic and systemic inflammation, and how it could potentiate PTOA disease. From the clinical studies discussed in this review, it is evident that inflammation plays a key role in both the initial phase after injury and in perpetuating post-injurious pathology towards clinical knee PTOA. This comprehensive review presents, for the first time, a timeline following the initial event of a knee trauma, in which specific inflammatory as well as other biochemical biomarkers, increase in the acute, subacute, chronic and early to late PTOA stages of disease (summarized in Figure 1) after knee trauma. This suggests that specific markers may be used as potential prognostic indicators of disease (e.g., MMP-3, ARGS or COMP fragments, IL-17) and could be used to assess whether a patient is or is not progressing towards the development of clinical PTOA, especially since some of these biomarkers are increased and measurable in serum/plasma.

However, while this review and other reviews and consensus reports suggest that such biochemical biomarkers could be used as indicators of PTOA progression [229-231], so far adequate validation, e.g., of MMP-3, is still lacking. As we show in this review, while MMP-3 as well as other biochemical biomarkers remain present for extensive periods of time in the SF after injury, and SF MMP-3 levels even correlated with IL-6 levels in the SF up to 7 months after knee injury [31], SF analysis is not always clinically feasible or SF is not reliably gained. Therefore, measuring suitable biochemical markers in the serum would prove to be more advantageous. However, studies have shown mixed results in terms of correlations between serum MMP-3 levels and clinical signs of synovitis (radiographic or MRI grading) or the grade of articular cartilage damage (arthroscopic grading) [61,232-234]. This suggests that a single marker alone or combined with these clinically established articular cartilage-focused imaging or grading methods may not be sufficient. An alternative approach is to use multi-modality measurements with predictors known to be associated with PTOA. The combination of clinical evaluation, radiographic OA grade and ultrasonographic indicators of inflammation (swelling/knee effusion), as well as pain intensity and disease duration, have been used to predict knee joint replacement surgery within 3 years after the initial patient visit [235]. Multivariable analysis has also predicted PTOA [236]. However, these predicting methods predict late-stage changes leading to joint replacement, but not the early processes leading to potentially reversible tissue damage. Moreover, successfully predicting PTOA within 2 to 3 years in patients after meniscus repair or partial meniscectomy after ACL tear is somewhat expectable, as advanced joint deterioration is known to be associated with both procedures $[237,238]$. Despite these facts, the impressive aspect is that they have successfully demonstrated that multi-modality measurements could be used for prediction.

Another approach is to focus on other diagnostic imaging techniques to diagnose the early and potentially reversible disease pathology, especially since methods, such as X-ray and MRI cannot yet statistically discriminate between healthy vs. early OA [239]. We recently showed that a clinically available confocal laser endomicroscope could be used to image a surrogate marker of otherwise clinically, but not yet detectable, early OA functional pathology prior to cell clustering [240]. Specifically, we showed that characteristics of the spatial organization of the superficial zone chondrocytes (SCSO) are indicative of early 
pathology $[94,107-110,136,241]$ and can be imaged clinically using a confocal laser endomicroscope. Combined with random forest modelling, this artificial intelligence (AI)-based non-destructive quantitative optical biopsy was capable of accurately differentiating between a healthy vs. early OA architectural fingerprint, suggesting that early OA pathology detection is indeed possible with current clinical technology [240]. Thus, such new imaging approaches, combined with modern analysis and/or predictive tools, such as AI, could be used with measurements of multiple easily measurable biochemical biomarker candidates (e.g., MMP-3 and possibly IL-17) from blood samples and combined with patient-related parameters over time and in parallel. Using such an integrated approach could facilitate the detection of earlier pathological and functional changes compared to current techniques. In this context, a multi-disciplinary international group of experts has published guidelines on the design and conduct of interventional studies aimed at preventing PTOA following acute knee injury [229], which are not only relevant to assessing treatment outcomes but also critical to understanding and diagnosing early clinical disease. This group advocates further strategies that enable the prediction and stratification of individual risks for development of future PTOA with an emphasis on an earlier time point, such as at the time of injury. Moreover, they point out that, given that 5-10-year interventional clinical trials are not feasible, more studies need to be done to determine which measurement(s) could act as acceptable surrogate short-term outcome predictors of future PTOA or therapeutic efficacy. This group also suggested that, when possible, samples including serum/plasma, urine and SF should be collected at all available time points, such as preoperatively, at the time of surgery, clinical aspiration, and treatment which, in terms of clinical treatment outcomes, could help identify relationships between early (e.g., 1-2 years) and later outcomes (e.g., 5-10 years). Thus, inclusion of easily measurable biomarkers, combined with imaging technologies, e.g., AI-supported endomicroscopy-assisted optical biopsy, that correlate local tissue architectures [240] with biomarkers and other parameters, such as clinical symptoms, age, sex, BMI and, e.g., the type of injury, could also better stratify joint- or injury-specific progression and improve our understanding of early disease pathology and detection.

The data discussed in this review demonstrated that inflammation and subsequent tissue destruction following trauma to the knee leads to a localized as well as systemic inflammation, much like RA. This persistent long-term low-grade chronic inflammation has already been suggested to be a key mediator in the pathogenesis of OA and a general phenomenon of OA $[17,18,242,243]$ and now we show similarly an important role in knee PTOA. While it is known that serum IL-6 concentrations increase with age and systemic IL-6 appears central to the pathophysiology of physical function decline, as well as many chronic diseases [244,245], "inflammaging", which is systemic mild inflammation in the absence of an apparent infection associated with the process of biological aging, also contributes to an array of age-related diseases including OA [246-248]. In this context, knee PTOA occurs earlier than idiopathic OA but, importantly, causes a similar response. Specifically, IL-6 is already detectable in the plasma within 1 year after knee trauma in young adult to middle-aged patients (age range $43.6 \pm 15.1$ years) having early clinical PTOA (KellgrenLawrence grade 1-2) [39]. While many co-factors could enhance progression towards PTOA, including aging, an early knee trauma predisposes young adolescents and young adults to PTOA $[4,236,249,250]$, suggesting that it could lead to earlier chronic disease and, thus, accelerate the process of "inflammaging".

In this context and in the consideration of why some patients progress towards disease while other do not, it is important to consider the complex dysregulated interplay between the innate and adaptive immune systems that could occur after knee trauma and how damage-associated molecular patterns (DAMPs) and senescence could tip the balance and incite early uncontrolled inflammation. Under conditions of tissue injury/cellular stress induced by, e.g., mechanical injury, hemorrhage, surgical procedures (e.g., knee injury) and in response to proteolytical release (e.g., MMP-mediated degradation) of ECM, DAMPs are released from the articular cartilage matrix or the native cells themselves. 
While a full description of DAMPs is outside the scope of this review and could be found elsewhere $[17,18,242]$, we will briefly point out how DAMPs released from cartilage matrix or from dying cells have been implicated in events that could drive chronic inflammation and could lead to systemic knee PTOA. DAMPs from damaged cartilage ECM, such as the 32-mer aggrecan fragment [251,252], small leucine-rich proteoglycans (SLRPs) decorin that functions to increase the retention of aggrecan in the ECM [253], biglycans [254], low MW hyaluronic acid, fibronectin [255,256], and prelamin (the precursor of lamin A) [257] as well as intracellular DAMPs (also known as alarmins) that are extracellularly released either passively or by exocytosis including the high mobility group box 1 (HMGB1) $[258,259]$ and uric acid, the final metabolic product of purine catabolism released from dying cells [67], have been implicated in articular cartilage destruction, inflammation and PTOA disease progression. These DAMPs are capable of activating a broad range of pattern-recognition receptors (PRR), e.g., Toll-like receptors (TLRs) or the cytoplasmic nucleotide-binding oligomerization domain-like receptor pyrin domain-containing-3 (NLRP3) inflammasome, present on or in various cells including chondrocytes, synoviocytes, fibroblasts, monocytes and macrophages that, in turn, trigger a range of inflammatory responses and chemotactic activity through various DAMP-PRR receptor signaling mechanisms. Therefore, the recognition of DAMPs not only by local cells within the joint, but also by recruited effector cells of the immune system, could lead to a hyper-inflammatory response.

Since DAMP-PRR signaling is also needed in tissue repair, it is difficult to decipher how the complexity of multiple DAMP-PRR signaling mechanisms contribute towards an imbalance in inflammatory signaling responses and, more specifically, how this change tissue repair to maladaptive in the knee joint but recent studies suggest that senescence could play a role. Articular cartilage tissue and chondrocytes of the knee joint express significantly more DAMPs (e.g., HMGB-1 and alarmins S100A8 and S100A9) than the hip joint. DAMPs are present in normal healthy chondrocytes, but increased in OA [260]. DAMPs also induce cellular senescence and are produced by senescent cells (SnCs) and, like DAMPs, cellular senescence has been suggested to contribute to low grade chronic systemic inflammation in OA [261-263] and in PTOA [189,264-266]. Senescent cells (SnCs) increase in response to aging but also increase upon injury, stress and inflammation and, thus, are relevant to trauma-related pathologies. The process of cellular senescence causes irreversible cell-cycle arrest and distinct morphological and phenotypic alterations resulting in adoption of a pro-inflammatory bio-active secretome phenotype, referred to as the "senescence-associated secretory phenotype" (SASP). SnCs release a wide-range of proteins, including DAMPs, as well as pro-inflammatory cytokines, MMPs, and chemokines, including those factors shown in Figure 1 that were significantly increased following trauma to the knee joint, such as IL-6, IL-1, TNF- $\alpha$ and MMP-3. Moreover, inflammatory cytokines present after knee trauma, such as IL-1 $\beta$, TNF- $\alpha$ and IL-17, drive chondrocytes [267] and fibroblasts [189] towards a senescent phenotype.

As with DAMP-PRR signaling, SnCs are needed for normal healing in acute inflammation and their presence limits fibrosis during tissue repair $[268,269]$. On the other hand, SnCs are also capable of promoting OA disease progression when transplanted into normal knee healthy joints of mature adult mice equivalent in age to 20-30-year-old humans [261] and in young animals in PTOA knee models [189,264]. Thus, ACLT injury induced senescence in both young and aged animals. The presence of SnCs increased with tissue severity, but also differed in the localization between young and old animals with SnCs localized in the superficial layer of articular cartilage in young animals vs. throughout the cartilage matrix in aged animals. Moreover, treatment with senolytic drugs in both young as well as aged mice protected against inflammation and helped eliminate SnCs and their resulting SASP which, in turn, enabled tissue recovery and the development of ACLT-induced PTOA $[189,264]$. The study of Faust et al. has shed some light on how this process causes a local Th17 immune response in the articular compartment of the joint and systemic chronic inflammation via the draining inguinal lymph nodes [189]. Their data suggest that high IL-6 or TGF- $\beta$ after injury skews naïve CD4+ T cells towards Th17 
cells and that these Th17 cells contribute to chronic disease. Hence, they suggest that these Th17 cells induce fibroblasts to become senescent and at the same time this in turn could further promote a Th17 phenotype in innate lymph cells resulting in a positive feedback loop and chronic inflammation. Moreover, many DAMP markers have been recognized as SASP markers. Others have shown that extracellular vesicles released from OA senescent chondrocytes are capable of transmitting the senescent phenotype to nearby cells and thereby inhibiting ECM deposition by healthy chondrocytes [270] and the number of SnCs positively correlated with OA severity [271]. It has also been shown that physiological loading increases the diffusion of inflammatory cytokines into injured articular cartilage [272]. These mechanisms could induce senescence in nearby cells and, along with the circulating Th17 cells [189], could reinforce the long-term production of the inflammatory, such as the prominent "inflammaging" IL-6 [244,245], and tissue-degenerating molecules that are increased in those with knee trauma, as shown in our comprised Figure 1. Thus, increased DAMPs that are released from damaged and apoptotic or necrotic cells could induce immunosenescent programming in damaged articular cartilage tissue. If the clearance of SnCs is diminished in certain individuals (possibly the $23-50 \%$ of those who progress to PTOA [2-8]), an amplifying loop of senescent-induced inflammation may accelerate the process of "inflammaging".

These data strongly emphasize the need to improve our understanding of the early mechanisms that result in an immune response shift and provocation towards the sustained and chronic inflammatory disease that occur following knee trauma, with particular emphasis on the low-grade pro-inflammatory state in healthy and hence young to middleaged adults. Moreover, as the molecular mechanisms and signaling pathways of these processes and how, e.g., senolytic agents, regulate this is still not clear; further contextspecific investigations are needed. Importantly, other co-morbidities, such as subsequent knee injuries [249], abnormal mechanical loading [273,274] following the primary injury, gender [275] (e.g., hormonal) differences, co-morbidities, such as high BMI [249], or the presence of other diseases, such as diabetes [276-278] and even genetic risk loci [279,280], that could predispose one to early chronic disease, also need to be considered in pre-clinical injury/inflammatory models to determine how they enhance the early development of chronic inflammation and reduce tissue repair capacity in the setting of PTOA progression. In this context, studies would benefit from focusing on acute vs. chronic models of inflammation, but also healthy vs. different diseased states of cells and tissues, which may provide more insight on the effect of the "starting point" on disease outcome. Patient stratification, and co-morbidity studies as well as biobank data could help in answering these questions.

In summary, chronic inflammation associated with knee trauma, which together lead to PTOA, cannot yet be clinically prevented. Although knowledge and awareness have increased in the past few years, there are many future challenges, yet also multiple promising avenues. Using the Bradford Hill Framework, we show that TNF- $\alpha$ and IL- 6 cytokines are causal factors, while IL-1 $\beta$ and IL-17 are credible factors in inducing progression towards knee PTOA. Recently, three out of four of these cytokines, namely IL- $1 \beta$, TNF- $\alpha$, and IL-6, have been linked to inducing a dedifferentiated phenotype by converging on signaling pathways that regulate cytoskeletal actin dynamics [281], suggesting a potential link between post-injurious inflammation and a disease-driving phenotype. This may potentially open up a novel avenue of disease intervention. Since PTOA occurs in younger patients compared to other forms of $\mathrm{OA}$, it is evident that early treatment strategies, as opposed to end-stage early knee replacement, are needed to control inflammation before clinical PTOA onset. The future lies not only in regulating the inflammatory aspects of this challenging disease, but more so in recognizing a PTOA-specific immunopathology at a much earlier stage, as this would ultimately allow for the development of clinical preventative interventions. 
Author Contributions: All authors made substantial contributions drafting this article. C.M.K. largely contributed to the clinical as well as the in vivo and ex vivo/in vitro section, the summary of concentrations of inflammatory cytokines used in models vs. the clinical presentation, helped design and go through data for Figures 1 and 2 and helped to edit the manuscript to its final form. R.A. largely contributed to writing parts of the in vivo and ex vivo/in vitro section and helped go through the data for Figure 2. J.M.H. contributed to parts of the clinical, in vivo and ex vivo/in vitro sections. M.L.H. conceived and designed the work, put the manuscript together, did the core of the writing and edited the manuscript to its final form. B.R. revised the manuscript critically for important intellectual content and edited the manuscript to its final form. All authors have read and agreed to the published version of the manuscript.

Funding: This research received no external funding.

Conflicts of Interest: The authors declare no conflict of interest.

\section{Abbreviations}

$\begin{array}{ll}\text { ACAN } & \text { Aggrecan } \\ \text { ACI } & \text { Autologous chondrocyte implantation } \\ \text { ACL } & \text { Anterior cruciate ligament } \\ \text { ACLT } & \text { Anterior cruciate ligament transection } \\ \text { ADAMTS } & \text { A disintegrin and metalloproteinase with thrombospondin motifs } \\ \text { AI } & \text { Artificial intelligence } \\ \text { ARGS } & \text { Alanine-Arginine-Glycine-Serine } \\ \text { BMI } & \text { Body mass index } \\ \text { C1,2C } & \text { Type I/II collagen degradation } \\ \text { C2C } & \text { Type II collagen cleavage product } \\ \text { C2M } & \text { MMP-mediated type II collagen } \\ \text { CCL2 } & \text { CC-chemokine ligand 2, also known as MCP-1 } \\ \text { CH } & \text { Chondrocyte } \\ \text { CHI3L1 } & \text { Chitinase 3-like 1 } \\ \text { CLU } & \text { Clusterin } \\ \text { COLI } & \text { Collagen I } \\ \text { COLII } & \text { Collagen II } \\ \text { COMP } & \text { Cartilage oligomeric matrix protein } \\ \text { CPII } & \text { Procollagen II c-propeptide } \\ \text { CRP } & \text { C-reactive protein } \\ \text { CS } & \text { Chondroitin sulphate } \\ \text { CTX-I } & \text { C-terminal crosslinked telopeptide type I collagen } \\ \text { CTX-II } & \text { C-terminal crosslinked telopeptide type II collagen } \\ \text { CXCL } & \text { Chemokine ligand } \\ \text { DAMPs } & \text { Damage-associated molecular patterns } \\ \text { ECM } & \text { Extracellular matrix } \\ \text { FB } & \text { Factor B } \\ \text { FRI } & \text { Fluorescence reflectance imaging } \\ \text { gp 130 } & \text { Glycol-protein 130 } \\ \text { HMGB1 } & \text { High mobility group box 1 } \\ \text { IFN- } \gamma & \text { Interferon gamma } \\ \text { IL } & \text { Interleukin } \\ \text { IL-1ra } & \text { IL-1 receptor antagonist } \\ \text { IL-6R } & \text { IL-6 receptor } \\ \text { iNOS } & \text { Inducible NO synthase } \\ \text { KOOS4 } & \text { Knee Injury and Osteoarthritis Outcome Score 4 } \\ \text { LIF } & \text { Leukemia inhibitor factor } \\ \text { LPS } & \text { Lipopolysaccharide } \\ \text { MASP } & \text { MBL-associated serine proteases } \\ \text { MBL } & \text { Mannose binding lectin } \\ & \end{array}$




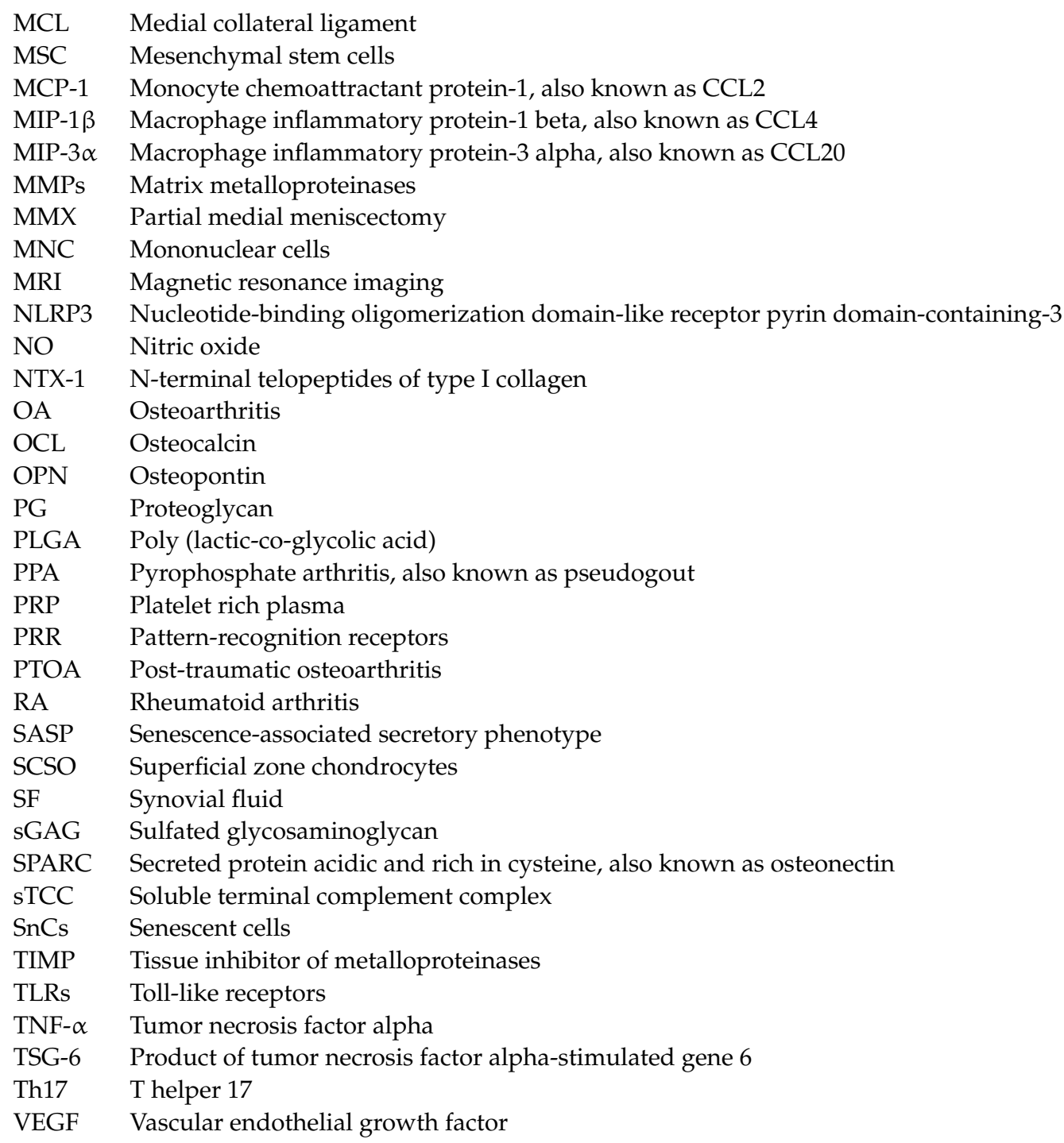

\section{References}

1. Brown, T.D.; Johnston, R.C.; Saltzman, C.L.; Marsh, J.L.; Buckwalter, J.A. Posttraumatic osteoarthritis: A first estimate of incidence, prevalence, and burden of disease. J. Orthop. Trauma 2006, 20, 739-744. [CrossRef]

2. Schenker, M.L.; Mauck, R.L.; Ahn, J.; Mehta, S. Pathogenesis and prevention of posttraumatic osteoarthritis after intra-articular fracture. J. Am. Acad. Orthop. Surg. 2014, 22, 20-28. [CrossRef]

3. Lohmander, L.S.; Englund, P.M.; Dahl, L.L.; Roos, E.M. The long-term consequence of anterior cruciate ligament and meniscus injuries: Osteoarthritis. Am. J. Sports Med. 2007, 35, 1756-1769. [CrossRef]

4. Gelber, A.C.; Hochberg, M.C.; Mead, L.A.; Wang, N.Y.; Wigley, F.M.; Klag, M.J. Joint injury in young adults and risk for subsequent knee and hip osteoarthritis. Ann. Intern. Med. 2000, 133, 321-328. [CrossRef]

5. Gillquist, J.; Messner, K. Anterior cruciate ligament reconstruction and the long-term incidence of gonarthrosis. Sports Med. 1999, 27, 143-156. [CrossRef]

6. Roos, H.; Lauren, M.; Adalberth, T.; Roos, E.M.; Jonsson, K.; Lohmander, L.S. Knee osteoarthritis after meniscectomy: Prevalence of radiographic changes after twenty-one years, compared with matched controls. Arthritis Rheumatol. 1998, 41, 687-693. [CrossRef]

7. Laird, A.; Keating, J.F. Acetabular fractures: A 16-year prospective epidemiological study. J. Bone Jt. Surg. Br. 2005, 87, 969-973. [CrossRef] [PubMed]

8. Weigel, D.P.; Marsh, J.L. High-energy fractures of the tibial plateau. Knee function after longer follow-up. J. Bone Jt. Surg. 2002, 84, 1541-1551. [CrossRef] [PubMed]

9. Felson, D.T.; Zhang, Y. An update on the epidemiology of knee and hip osteoarthritis with a view to prevention. Arthritis Rheumatol. 1998, 41, 1343-1355. [CrossRef]

10. Muthuri, S.G.; McWilliams, D.F.; Doherty, M.; Zhang, W. History of knee injuries and knee osteoarthritis: A meta-analysis of observational studies. Osteoarthr. Cartil. 2011, 19, 1286-1293. [CrossRef] 
11. Olson, S.A.; Horne, P.; Furman, B.; Huebner, J.; Al-Rashid, M.; Kraus, V.B.; Guilak, F. The role of cytokines in posttraumatic arthritis. J. Am. Acad. Orthop. Surg. 2014, 22, 29-37. [CrossRef]

12. Wojdasiewicz, P.; Poniatowski, L.A.; Szukiewicz, D. The role of inflammatory and anti-inflammatory cytokines in the pathogenesis of osteoarthritis. Mediat. Inflamm. 2014, 2014, 561459. [CrossRef]

13. Boehme, K.A.; Rolauffs, B. Onset and progression of human osteoarthritis-can growth factors, inflammatory cytokines, or differential mirna expression concomitantly induce proliferation, ecm degradation, and inflammation in articular cartilage? Int. J. Mol. Sci. 2018, 19, 2282. [CrossRef] [PubMed]

14. Chubinskaya, S.; Wimmer, M.A. Key pathways to prevent posttraumatic arthritis for future molecule-based therapy. Cartilage 2013, 4, 13S-21S. [CrossRef]

15. Punzi, L.; Galozzi, P.; Luisetto, R.; Favero, M.; Ramonda, R.; Oliviero, F.; Scanu, A. Post-traumatic arthritis: Overview on pathogenic mechanisms and role of inflammation. RMD Open 2016, 2, e000279. [CrossRef] [PubMed]

16. Lieberthal, J.; Sambamurthy, N.; Scanzello, C.R. Inflammation in joint injury and post-traumatic osteoarthritis. Osteoarthr. Cartil. 2015, 23, 1825-1834. [CrossRef]

17. Robinson, W.H.; Lepus, C.M.; Wang, Q.; Raghu, H.; Mao, R.; Lindstrom, T.M.; Sokolove, J. Low-grade inflammation as a key mediator of the pathogenesis of osteoarthritis. Nat. Rev. Rheumatol. 2016, 12, 580-592. [CrossRef] [PubMed]

18. Sokolove, J.; Lepus, C.M. Role of inflammation in the pathogenesis of osteoarthritis: Latest findings and interpretations. Adv. Musculoskelet. Dis. 2013, 5, 77-94. [CrossRef]

19. Fedak, K.M.; Bernal, A.; Capshaw, Z.A.; Gross, S. Applying the bradford hill criteria in the 21st century: How data integration has changed causal inference in molecular epidemiology. Emerg. Themes Epidemiol. 2015, 12, 14. [CrossRef] [PubMed]

20. Baer, A.N.; Patel, V.; McCormack, R. The approach to the painful joint. 2019. Available online: https://emedicine.medscape.com/ article/336054-overview (accessed on 14 November 2020).

21. Haller, J.M.; McFadden, M.; Kubiak, E.N.; Higgins, T.F. Inflammatory cytokine response following acute tibial plateau fracture. J. Bone Jt. Surg. 2015, 97, 478-483. [CrossRef]

22. Haller, J.M.; Swearingen, C.A.; Partridge, D.; McFadden, M.; Thirunavukkarasu, K.; Higgins, T.F. Intraarticular matrix metalloproteinases and aggrecan degradation are elevated after articular fracture. Clin. Orthop. Relat. Res. 2015, 473, 3280-3288. [CrossRef] [PubMed]

23. Sward, P.; Frobell, R.; Englund, M.; Roos, H.; Struglics, A. Cartilage and bone markers and inflammatory cytokines are increased in synovial fluid in the acute phase of knee injury (hemarthrosis)—A cross-sectional analysis. Osteoarthr. Cartil. 2012, 20, 1302-1308. [CrossRef]

24. Bigoni, M.; Sacerdote, P.; Turati, M.; Franchi, S.; Gandolla, M.; Gaddi, D.; Moretti, S.; Munegato, D.; Augusti, C.A.; Bresciani, E.; et al. Acute and late changes in intraarticular cytokine levels following anterior cruciate ligament injury. J. Orthop. Res. 2013, 31, 315-321. [CrossRef]

25. Irie, K.; Uchiyama, E.; Iwaso, H. Intraarticular inflammatory cytokines in acute anterior cruciate ligament injured knee. Knee 2003, 10, 93-96. [CrossRef]

26. Elsaid, K.A.; Fleming, B.C.; Oksendahl, H.L.; Machan, J.T.; Fadale, P.D.; Hulstyn, M.J.; Shalvoy, R.; Jay, G.D. Decreased lubricin concentrations and markers of joint inflammation in the synovial fluid of patients with anterior cruciate ligament injury. Arthritis Rheumatol. 2008, 58, 1707-1715. [CrossRef] [PubMed]

27. Catterall, J.B.; Stabler, T.V.; Flannery, C.R.; Kraus, V.B. Changes in serum and synovial fluid biomarkers after acute injury (nct00332254). Arthritis Res. Ther. 2010, 12, R229. [CrossRef]

28. Watt, F.E.; Paterson, E.; Freidin, A.; Kenny, M.; Judge, A.; Saklatvala, J.; Williams, A.; Vincent, T.L. Acute molecular changes in synovial fluid following human knee injury: Association with early clinical outcomes. Arthritis Rheumatol. 2016, 68, 2129-2140. [CrossRef]

29. Lattermann, C.; Jacobs, C.A.; Bunnell, M.P.; Jochimsen, K.N.; Abt, J.P.; Reinke, E.K.; Gammon, L.G.; Huebner, J.L.; Kraus, V.B.; Spindler, K.P. Logistical challenges and design considerations for studies using acute anterior cruciate ligament injury as a potential model for early posttraumatic osteoarthritis. J. Orthop. Res. 2017, 35, 641-650. [CrossRef]

30. Dahlberg, L.; Roos, H.; Saxne, T.; Heinegard, D.; Lark, M.W.; Hoerrner, L.A.; Lohmander, L.S. Cartilage metabolism in the injured and uninjured knee of the same patient. Ann. Rheum. Dis. 1994, 53, 823-827. [CrossRef]

31. Higuchi, H.; Shirakura, K.; Kimura, M.; Terauchi, M.; Shinozaki, T.; Watanabe, H.; Takagishi, K. Changes in biochemical parameters after anterior cruciate ligament injury. Int. Orthop. 2006, 30, 43-47. [CrossRef]

32. Struglics, A.; Larsson, S.; Kumahashi, N.; Frobell, R.; Lohmander, L.S. Changes in cytokines and aggrecan args neoepitope in synovial fluid and serum and in c-terminal crosslinking telopeptide of type ii collagen and n-terminal crosslinking telopeptide of type i collagen in urine over five years after anterior cruciate ligament rupture: An exploratory analysis in the knee anterior cruciate ligament, nonsurgical versus surgical treatment trial. Arthritis Rheumatol. 2015, 67, 1816-1825.

33. Sarafan, N.; Fakoor, M.; Mehdinasab, A.; Bahadoram, M.; Ashtary-Larky, D.; Mahdavi, H.; Javanmardi, F. Post-traumatic arthritis: The role of cytokine levels in serum and synovial fluid. Glob. J. Health Sci. 2018, 10. [CrossRef]

34. Lohmander, L.S.; Atley, L.M.; Pietka, T.A.; Eyre, D.R. The release of crosslinked peptides from type ii collagen into human synovial fluid is increased soon after joint injury and in osteoarthritis. Arthritis Rheumatol. 2003, 48, 3130-3139. [CrossRef] [PubMed] 
35. Lohmander, L.S.; Ionescu, M.; Jugessur, H.; Poole, A.R. Changes in joint cartilage aggrecan after knee injury and in osteoarthritis. Arthritis Rheumatol. 1999, 42, 534-544. [CrossRef]

36. Struglics, A.; Okroj, M.; Sward, P.; Frobell, R.; Saxne, T.; Lohmander, L.S.; Blom, A.M. The complement system is activated in synovial fluid from subjects with knee injury and from patients with osteoarthritis. Arthritis Res. Ther. 2016, 18, 223. [CrossRef] [PubMed]

37. Struglics, A.; Larsson, S.; Pramhed, A.; Frobell, R.; Sward, P. Changes in synovial fluid and serum concentrations of cartilage oligomeric matrix protein over 5 years after anterior cruciate ligament rupture: An exploratory analysis in the kanon trial. Osteoarthr. Cartil. 2018, 26, 1351-1358. [CrossRef]

38. Larsson, S.; Lohmander, L.S.; Struglics, A. Synovial fluid level of aggrecan args fragments is a more sensitive marker of joint disease than glycosaminoglycan or aggrecan levels: A cross-sectional study. Arthritis Res. Ther. 2009, 11, R92. [CrossRef]

39. Panina, S.B.; Krolevets, I.V.; Milyutina, N.P.; Sagakyants, A.B.; Kornienko, I.V.; Ananyan, A.A.; Zabrodin, M.A.; Plotnikov, A.A.; Vnukov, V.V. Circulating levels of proinflammatory mediators as potential biomarkers of post-traumatic knee osteoarthritis development. J. Orthop. Traumatol. 2017, 18, 349-357. [CrossRef] [PubMed]

40. Alexander, S.; Watt, F.; Sawaji, Y.; Hermansson, M.; Saklatvala, J. Activin a is an anticatabolic autocrine cytokine in articular cartilage whose production is controlled by fibroblast growth factor 2 and nf-kappab. Arthritis Rheumatol. 2007, 56, 3715-3725. [CrossRef]

41. Chou, C.H.; Attarian, D.E.; Wisniewski, H.G.; Band, P.A.; Kraus, V.B. Tsg-6-A double-edged sword for osteoarthritis (oa). Osteoarthr. Cartil. 2018, 26, 245-254. [CrossRef]

42. Wisniewski, H.G.; Colon, E.; Liublinska, V.; Karia, R.J.; Stabler, T.V.; Attur, M.; Abramson, S.B.; Band, P.A.; Kraus, V.B. Tsg-6 activity as a novel biomarker of progression in knee osteoarthritis. Osteoarthr. Cartil. 2014, 22, 235-241. [CrossRef] [PubMed]

43. Zou, L.; Liu, J.; Lu, H. Correlation of concentrations of activin a with occurrence and severity of knee osteoarthritis. J. Musculoskelet. Neuronal. Interact. 2018, 18, 320-322. [PubMed]

44. Hart, M.L.; Walsh, M.C.; Stahl, G.L. Initiation of complement activation following oxidative stress. In vitro and in vivo observations. Mol. Immunol. 2004, 41, 165-171. [CrossRef]

45. John, T.; Stahel, P.F.; Morgan, S.J.; Schulze-Tanzil, G. Impact of the complement cascade on posttraumatic cartilage inflammation and degradation. Histol. Histopathol. 2007, 22, 781-790.

46. Silawal, S.; Triebel, J.; Bertsch, T.; Schulze-Tanzil, G. Osteoarthritis and the complement cascade. Clin. Med. Insights Arthritis Musculoskelet. Disord. 2018, 11, 1179544117751430. [CrossRef] [PubMed]

47. Gobezie, R.; Kho, A.; Krastins, B.; Sarracino, D.A.; Thornhill, T.S.; Chase, M.; Millett, P.J.; Lee, D.M. High abundance synovial fluid proteome: Distinct profiles in health and osteoarthritis. Arthritis Res. Ther. 2007, 9, R36. [CrossRef]

48. Corvetta, A.; Pomponio, G.; Rinaldi, N.; Luchetti, M.M.; Di Loreto, C.; Stramazzotti, D. Terminal complement complex in synovial tissue from patients affected by rheumatoid arthritis, osteoarthritis and acute joint trauma. Clin. Exp. Rheumatol. 1992, 10, 433-438. [PubMed]

49. Ritter, S.Y.; Subbaiah, R.; Bebek, G.; Crish, J.; Scanzello, C.R.; Krastins, B.; Sarracino, D.; Lopez, M.F.; Crow, M.K.; Aigner, T.; et al. Proteomic analysis of synovial fluid from the osteoarthritic knee: Comparison with transcriptome analyses of joint tissues. Arthritis Rheumatol. 2013, 65, 981-992. [CrossRef]

50. Bollmann, M.; Colombo, F.; Marco, P.L.D.M.; Brandstaedter, K.; Lohmann, C.H.; Bertrand, J. Inhibition of the complement system component c5 as possible treatment in oa. Osteoarthr. Cartil. 2018, 26, S108. [CrossRef]

51. Wang, Q.; Rozelle, A.L.; Lepus, C.M.; Scanzello, C.R.; Song, J.J.; Larsen, D.M.; Crish, J.F.; Bebek, G.; Ritter, S.Y.; Lindstrom, T.M.; et al. Identification of a central role for complement in osteoarthritis. Nat. Med. 2011, 17, 1674-1679. [CrossRef]

52. Riegger, J.; Huber-Lang, M.; Brenner, R.E. Crucial role of the terminal complement complex in chondrocyte death and hypertrophy after cartilage trauma. Osteoarthr. Cartil. 2020. [CrossRef] [PubMed]

53. Fernandez-Puente, P.; Mateos, J.; Fernandez-Costa, C.; Oreiro, N.; Fernandez-Lopez, C.; Ruiz-Romero, C.; Blanco, F.J. Identification of a panel of novel serum osteoarthritis biomarkers. J. Proteome Res. 2011, 10, 5095-5101. [CrossRef]

54. Ammitzboll, C.G.; Thiel, S.; Ellingsen, T.; Deleuran, B.; Jorgensen, A.; Jensenius, J.C.; Stengaard-Pedersen, K. Levels of lectin pathway proteins in plasma and synovial fluid of rheumatoid arthritis and osteoarthritis. Rheumatol. Int. 2012, 32, 1457-1463. [CrossRef]

55. Teunis, T.; Beekhuizen, M.; Van Osch, G.V.; Schuurman, A.H.; Creemers, L.B.; van Minnen, L.P. Soluble mediators in posttraumatic wrist and primary knee osteoarthritis. Arch. Bone Jt. Surg. 2014, 2, 146-150.

56. Zhu, Z.; Otahal, P.; Wang, B.; Jin, X.; Laslett, L.L.; Wluka, A.E.; Antony, B.; Han, W.; Wang, X.; Winzenberg, T.; et al. Cross-sectional and longitudinal associations between serum inflammatory cytokines and knee bone marrow lesions in patients with knee osteoarthritis. Osteoarthr. Cartil. 2017, 25, 499-505. [CrossRef]

57. Wang, K.; Xu, J.; Cai, J.; Zheng, S.; Yang, X.; Ding, C. Serum levels of resistin and interleukin-17 are associated with increased cartilage defects and bone marrow lesions in patients with knee osteoarthritis. Mod. Rheumatol. 2017, 27, 339-344. [CrossRef] [PubMed]

58. Liu, Y.; Peng, H.; Meng, Z.; Wei, M. Correlation of il-17 level in synovia and severity of knee osteoarthritis. Med. Sci. Monit. 2015, 21, 1732-1736. [PubMed]

59. Bai, Y.; Gao, S.; Liu, Y.; Jin, S.; Zhang, H.; Su, K. Correlation between interleukin-17 gene polymorphism and osteoarthritis susceptibility in han chinese population. BMC Med. Genet. 2019, 20, 20. [CrossRef] 
60. Snelling, S.J.; Bas, S.; Puskas, G.J.; Dakin, S.G.; Suva, D.; Finckh, A.; Gabay, C.; Hoffmeyer, P.; Carr, A.J.; Lubbeke, A. Presence of il-17 in synovial fluid identifies a potential inflammatory osteoarthritic phenotype. PLoS ONE 2017, 12, e0175109. [CrossRef]

61. Pengas, I.; Eldridge, S.; Assiotis, A.; McNicholas, M.; Mendes, J.E.; Laver, L. Mmp-3 in the peripheral serum as a biomarker of knee osteoarthritis, 40 years after open total knee meniscectomy. J. Exp. Orthop. 2018, 5, 21. [CrossRef]

62. Bao, J.P.; Chen, W.P.; Feng, J.; Hu, P.F.; Shi, Z.L.; Wu, L.D. Leptin plays a catabolic role on articular cartilage. Mol. Biol. Rep. 2010, 37, 3265-3272. [CrossRef] [PubMed]

63. Beekhuizen, M.; Gierman, L.M.; van Spil, W.E.; Van Osch, G.J.; Huizinga, T.W.; Saris, D.B.; Creemers, L.B.; Zuurmond, A.M. An explorative study comparing levels of soluble mediators in control and osteoarthritic synovial fluid. Osteoarthr. Cartil. 2013, 21, 918-922. [CrossRef]

64. Imamura, M.; Ezquerro, F.; Marcon Alfieri, F.; Vilas Boas, L.; Tozetto-Mendoza, T.R.; Chen, J.; Ozcakar, L.; Arendt-Nielsen, L.; Rizzo Battistella, L. Serum levels of proinflammatory cytokines in painful knee osteoarthritis and sensitization. Int. J. Inflam. 2015, 2015, 329792. [CrossRef] [PubMed]

65. Ersoy, Y.; Ozerol, E.; Baysal, O.; Temel, I.; MacWalter, R.S.; Meral, U.; Altay, Z.E. Serum nitrate and nitrite levels in patients with rheumatoid arthritis, ankylosing spondylitis, and osteoarthritis. Ann. Rheum. Dis. 2002, 61, 76-78. [CrossRef] [PubMed]

66. Krasnokutsky, S.; Oshinsky, C.; Attur, M.; Ma, S.; Zhou, H.; Zheng, F.; Chen, M.; Patel, J.; Samuels, J.; Pike, V.C.; et al. Serum urate levels predict joint space narrowing in non-gout patients with medial knee osteoarthritis. Arthritis Rheumatol. 2017, 69, 1213-1220. [CrossRef] [PubMed]

67. Denoble, A.E.; Huffman, K.M.; Stabler, T.V.; Kelly, S.J.; Hershfield, M.S.; McDaniel, G.E.; Coleman, R.E.; Kraus, V.B. Uric acid is a danger signal of increasing risk for osteoarthritis through inflammasome activation. Proc. Natl. Acad. Sci. USA 2011, 108, 2088-2093. [CrossRef]

68. Olsson, O.; Isacsson, A.; Englund, M.; Frobell, R.B. Epidemiology of intra- and peri-articular structural injuries in traumatic knee joint hemarthrosis-Data from 1145 consecutive knees with subacute mri. Osteoarthr. Cartil. 2016, 24, 1890-1897. [CrossRef]

69. Pacquelet, S.; Presle, N.; Boileau, C.; Dumond, H.; Netter, P.; Martel-Pelletier, J.; Pelletier, J.P.; Terlain, B.; Jouzeau, J.Y. Interleukin 17 , a nitric oxide-producing cytokine with a peroxynitrite-independent inhibitory effect on proteoglycan synthesis. J. Rheumatol. 2002, 29, 2602-2610.

70. Wang, Z.; Zheng, C.; Zhong, Y.; He, J.; Cao, X.; Xia, H.; Ba, H.; Li, P.; Wu, S.; Peng, C. Interleukin-17 can induce osteoarthritis in rabbit knee joints similar to hulth's method. BioMed Res. Int. 2017, 2017, 2091325. [CrossRef]

71. Malfait, A.M.; Tortorella, M.; Thompson, J.; Hills, R.; Meyer, D.M.; Jaffee, B.D.; Chinn, K.; Ghoreishi-Haack, N.; Markosyan, S.; Arner, E.C. Intra-articular injection of tumor necrosis factor-alpha in the rat: An acute and reversible in vivo model of cartilage proteoglycan degradation. Osteoarthr. Cartil. 2009, 17, 627-635. [CrossRef]

72. Ogura, H.; Murakami, M.; Okuyama, Y.; Tsuruoka, M.; Kitabayashi, C.; Kanamoto, M.; Nishihara, M.; Iwakura, Y.; Hirano, T. Interleukin-17 promotes autoimmunity by triggering a positive-feedback loop via interleukin-6 induction. Immunity 2008, 29, 628-636. [CrossRef] [PubMed]

73. Van Meegeren, M.E.; Roosendaal, G.; Jansen, N.W.; Lafeber, F.P.; Mastbergen, S.C. Blood-induced joint damage: The devastating effects of acute joint bleeds versus micro-bleeds. Cartilage 2013, 4, 313-320. [CrossRef]

74. Myers, S.L.; Brandt, K.D.; O'Connor, B.L.; Visco, D.M.; Albrecht, M.E. Synovitis and osteoarthritic changes in canine articular cartilage after anterior cruciate ligament transection. Effect of surgical hemostasis. Arthritis Rheumatol. 1990, 33, $1406-1415$. [CrossRef]

75. Jansen, N.W.; Roosendaal, G.; Bijlsma, J.W.; Degroot, J.; Lafeber, F.P. Exposure of human cartilage tissue to low concentrations of blood for a short period of time leads to prolonged cartilage damage: An in vitro study. Arthritis Rheumatol. 2007, 56, 199-207. [CrossRef]

76. Van Vulpen, L.F.D.; Popov-Celeketic, J.; van Meegeren, M.E.R.; Coeleveld, K.; van Laar, J.M.; Hack, C.E.; Schutgens, R.E.G.; Mastbergen, S.C.; Lafeber, F. A fusion protein of interleukin-4 and interleukin-10 protects against blood-induced cartilage damage in vitro and in vivo. J. Thromb. Haemost. 2017, 15, 1788-1798. [CrossRef]

77. van Meegeren, M.E.; Roosendaal, G.; Jansen, N.W.; Wenting, M.J.; van Wesel, A.C.; van Roon, J.A.; Lafeber, F.P. Il-4 alone and in combination with il-10 protects against blood-induced cartilage damage. Osteoarthr. Cartil. 2012, 20, 764-772. [CrossRef] [PubMed]

78. Jansen, N.W.; Roosendaal, G.; Hooiveld, M.J.; Bijlsma, J.W.; van Roon, J.A.; Theobald, M.; Lafeber, F.P. Interleukin-10 protects against blood-induced joint damage. Br. J. Haematol. 2008, 142, 953-961. [CrossRef]

79. Melin Furst, C.; Ahrman, E.; Bratteby, K.; Waldemarson, S.; Malmstrom, J.; Blom, A.M. Quantitative mass spectrometry to study inflammatory cartilage degradation and resulting interactions with the complement system. J. Immunol. 2016, 197, 3415-3424. [CrossRef]

80. Sohn, D.H.; Sokolove, J.; Sharpe, O.; Erhart, J.C.; Chandra, P.E.; Lahey, L.J.; Lindstrom, T.M.; Hwang, I.; Boyer, K.A.; Andriacchi, T.P.; et al. Plasma proteins present in osteoarthritic synovial fluid can stimulate cytokine production via toll-like receptor 4 . Arthritis Res. Ther. 2012, 14, R7. [CrossRef]

81. Colten, H.R.; Ooi, Y.M.; Edelson, P.J. Synthesis and secretion of complement proteins by macrophages. Ann. N. Y. Acad. Sci. 1979, 332, 482-490. [CrossRef] 
82. Lubbers, R.; van Schaarenburg, R.A.; Kwekkeboom, J.C.; Levarht, E.W.N.; Bakker, A.M.; Mahdad, R.; Monteagudo, S.; Cherifi, C.; Lories, R.J.; Toes, R.E.M.; et al. Complement component c1q is produced by isolated articular chondrocytes. Osteoarthr. Cartil. 2020, 28, 675-684. [CrossRef]

83. Bradley, K.; North, J.; Saunders, D.; Schwaeble, W.; Jeziorska, M.; Woolley, D.E.; Whaley, K. Synthesis of classical pathway complement components by chondrocytes. Immunology 1996, 88, 648-656.

84. Schulze-Tanzil, G.; Kohl, B.; El Sayed, K.; Arens, S.; Ertel, W.; Stolzel, K.; John, T. Anaphylatoxin receptors and complement regulatory proteins in human articular and non-articular chondrocytes: Interrelation with cytokines. Cell Tissue Res. 2012, 350, 465-475. [CrossRef]

85. Ignatius, A.; Schoengraf, P.; Kreja, L.; Liedert, A.; Recknagel, S.; Kandert, S.; Brenner, R.E.; Schneider, M.; Lambris, J.D.; HuberLang, M. Complement c3a and c5a modulate osteoclast formation and inflammatory response of osteoblasts in synergism with il-1beta. J. Cell. Biochem. 2011, 112, 2594-2605. [CrossRef]

86. Assirelli, E.; Dolzani, P.; Pulsatelli, L.; Addimanda, O.; Lisignoli, G.; Mariani, E.; Meliconi, R. Complement factor expression in osteoarthritis joint compartments. Osteoarthr. Cartil. 2016, 24, S383-S384. [CrossRef]

87. Furman, B.D.; Strand, J.; Hembree, W.C.; Ward, B.D.; Guilak, F.; Olson, S.A. Joint degeneration following closed intraarticular fracture in the mouse knee: A model of posttraumatic arthritis. J. Orthop. Res. 2007, 25, 578-592. [CrossRef]

88. Furman, B.D.; Mangiapani, D.S.; Zeitler, E.; Bailey, K.N.; Horne, P.H.; Huebner, J.L.; Kraus, V.B.; Guilak, F.; Olson, S.A. Targeting pro-inflammatory cytokines following joint injury: Acute intra-articular inhibition of interleukin-1 following knee injury prevents post-traumatic arthritis. Arthritis Res. Ther. 2014, 16, R134. [CrossRef]

89. Lewis, J.S.; Hembree, W.C.; Furman, B.D.; Tippets, L.; Cattel, D.; Huebner, J.L.; Little, D.; DeFrate, L.E.; Kraus, V.B.; Guilak, F.; et al. Acute joint pathology and synovial inflammation is associated with increased intra-articular fracture severity in the mouse knee. Osteoarthr. Cartil. 2011, 19, 864-873. [CrossRef]

90. Duan, X.; Sandell, L.J.; Chinzei, N.; Holguin, N.; Silva, M.J.; Schiavinato, A.; Rai, M.F. Therapeutic efficacy of intra-articular hyaluronan derivative and platelet-rich plasma in mice following axial tibial loading. PLoS ONE 2017, 12, e0175682. [CrossRef]

91. Ghosh, P.; Guidolin, D. Potential mechanism of action of intra-articular hyaluronan therapy in osteoarthritis: Are the effects molecular weight dependent? Semin. Arthritis Rheum. 2002, 32, 10-37. [CrossRef]

92. Christiansen, B.A.; Guilak, F.; Lockwood, K.A.; Olson, S.A.; Pitsillides, A.A.; Sandell, L.J.; Silva, M.J.; van der Meulen, M.C.; Haudenschild, D.R. Non-invasive mouse models of post-traumatic osteoarthritis. Osteoarthr. Cartil. 2015, 23, 1627-1638. [CrossRef]

93. Rolauffs, B.; Kurz, B.; Felka, T.; Rothdiener, M.; Uynuk-Ool, T.; Aurich, M.; Frank, E.; Bahrs, C.; Badke, A.; Stockle, U.; et al. Stress-vs-time signals allow the prediction of structurally catastrophic events during fracturing of immature cartilage and predetermine the biomechanical, biochemical, and structural impairment. J. Struct. Biol. 2013, 183, 501-511. [CrossRef]

94. Rolauffs, B.; Muehleman, C.; Li, J.; Kurz, B.; Kuettner, K.E.; Frank, E.; Grodzinsky, A.J. Vulnerability of the superficial zone of immature articular cartilage to compressive injury. Arthritis Rheumatol. 2010, 62, 3016-3027. [CrossRef]

95. DiMicco, M.A.; Patwari, P.; Siparsky, P.N.; Kumar, S.; Pratta, M.A.; Lark, M.W.; Kim, Y.J.; Grodzinsky, A.J. Mechanisms and kinetics of glycosaminoglycan release following in vitro cartilage injury. Arthritis Rheumatol. 2004, 50, 840-848. [CrossRef] [PubMed]

96. Lockwood, K.A.; Chu, B.T.; Anderson, M.J.; Haudenschild, D.R.; Christiansen, B.A. Comparison of loading rate-dependent injury modes in a murine model of post-traumatic osteoarthritis. J. Orthop. Res. 2014, 32, 79-88. [CrossRef]

97. Satkunananthan, P.B.; Anderson, M.J.; De Jesus, N.M.; Haudenschild, D.R.; Ripplinger, C.M.; Christiansen, B.A. In vivo fluorescence reflectance imaging of protease activity in a mouse model of post-traumatic osteoarthritis. Osteoarthr. Cartil. 2014, 22, 1461-1469. [CrossRef]

98. Wu, P.; Holguin, N.; Silva, M.J.; Fu, M.; Liao, W.; Sandell, L.J. Early response of mouse joint tissue to noninvasive knee injury suggests treatment targets. Arthritis Rheumatol. 2014, 66, 1256-1265. [CrossRef]

99. Bajpayee, A.G.; De la Vega, R.E.; Scheu, M.; Varady, N.H.; Yannatos, I.A.; Brown, L.A.; Krishnan, Y.; Fitzsimons, T.J.; Bhattacharya, P.; Frank, E.H.; et al. Sustained intra-cartilage delivery of low dose dexamethasone using a cationic carrier for treatment of post traumatic osteoarthritis. Eur. Cells Mater. 2017, 34, 341-364.

100. Pickarski, M.; Hayami, T.; Zhuo, Y.; Duong, L.T. Molecular changes in articular cartilage and subchondral bone in the rat anterior cruciate ligament transection and meniscectomized models of osteoarthritis. BMC Musculoskelet. Disord. 2011, 12, 197. [CrossRef]

101. Teeple, E.; Jay, G.D.; Elsaid, K.A.; Fleming, B.C. Animal models of osteoarthritis: Challenges of model selection and analysis. AAPS J. 2013, 15, 438-446. [CrossRef]

102. Kuettner, K.E.; Cole, A.A. Cartilage degeneration in different human joints. Osteoarthr. Cartil. 2005, 13, 93-103. [CrossRef]

103. McCoy, A.M. Animal models of osteoarthritis: Comparisons and key considerations. Vet. Pathol. 2015, 52, 803-818. [CrossRef]

104. Fitzgerald, J. Enhanced cartilage repair in 'healer' mice-new leads in the search for better clinical options for cartilage repair. Semin. Cell Dev. Biol. 2017, 62, 78-85.

105. Rai, M.F.; Sandell, L.J. Regeneration of articular cartilage in healer and non-healer mice. Matrix Biol. 2014, 39, 50-55. [CrossRef] [PubMed]

106. Malda, J.; Benders, K.E.; Klein, T.J.; de Grauw, J.C.; Kik, M.J.; Hutmacher, D.W.; Saris, D.B.; van Weeren, P.R.; Dhert, W.J. Comparative study of depth-dependent characteristics of equine and human osteochondral tissue from the medial and lateral femoral condyles. Osteoarthr. Cartil. 2012, 20, 1147-1151. [CrossRef] [PubMed] 
107. Aicher, W.K.; Rolauffs, B. The spatial organisation of joint surface chondrocytes: Review of its potential roles in tissue functioning, disease and early, preclinical diagnosis of osteoarthritis. Ann. Rheum. Dis. 2014, 73, 645-653. [CrossRef]

108. Rolauffs, B.; Rothdiener, M.; Bahrs, C.; Badke, A.; Weise, K.; Kuettner, K.E.; Kurz, B.; Aurich, M.; Grodzinsky, A.J.; Aicher, W.K. Onset of preclinical osteoarthritis: The angular spatial organization permits early diagnosis. Arthritis Rheumatol. 2011, 63, 1637-1647. [CrossRef]

109. Rolauffs, B.; Williams, J.M.; Aurich, M.; Grodzinsky, A.J.; Kuettner, K.E.; Cole, A.A. Proliferative remodeling of the spatial organization of human superficial chondrocytes distant from focal early osteoarthritis. Arthritis Rheumatol. 2010, 62, 489-498.

110. Rolauffs, B.; Williams, J.M.; Grodzinsky, A.J.; Kuettner, K.E.; Cole, A.A. Distinct horizontal patterns in the spatial organization of superficial zone chondrocytes of human joints. J. Struct. Biol. 2008, 162, 335-344. [CrossRef] [PubMed]

111. Ward, B.D.; Furman, B.D.; Huebner, J.L.; Kraus, V.B.; Guilak, F.; Olson, S.A. Absence of posttraumatic arthritis following intraarticular fracture in the mrl/mpj mouse. Arthritis Rheumatol. 2008, 58, 744-753. [CrossRef] [PubMed]

112. Olson, S.A.; Furman, B.D.; Kraus, V.B.; Huebner, J.L.; Guilak, F. Therapeutic opportunities to prevent post-traumatic arthritis: Lessons from the natural history of arthritis after articular fracture. J. Orthop. Res. 2015, 33, 1266-1277. [CrossRef] [PubMed]

113. Santoro, A.; Conde, J.; Scotece, M.; Abella, V.; Lopez, V.; Pino, J.; Gomez, R.; Gomez-Reino, J.J.; Gualillo, O. Choosing the right chondrocyte cell line: Focus on nitric oxide. J. Orthop. Res. 2015, 33, 1784-1788. [CrossRef]

114. Park, E.; Hart, M.L.; Rolauffs, B.; Stegemann, J.P.; Ramkumar, T.A. Bioresponsive microspheres for on-demand delivery of anti-inflammatory cytokines for articular cartilage repair. J. Biomed. Mater. Res. A 2020, 108, 722-733. [CrossRef]

115. Otero, M.; Lago, R.; Lago, F.; Reino, J.J.; Gualillo, O. Signalling pathway involved in nitric oxide synthase type ii activation in chondrocytes: Synergistic effect of leptin with interleukin-1. Arthritis Res. Ther. 2005, 7, R581-R591. [CrossRef]

116. Otero, M.; Gomez Reino, J.J.; Gualillo, O. Synergistic induction of nitric oxide synthase type ii: In vitro effect of leptin and interferon-gamma in human chondrocytes and atdc5 chondrogenic cells. Arthritis Rheumatol. 2003, 48, 404-409. [CrossRef] [PubMed]

117. Mayhewy, M.; Kevorkian, L.; Swingler, T.; Bevan, D.; Stubberfield, C.; Moore, A.; Gavrilovi, J. A modified and enhanced atdc-5 chondrogenesis model produces an articular-like. Osteoarthr. Cartil. $2014,22$.

118. Hubka, K.M.; Dahlin, R.L.; Meretoja, V.V.; Kasper, F.K.; Mikos, A.G. Enhancing chondrogenic phenotype for cartilage tissue engineering: Monoculture and coculture of articular chondrocytes and mesenchymal stem cells. Tissue Eng. Part B Rev. 2014, 20, 641-654. [CrossRef]

119. Benya, P.D.; Padilla, S.R.; Nimni, M.E. Independent regulation of collagen types by chondrocytes during the loss of differentiated function in culture. Cell 1978, 15, 1313-1321. [CrossRef]

120. Benya, P.D.; Shaffer, J.D. Dedifferentiated chondrocytes reexpress the differentiated collagen phenotype when cultured in agarose gels. Cell 1982, 30, 215-224. [CrossRef]

121. Caron, M.M.; Emans, P.J.; Coolsen, M.M.; Voss, L.; Surtel, D.A.; Cremers, A.; van Rhijn, L.W.; Welting, T.J. Redifferentiation of dedifferentiated human articular chondrocytes: Comparison of $2 \mathrm{~d}$ and $3 \mathrm{~d}$ cultures. Osteoarthr. Cartil. 2012, 20, 1170-1178. [CrossRef]

122. Aurich, M.; Hofmann, G.O.; Gras, F.; Rolauffs, B. Human osteochondritis dissecans fragment-derived chondrocyte characteristics ex vivo, after monolayer expansion-induced de-differentiation, and after re-differentiation in alginate bead culture. $B M C$ Musculoskelet. Disord. 2018, 19, 168. [CrossRef] [PubMed]

123. Hsieh-Bonassera, N.D.; Wu, I.; Lin, J.K.; Schumacher, B.L.; Chen, A.C.; Masuda, K.; Bugbee, W.D.; Sah, R.L. Expansion and redifferentiation of chondrocytes from osteoarthritic cartilage: Cells for human cartilage tissue engineering. Tissue Eng. Part $A$ 2009, 15, 3513-3523. [CrossRef] [PubMed]

124. Babur, B.K.; Ghanavi, P.; Levett, P.; Lott, W.B.; Klein, T.; Cooper-White, J.J.; Crawford, R.; Doran, M.R. The interplay between chondrocyte redifferentiation pellet size and oxygen concentration. PLoS ONE 2013, 8, e58865. [CrossRef]

125. Meretoja, V.V.; Dahlin, R.L.; Wright, S.; Kasper, F.K.; Mikos, A.G. Articular chondrocyte redifferentiation in 3d co-cultures with mesenchymal stem cells. Tissue Eng. Part C Methods 2014, 20, 514-523. [CrossRef] [PubMed]

126. Schuh, E.; Hofmann, S.; Stok, K.; Notbohm, H.; Muller, R.; Rotter, N. Chondrocyte redifferentiation in 3d: The effect of adhesion site density and substrate elasticity. J. Biomed. Mater. Res. A 2012, 100, 38-47. [CrossRef] [PubMed]

127. Levett, P.A.; Melchels, F.P.; Schrobback, K.; Hutmacher, D.W.; Malda, J.; Klein, T.J. Chondrocyte redifferentiation and construct mechanical property development in single-component photocrosslinkable hydrogels. J. Biomed. Mater. Res. A 2014, 102, 2544-2553. [CrossRef] [PubMed]

128. Jimenez, G.; Lopez-Ruiz, E.; Kwiatkowski, W.; Montanez, E.; Arrebola, F.; Carrillo, E.; Gray, P.C.; Izpisua Belmonte, J.C.; Choe, S.; Peran, M.; et al. Activin a/bmp2 chimera ab235 drives efficient redifferentiation of long term cultured autologous chondrocytes. Sci. Rep. 2015, 5, 16400. [CrossRef]

129. Rothdiener, M.; Uynuk-Ool, T.; Sudkamp, N.; Aurich, M.; Grodzinsky, A.J.; Kurz, B.; Rolauffs, B. Human osteoarthritic chondrons outnumber patient- and joint-matched chondrocytes in hydrogel culture-future application in autologous cell-based oa cartilage repair? J. Tissue Eng. Regen. Med. 2018, 12, e1206-e1220. [CrossRef] [PubMed]

130. Aurich, M.; Hofmann, G.O.; Best, N.; Rolauffs, B. Induced redifferentiation of human chondrocytes from articular cartilage lesion in alginate bead culture after monolayer dedifferentiation: An alternative cell source for cell-based therapies? Tissue Eng. Part A 2018, 24, 275-286. [CrossRef] 
131. Aurich, M.; Eger, W.; Rolauffs, B.; Margulis, A.; Kuettner, K.E.; Mollenhauer, J.A.; Cole, A.A. Ankle chondrocytes are more resistant to interleukin-1 than chondrocytes derived from the knee. Orthopade 2006, 35, 784-790. [CrossRef]

132. Aurich, M.; Squires, G.R.; Reiner, A.; Mollenhauer, J.A.; Kuettner, K.E.; Poole, A.R.; Cole, A.A. Differential matrix degradation and turnover in early cartilage lesions of human knee and ankle joints. Arthritis Rheumatol. 2005, 52, 112-119. [CrossRef] [PubMed]

133. Eger, W.; Aurich, M.; Schumacher, B.L.; Mollenhauer, J.; Kuettner, K.E.; Cole, A.A. Differences in metabolism of chondrocytes of the knee and ankle joint. Z. Orthop. Grenzgeb. 2003, 141, 18-20. [PubMed]

134. Aurich, M.; Hofmann, G.O.; Rolauffs, B. Differences in type ii collagen turnover of osteoarthritic human knee and ankle joints. Int. Orthop. 2017. [CrossRef]

135. Aurich, M.; Hofmann, G.O.; Muckley, T.; Mollenhauer, J.; Rolauffs, B. In vitro phenotypic modulation of chondrocytes from knees of patients with osteochondritis dissecans: Implications for chondrocyte implantation procedures. J. Bone Jt. Surg. Br. 2012, 94, 62-67. [CrossRef]

136. Felka, T.; Rothdiener, M.; Bast, S.; Uynuk-Ool, T.; Zouhair, S.; Ochs, B.G.; De Zwart, P.; Stoeckle, U.; Aicher, W.K.; Hart, M.L.; et al. Loss of spatial organization and destruction of the pericellular matrix in early osteoarthritis in vivo and in a novel in vitro methodology. Osteoarthr. Cartil. 2016, 24, 1200-1209. [CrossRef] [PubMed]

137. Tsuchida, A.I.; Beekhuizen, M.; Hart, M.C.; Radstake, T.R.; Dhert, W.J.; Saris, D.B.; van Osch, G.J.; Creemers, L.B. Cytokine profiles in the joint depend on pathology, but are different between synovial fluid, cartilage tissue and cultured chondrocytes. Arthritis Res. Ther. 2014, 16, 441. [CrossRef]

138. Lin, Z.; Fitzgerald, J.B.; Xu, J.; Willers, C.; Wood, D.; Grodzinsky, A.J.; Zheng, M.H. Gene expression profiles of human chondrocytes during passaged monolayer cultivation. J. Orthop. Res. 2008, 26, 1230-1237. [CrossRef] [PubMed]

139. Kurz, B.; Lemke, A.K.; Fay, J.; Pufe, T.; Grodzinsky, A.J.; Schunke, M. Pathomechanisms of cartilage destruction by mechanical injury. Ann. Anat. 2005, 187, 473-485. [CrossRef]

140. Nickien, M.; Heuijerjans, A.; Ito, K.; van Donkelaar, C.C. Comparison between in vitro and in vivo cartilage overloading studies based on a systematic literature review. J. Orthop. Res. 2018. [CrossRef]

141. Behrendt, P.; Preusse-Prange, A.; Kluter, T.; Haake, M.; Rolauffs, B.; Grodzinsky, A.J.; Lippross, S.; Kurz, B. Il-10 reduces apoptosis and extracellular matrix degradation after injurious compression of mature articular cartilage. Osteoarthr. Cartil. 2016, 24, 1981-1988. [CrossRef] [PubMed]

142. Behrendt, P.; Feldheim, M.; Preusse-Prange, A.; Weitkamp, J.T.; Haake, M.; Eglin, D.; Rolauffs, B.; Fay, J.; Seekamp, A.; Grodzinsky, A.J.; et al. Chondrogenic potential of il-10 in mechanically injured cartilage and cellularized collagen aci grafts. Osteoarthr. Cartil. 2018, 26, 264-275. [CrossRef] [PubMed]

143. Wang, Y.; Li, Y.; Khabut, A.; Chubinskaya, S.; Grodzinsky, A.J.; Onnerfjord, P. Quantitative proteomics analysis of cartilage response to mechanical injury and cytokine treatment. Matrix Biol. 2017, 63, 11-22. [CrossRef] [PubMed]

144. Patwari, P.; Cook, M.N.; DiMicco, M.A.; Blake, S.M.; James, I.E.; Kumar, S.; Cole, A.A.; Lark, M.W.; Grodzinsky, A.J. Proteoglycan degradation after injurious compression of bovine and human articular cartilage in vitro: Interaction with exogenous cytokines Arthritis Rheumatol. 2003, 48, 1292-1301. [CrossRef]

145. Lu, Y.C.; Evans, C.H.; Grodzinsky, A.J. Effects of short-term glucocorticoid treatment on changes in cartilage matrix degradation and chondrocyte gene expression induced by mechanical injury and inflammatory cytokines. Arthritis Res. Ther. 2011, 13, R142. [CrossRef]

146. Sui, Y.; Lee, J.H.; DiMicco, M.A.; Vanderploeg, E.J.; Blake, S.M.; Hung, H.H.; Plaas, A.H.; James, I.E.; Song, X.Y.; Lark, M.W.; et al. Mechanical injury potentiates proteoglycan catabolism induced by interleukin- 6 with soluble interleukin-6 receptor and tumor necrosis factor alpha in immature bovine and adult human articular cartilage. Arthritis Rheumatol. 2009, 60, 2985-2996. [CrossRef]

147. Stevens, A.L.; Wishnok, J.S.; White, F.M.; Grodzinsky, A.J.; Tannenbaum, S.R. Mechanical injury and cytokines cause loss of cartilage integrity and upregulate proteins associated with catabolism, immunity, inflammation, and repair. Mol. Cell Proteomics 2009, 8, 1475-1489. [CrossRef]

148. Torzilli, P.A.; Bhargava, M.; Chen, C.T. Mechanical loading of articular cartilage reduces il-1-induced enzyme expression. Cartilage 2011, 2, 364-373. [CrossRef] [PubMed]

149. Bajpayee, A.G.; Quadir, M.A.; Hammond, P.T.; Grodzinsky, A.J. Charge based intra-cartilage delivery of single dose dexamethasone using avidin nano-carriers suppresses cytokine-induced catabolism long term. Osteoarthr. Cartil. 2016, 24, 71-81. [CrossRef] [PubMed]

150. Sinkeviciute, D.; Aspberg, A.; He, Y.; Bay-Jensen, A.C.; Onnerfjord, P. Characterization of the interleukin-17 effect on articular cartilage in a translational model: An explorative study. BMC Rheumatol. 2020, 4, 30. [CrossRef]

151. Clutterbuck, A.L.; Smith, J.R.; Allaway, D.; Harris, P.; Liddell, S.; Mobasheri, A. High throughput proteomic analysis of the secretome in an explant model of articular cartilage inflammation. J. Proteom. 2011, 74, 704-715. [CrossRef] [PubMed]

152. Kongdang, P.; Chokchaitaweesuk, C.; Tangyuenyong, S.; Ongchai, S. Proinflammatory effects of il-1beta combined with il-17a promoted cartilage degradation and suppressed genes associated with cartilage matrix synthesis in vitro. Molecules 2019, $24,3682$. [CrossRef]

153. Lubberts, E.; Joosten, L.A.; van de Loo, F.A.; van den Gersselaar, L.A.; van den Berg, W.B. Reduction of interleukin-17-induced inhibition of chondrocyte proteoglycan synthesis in intact murine articular cartilage by interleukin-4. Arthritis Rheumatol. 2000, 43, 1300-1306. [CrossRef] 
154. Li, Y.; Frank, E.H.; Wang, Y.; Chubinskaya, S.; Huang, H.H.; Grodzinsky, A.J. Moderate dynamic compression inhibits procatabolic response of cartilage to mechanical injury, tumor necrosis factor-alpha and interleukin-6, but accentuates degradation above a strain threshold. Osteoarthr. Cartil. 2013, 21, 1933-1941. [CrossRef]

155. Jackson, M.T.; Moradi, B.; Smith, M.M.; Jackson, C.J.; Little, C.B. Activation of matrix metalloproteinases 2, 9, and 13 by activated protein c in human osteoarthritic cartilage chondrocytes. Arthritis Rheumatol. 2014, 66, 1525-1536. [CrossRef] [PubMed]

156. Li, Y.; Wang, Y.; Chubinskaya, S.; Schoeberl, B.; Florine, E.; Kopesky, P.; Grodzinsky, A.J. Effects of insulin-like growth factor-1 and dexamethasone on cytokine-challenged cartilage: Relevance to post-traumatic osteoarthritis. Osteoarthr. Cartil. 2015, 23, 266-274. [CrossRef]

157. Schuerwegh, A.J.; Dombrecht, E.J.; Stevens, W.J.; Van Offel, J.F.; Bridts, C.H.; De Clerck, L.S. Influence of pro-inflammatory (il-1 alpha, il-6, tnf-alpha, ifn-gamma) and anti-inflammatory (il-4) cytokines on chondrocyte function. Osteoarthr. Cartil. 2003, 11, 681-687. [CrossRef]

158. Takahashi, A.; de Andres, M.C.; Hashimoto, K.; Itoi, E.; Oreffo, R.O. Epigenetic regulation of interleukin-8, an inflammatory chemokine, in osteoarthritis. Osteoarthr. Cartil. 2015, 23, 1946-1954. [CrossRef]

159. Ahmad, R.; Qureshi, H.Y.; El Mabrouk, M.; Sylvester, J.; Ahmad, M.; Zafarullah, M. Inhibition of interleukin 1-induced matrix metalloproteinase 13 expression in human chondrocytes by interferon gamma. Ann. Rheum. Dis. 2007, 66, 782-789. [CrossRef] [PubMed]

160. Henrotin, Y.E.; De Groote, D.D.; Labasse, A.H.; Gaspar, S.E.; Zheng, S.X.; Geenen, V.G.; Reginster, J.Y. Effects of exogenous il-1 beta, tnf alpha, il-6, il-8 and lif on cytokine production by human articular chondrocytes. Osteoarthr. Cartil. 1996, 4, 163-173. [CrossRef]

161. Roman-Blas, J.A.; Stokes, D.G.; Jimenez, S.A. Modulation of tgf-beta signaling by proinflammatory cytokines in articular chondrocytes. Osteoarthr. Cartil. 2007, 15, 1367-1377. [CrossRef]

162. Martin, G.; Andriamanalijaona, R.; Mathy-Hartert, M.; Henrotin, Y.; Pujol, J.P. Comparative effects of il-1beta and hydrogen peroxide (h2o2) on catabolic and anabolic gene expression in juvenile bovine chondrocytes. Osteoarthr. Cartil. 2005, 13, 915-924. [CrossRef]

163. Chowdhury, T.T.; Bader, D.L.; Lee, D.A. Anti-inflammatory effects of il-4 and dynamic compression in il-1beta stimulated chondrocytes. Biochem. Biophys. Res. Commun. 2006, 339, 241-247. [CrossRef]

164. Chen, X.Y.; Hao, Y.R.; Wang, Z.; Zhou, J.L.; Jia, Q.X.; Qiu, B. The effect of vascular endothelial growth factor on aggrecan and type ii collagen expression in rat articular chondrocytes. Rheumatol. Int. 2012, 32, 3359-3364. [CrossRef]

165. Bougault, C.; Gosset, M.; Houard, X.; Salvat, C.; Godmann, L.; Pap, T.; Jacques, C.; Berenbaum, F. Stress-induced cartilage degradation does not depend on the nlrp3 inflammasome in human osteoarthritis and mouse models. Arthritis Rheumatol. 2012, 64, 3972-3981. [CrossRef]

166. Muller, R.D.; John, T.; Kohl, B.; Oberholzer, A.; Gust, T.; Hostmann, A.; Hellmuth, M.; Laface, D.; Hutchins, B.; Laube, G.; et al. Il-10 overexpression differentially affects cartilage matrix gene expression in response to tnf-alpha in human articular chondrocytes in vitro. Cytokine 2008, 44, 377-385. [CrossRef] [PubMed]

167. John, T.; Muller, R.D.; Oberholzer, A.; Zreiqat, H.; Kohl, B.; Ertel, W.; Hostmann, A.; Tschoeke, S.K.; Schulze-Tanzil, G. Interleukin10 modulates pro-apoptotic effects of tnf-alpha in human articular chondrocytes in vitro. Cytokine 2007, 40, 226-234. [CrossRef]

168. Scotece, M.; Conde, J.; Abella, V.; Lopez, V.; Lago, F.; Pino, J.; Gomez-Reino, J.J.; Gualillo, O. Nucb2/nesfatin-1: A new adipokine expressed in human and murine chondrocytes with pro-inflammatory properties, an in vitro study. J. Orthop. Res. 2014, 32, 653-660. [CrossRef]

169. LeGrand, A.; Fermor, B.; Fink, C.; Pisetsky, D.S.; Weinberg, J.B.; Vail, T.P.; Guilak, F. Interleukin-1, tumor necrosis factor alpha, and interleukin-17 synergistically up-regulate nitric oxide and prostaglandin e2 production in explants of human osteoarthritic knee menisci. Arthritis Rheumatol. 2001, 44, 2078-2083. [CrossRef]

170. Na, H.S.; Park, J.S.; Cho, K.H.; Kwon, J.Y.; Choi, J.; Jhun, J.; Kim, S.J.; Park, S.H.; Cho, M.L. Interleukin-1-interleukin-17 signaling axis induces cartilage destruction and promotes experimental osteoarthritis. Front. Immunol. 2020, 11, 730. [CrossRef] [PubMed]

171. Attur, M.G.; Patel, R.N.; Abramson, S.B.; Amin, A.R. Interleukin-17 up-regulation of nitric oxide production in human osteoarthritis cartilage. Arthritis Rheumatol. 1997, 40, 1050-1053. [CrossRef] [PubMed]

172. Shalom-Barak, T.; Quach, J.; Lotz, M. Interleukin-17-induced gene expression in articular chondrocytes is associated with activation of mitogen-activated protein kinases and nf-kappab. J. Biol. Chem. 1998, 273, 27467-27473. [CrossRef] [PubMed]

173. Honorati, M.C.; Bovara, M.; Cattini, L.; Piacentini, A.; Facchini, A. Contribution of interleukin 17 to human cartilage degradation and synovial inflammation in osteoarthritis. Osteoarthr. Cartil. 2002, 10, 799-807. [CrossRef]

174. Mimpen, J.Y.; Snelling, S.J.B. Chondroprotective factors in osteoarthritis: A joint affair. Curr. Rheumatol. Rep. 2019, $21,41$. [CrossRef] [PubMed]

175. Tanigawa, S.; Aida, Y.; Kawato, T.; Honda, K.; Nakayama, G.; Motohashi, M.; Suzuki, N.; Ochiai, K.; Matsumura, H.; Maeno, M Interleukin-17f affects cartilage matrix turnover by increasing the expression of collagenases and stromelysin- 1 and by decreasing the expression of their inhibitors and extracellular matrix components in chondrocytes. Cytokine 2011, 56, 376-386. [CrossRef]

176. Martel-Pelletier, J.; Mineau, F.; Jovanovic, D.; Di Battista, J.A.; Pelletier, J.P. Mitogen-activated protein kinase and nuclear factor kappab together regulate interleukin-17-induced nitric oxide production in human osteoarthritic chondrocytes: Possible role of transactivating factor mitogen-activated protein kinase-activated proten kinase (mapkapk). Arthritis Rheumatol. 1999, 42, 2399-2409. 
177. Chabaud, M.; Durand, J.M.; Buchs, N.; Fossiez, F.; Page, G.; Frappart, L.; Miossec, P. Human interleukin-17: A t cell-derived proinflammatory cytokine produced by the rheumatoid synovium. Arthritis Rheumatol. 1999, 42, 963-970. [CrossRef]

178. Katz, Y.; Nadiv, O.; Beer, Y. Interleukin-17 enhances tumor necrosis factor alpha-induced synthesis of interleukins 1,6, and 8 in skin and synovial fibroblasts: A possible role as a "fine-tuning cytokine" in inflammation processes. Arthritis Rheumatol. 2001, 44, 2176-2184. [CrossRef]

179. Kondo, M.; Yamaoka, K.; Sonomoto, K.; Fukuyo, S.; Oshita, K.; Okada, Y.; Tanaka, Y. Il-17 inhibits chondrogenic differentiation of human mesenchymal stem cells. PLoS ONE 2013, 8, e79463. [CrossRef] [PubMed]

180. Niemeyer, P.; Albrecht, D.; Andereya, S.; Angele, P.; Ateschrang, A.; Aurich, M.; Baumann, M.; Bosch, U.; Erggelet, C.; Fickert, S.; et al. Autologous chondrocyte implantation (ACI) for cartilage defects of the knee: A guideline by the working group "clinical tissue regeneration" of the German Society of Orthopaedics and Trauma (DGOU). Knee 2016. [CrossRef]

181. Aurich, M.; Bedi, H.S.; Smith, P.J.; Rolauffs, B.; Muckley, T.; Clayton, J.; Blackney, M. Arthroscopic treatment of osteochondral lesions of the ankle with matrix-associated chondrocyte implantation: Early clinical and magnetic resonance imaging results. Am. J. Sports Med. 2011, 39, 311-319. [CrossRef]

182. Ochs, B.G.; Muller-Horvat, C.; Albrecht, D.; Schewe, B.; Weise, K.; Aicher, W.K.; Rolauffs, B. Remodeling of articular cartilage and subchondral bone after bone grafting and matrix-associated autologous chondrocyte implantation for osteochondritis dissecans of the knee. Am. J. Sports Med. 2011, 39, 764-773. [CrossRef] [PubMed]

183. Selig, M.; Lauer, J.C.; Hart, M.L.; Rolauffs, B. Mechanotransduction and stiffness-sensing: Mechanisms and opportunities to control multiple molecular aspects of cell phenotype as a design cornerstone of cell-instructive biomaterials for articular cartilage repair. Int. J. Mol. Sci. 2020, 21, 5399. [CrossRef]

184. Lubrano, E.; Perrotta, F.M. Secukinumab for ankylosing spondylitis and psoriatic arthritis. Ther. Clin. Risk Manag. 2016, 12, 1587-1592. [CrossRef]

185. Sandy, J.D.; Chan, D.D.; Trevino, R.L.; Wimmer, M.A.; Plaas, A. Human genome-wide expression analysis reorients the study of inflammatory mediators and biomechanics in osteoarthritis. Osteoarthr. Cartil. 2015, 23, 1939-1945. [CrossRef]

186. Ruiz de Morales, J.M.G.; Puig, L.; Dauden, E.; Canete, J.D.; Pablos, J.L.; Martin, A.O.; Juanatey, C.G.; Adan, A.; Montalban, X.; Borruel, N.; et al. Critical role of interleukin (il)-17 in inflammatory and immune disorders: An updated review of the evidence focusing in controversies. Autoimmun. Rev. 2020, 19, 102429. [CrossRef]

187. Miossec, P.; Kolls, J.K. Targeting il-17 and th17 cells in chronic inflammation. Nat. Rev. Drug Discov. 2012, 11, 763-776. [CrossRef] [PubMed]

188. Zenobia, C.; Hajishengallis, G. Basic biology and role of interleukin-17 in immunity and inflammation. Periodontol. 2000 2015, 69, 142-159. [CrossRef] [PubMed]

189. Faust, H.J.; Zhang, H.; Han, J.; Wolf, M.T.; Jeon, O.H.; Sadtler, K.; Pena, A.N.; Chung, L.; Maestas, D.R., Jr.; Tam, A.J.; et al. Il-17 and immunologically induced senescence regulate response to injury in osteoarthritis. J. Clin. Investig. 2020, 130, 5493-5507. [CrossRef]

190. Akeson, G.; Malemud, C.J. A role for soluble il-6 receptor in osteoarthritis. J. Funct. Morphol. Kinesiol. 2017, 2, 27. [CrossRef]

191. Wiegertjes, R.; van de Loo, F.A.J.; Blaney Davidson, E.N. A roadmap to target interleukin-6 in osteoarthritis. Rheumatology (Oxford) 2020, 59, 2681-2694. [CrossRef]

192. Ahrman, E.; Lorenzo, P.; Holmgren, K.; Grodzinsky, A.J.; Dahlberg, L.E.; Saxne, T.; Heinegard, D.; Onnerfjord, P. Novel cartilage oligomeric matrix protein (comp) neoepitopes identified in synovial fluids from patients with joint diseases using affinity chromatography and mass spectrometry. J. Biol. Chem. 2014, 289, 20908-20916. [CrossRef]

193. Flannery, C.R.; Little, C.B.; Hughes, C.E.; Curtis, C.L.; Caterson, B.; Jones, S.A. Il-6 and its soluble receptor augment aggrecanasemediated proteoglycan catabolism in articular cartilage. Matrix Biol. 2000, 19, 549-553. [CrossRef]

194. Pasquali Ronchetti, I.; Guerra, D.; Taparelli, F.; Boraldi, F.; Bergamini, G.; Mori, G.; Zizzi, F.; Frizziero, L. Morphological analysis of knee synovial membrane biopsies from a randomized controlled clinical study comparing the effects of sodium hyaluronate (hyalgan) and methylprednisolone acetate (depomedrol) in osteoarthritis. Rheumatology (Oxford) 2001, 40, 158-169. [CrossRef] [PubMed]

195. Daghestani, H.N.; Pieper, C.F.; Kraus, V.B. Soluble macrophage biomarkers indicate inflammatory phenotypes in patients with knee osteoarthritis. Arthritis Rheumatol. 2015, 67, 956-965. [CrossRef] [PubMed]

196. Wood, M.J.; Leckenby, A.; Reynolds, G.; Spiering, R.; Pratt, A.G.; Rankin, K.S.; Isaacs, J.D.; Haniffa, M.A.; Milling, S.; Hilkens, C.M. Macrophage proliferation distinguishes 2 subgroups of knee osteoarthritis patients. JCI Insight 2019, 4. [CrossRef] [PubMed]

197. Gomez-Aristizabal, A.; Gandhi, R.; Mahomed, N.N.; Marshall, K.W.; Viswanathan, S. Synovial fluid monocyte/macrophage subsets and their correlation to patient-reported outcomes in osteoarthritic patients: A cohort study. Arthritis Res. Ther. 2019, 21, 26. [CrossRef]

198. Sward, P.; Wang, Y.; Hansson, M.; Lohmander, L.S.; Grodzinsky, A.J.; Struglics, A. Coculture of bovine cartilage with synovium and fibrous joint capsule increases aggrecanase and matrix metalloproteinase activity. Arthritis Res. Ther. 2017, 19, 157. [CrossRef] [PubMed]

199. Lee, J.H.; Fitzgerald, J.B.; DiMicco, M.A.; Cheng, D.M.; Flannery, C.R.; Sandy, J.D.; Plaas, A.H.; Grodzinsky, A.J. Co-culture of mechanically injured cartilage with joint capsule tissue alters chondrocyte expression patterns and increases adamts5 production. Arch. Biochem. Biophys. 2009, 489, 118-126. [CrossRef] 
200. Patwari, P.; Lin, S.N.; Kurz, B.; Cole, A.A.; Kumar, S.; Grodzinsky, A.J. Potent inhibition of cartilage biosynthesis by coincubation with joint capsule through an il-1-independent pathway. Scand. J. Med. Sci. Sports 2009, 19, 528-535. [CrossRef]

201. Beekhuizen, M.; Bastiaansen-Jenniskens, Y.M.; Koevoet, W.; Saris, D.B.; Dhert, W.J.; Creemers, L.B.; van Osch, G.J. Osteoarthritic synovial tissue inhibition of proteoglycan production in human osteoarthritic knee cartilage: Establishment and characterization of a long-term cartilage-synovium coculture. Arthritis Rheumatol. 2011, 63, 1918-1927. [CrossRef] [PubMed]

202. Hoff, P.; Buttgereit, F.; Burmester, G.R.; Jakstadt, M.; Gaber, T.; Andreas, K.; Matziolis, G.; Perka, C.; Rohner, E. Osteoarthritis synovial fluid activates pro-inflammatory cytokines in primary human chondrocytes. Int. Orthop. 2013, 37, 145-151. [CrossRef] [PubMed]

203. Samavedi, S.; Diaz-Rodriguez, P.; Erndt-Marino, J.D.; Hahn, M.S. A three-dimensional chondrocyte-macrophage coculture system to probe inflammation in experimental osteoarthritis. Tissue Eng. Part A 2017, 23, 101-114. [CrossRef]

204. Utomo, L.; Bastiaansen-Jenniskens, Y.M.; Verhaar, J.A.; van Osch, G.J. Cartilage inflammation and degeneration is enhanced by pro-inflammatory $(\mathrm{m} 1)$ macrophages in vitro, but not inhibited directly by anti-inflammatory (m2) macrophages. Osteoarthr. Cartil. 2016, 24, 2162-2170. [CrossRef] [PubMed]

205. Johnson, C.I.; Argyle, D.J.D. In vitro models for the study of osteoarthritis. Vet. J. 2015. [CrossRef] [PubMed]

206. Imgenberg, J.; Rolauffs, B.; Grodzinsky, A.J.; Schunke, M.; Kurz, B. Estrogen reduces mechanical injury-related cell death and proteoglycan degradation in mature articular cartilage independent of the presence of the superficial zone tissue. Osteoarthr. Cartil. 2013, 21, 1738-1745. [CrossRef]

207. Quinn, T.M.; Maung, A.A.; Grodzinsky, A.J.; Hunziker, E.B.; Sandy, J.D. Physical and biological regulation of proteoglycan turnover around chondrocytes in cartilage explants. Implications for tissue degradation and repair. Ann. N. Y. Acad. Sci. 1999, 878, 420-441. [CrossRef] [PubMed]

208. Cai, H.; Sun, H.J.; Wang, Y.H.; Zhang, Z. Relationships of common polymorphisms in IL-6, IL-1a, and IL-1b genes with susceptibility to osteoarthritis: A meta-analysis. Clin. Rheumatol. 2015, 34, 1443-1453. [CrossRef] [PubMed]

209. Livshits, G.; Zhai, G.; Hart, D.J.; Kato, B.S.; Wang, H.; Williams, F.M.; Spector, T.D. Interleukin-6 is a significant predictor of radiographic knee osteoarthritis: The chingford study. Arthritis Rheumatol. 2009, 60, 2037-2045. [CrossRef]

210. de Hooge, A.S.; van de Loo, F.A.; Bennink, M.B.; Arntz, O.J.; de Hooge, P.; van den Berg, W.B. Male il-6 gene knock out mice developed more advanced osteoarthritis upon aging. Osteoarthr. Cartil. 2005, 13, 66-73. [CrossRef]

211. Daheshia, M.; Yao, J.Q. The interleukin 1beta pathway in the pathogenesis of osteoarthritis. J. Rheumatol. 2008, 35, $2306-2312$. [CrossRef] [PubMed]

212. Farrugia, M.; Baron, B. The role of tnf-alpha in rheumatoid arthritis: A focus on regulatory t cells. J. Clin. Transl. Res. 2016, 2, 84-90. [CrossRef] [PubMed]

213. Kang, S.; Tanaka, T.; Narazaki, M.; Kishimoto, T. Targeting interleukin-6 signaling in clinic. Immunity 2019, 50, 1007-1023. [CrossRef]

214. Kay, J.; Calabrese, L. The role of interleukin-1 in the pathogenesis of rheumatoid arthritis. Rheumatology (Oxford) 2004,43 (Suppl. 3), iii2-iii9. [CrossRef]

215. Cheng, R.; Wu, Z.; Li, M.; Shao, M.; Hu, T. Interleukin-1beta is a potential therapeutic target for periodontitis: A narrative review. Int. J. Oral. Sci. 2020, 12, 2. [CrossRef]

216. Altobelli, E.; Angeletti, P.M.; Piccolo, D.; De Angelis, R. Synovial fluid and serum concentrations of inflammatory markers in rheumatoid arthritis, psoriatic arthritis and osteoarthitis: A systematic review. Curr. Rheumatol. Rev. 2017, 13, 170-179. [CrossRef]

217. Holbrook, J.; Lara-Reyna, S.; Jarosz-Griffiths, H.; McDermott, M. Tumour necrosis factor signalling in health and disease. F1000 Res. 2019, 8. [CrossRef] [PubMed]

218. Azuma, M.M.; Samuel, R.O.; Gomes-Filho, J.E.; Dezan-Junior, E.; Cintra, L.T. The role of il-6 on apical periodontitis: A systematic review. Int. Endod. J. 2014, 47, 615-621. [CrossRef]

219. Yoshida, Y.; Tanaka, T. Interleukin 6 and rheumatoid arthritis. BioMed Res. Int. 2014, 2014, 698313. [CrossRef]

220. Taams, L.S. Interleukin-17 in rheumatoid arthritis: Trials and tribulations. J. Exp. Med. 2020, 217. [CrossRef]

221. Hajishengallis, G. Immunomicrobial pathogenesis of periodontitis: Keystones, pathobionts, and host response. Trends Immunol. 2014, 35, 3-11. [CrossRef]

222. Yamshchikov, V.F.; Mishina, M.; Cominelli, F. A possible role of IL-1ra 3'-untranslated region in modulation of protein production. Cytokine 2002, 17, 98-107. [CrossRef]

223. Wu, X.; Kondragunta, V.; Kornman, K.S.; Wang, H.Y.; Duff, G.W.; Renner, J.B.; Jordan, J.M. Il-1 receptor antagonist gene as a predictive biomarker of progression of knee osteoarthritis in a population cohort. Osteoarthr. Cartil. 2013, 21, 930-938. [CrossRef]

224. van Meegeren, M.E.; Roosendaal, G.; Coeleveld, K.; Nieuwenhuizen, L.; Mastbergen, S.C.; Lafeber, F.P. A single intra-articular injection with il-4 plus il-10 ameliorates blood-induced cartilage degeneration in haemophilic mice. Br. J. Haematol. 2013, 160, 515-520. [CrossRef]

225. Nabbe, K.C.; van Lent, P.L.; Holthuysen, A.E.; Sloetjes, A.W.; Koch, A.E.; Radstake, T.R.; van den Berg, W.B. Local il-13 gene transfer prior to immune-complex arthritis inhibits chondrocyte death and matrix-metalloproteinase-mediated cartilage matrix degradation despite enhanced joint inflammation. Arthritis Res. Ther. 2005, 7, R392-R401. [CrossRef]

226. Chamberlain, C.S.; Leiferman, E.M.; Frisch, K.E.; Brickson, S.L.; Murphy, W.L.; Baer, G.S.; Vanderby, R. Interleukin expression after injury and the effects of interleukin-1 receptor antagonist. PLOS ONE 2013, 8, e71631. [CrossRef] 
227. Elsaid, K.A.; Ubhe, A.; Shaman, Z.; D'Souza, G. Intra-articular interleukin-1 receptor antagonist (il1-ra) microspheres for posttraumatic osteoarthritis: In vitro biological activity and in vivo disease modifying effect. J. Exp. Orthop. 2016, 3, 18. [CrossRef]

228. Chamberlain, C.S.; Leiferman, E.M.; Frisch, K.E.; Duenwald-Kuehl, S.E.; Brickson, S.L.; Murphy, W.L.; Baer, G.S.; Vanderby, R. Interleukin-1 receptor antagonist modulates inflammation and scarring after ligament injury. Connect. Tissue Res. 2014, 55, 177-186. [CrossRef] [PubMed]

229. Watt, F.E.; Corp, N.; Kingsbury, S.R.; Frobell, R.; Englund, M.; Felson, D.T.; Levesque, M.; Majumdar, S.; Wilson, C.; Beard, D.J.; et al. Towards prevention of post-traumatic osteoarthritis: Report from an international expert working group on considerations for the design and conduct of interventional studies following acute knee injury. Osteoarthr. Cartil. 2019, 27, 23-33. [CrossRef] [PubMed]

230. Arden, N.; Richette, P.; Cooper, C.; Bruyere, O.; Abadie, E.; Branco, J.; Brandi, M.L.; Berenbaum, F.; Clerc, C.; Dennison, E.; et al. Can we identify patients with high risk of osteoarthritis progression who will respond to treatment? A focus on biomarkers and frailty. Drugs Aging 2015, 32, 525-535. [CrossRef] [PubMed]

231. van Spil, W.E.; Szilagyi, I.A. Osteoarthritis year in review 2019: Biomarkers (biochemical markers). Osteoarthr. Cartil. 2020, 28, 296-315. [CrossRef]

232. Anitua, E.; Sanchez, M.; de la Fuente, M.; Azofra, J.; Zalduendo, M.; Aguirre, J.J.; Andia, I. Relationship between investigative biomarkers and radiographic grading in patients with knee osteoarthritis. Int. J. Rheumatol. 2009, 2009, 747432. [CrossRef] [PubMed]

233. Deveza, L.A.; Kraus, V.B.; Collins, J.E.; Guermazi, A.; Roemer, F.W.; Nevitt, M.C.; Hunter, D.J. Is synovitis detected on noncontrast-enhanced magnetic resonance imaging associated with serum biomarkers and clinical signs of effusion? Data from the osteoarthritis initiative. Scand. J. Rheumatol. 2018, 47, 235-242. [CrossRef] [PubMed]

234. Bobacz, K.; Maier, R.; Fialka, C.; Ekhart, H.; Woloszczuk, W.; Geyer, G.; Erlacher, L.; Smolen, J.; Graninger, W.B. Is pro-matrix metalloproteinase-3 a marker for posttraumatic cartilage degradation? Osteoarthr. Cartil. 2003, 11, 665-672. [CrossRef]

235. Conaghan, P.G.; D'Agostino, M.A.; Le Bars, M.; Baron, G.; Schmidely, N.; Wakefield, R.; Ravaud, P.; Grassi, W.; Martin-Mola, E.; So, A.; et al. Clinical and ultrasonographic predictors of joint replacement for knee osteoarthritis: Results from a large, 3-year, prospective EULAR study. Ann. Rheum. Dis. 2010, 69, 644-647. [CrossRef] [PubMed]

236. Group, M.K.; Jones, M.H.; Oak, S.R.; Andrish, J.T.; Brophy, R.H.; Cox, C.L.; Dunn, W.R.; Flanigan, D.C.; Fleming, B.C.; Huston, L.J.; et al. Predictors of radiographic osteoarthritis 2 to 3 years after anterior cruciate ligament reconstruction: Data from the moon on-site nested cohort. Orthop. J. Sports Med. 2019, 7, 2325967119867085.

237. Bodkin, S.G.; Werner, B.C.; Slater, L.V.; Hart, J.M. Post-traumatic osteoarthritis diagnosed within 5 years following ACI reconstruction. Knee Surg. Sports Traumatol. Arthrosc. 2020, 28, 790-796. [CrossRef]

238. Khan, T.; Alvand, A.; Prieto-Alhambra, D.; Culliford, D.J.; Judge, A.; Jackson, W.F.; Scammell, B.E.; Arden, N.K.; Price, A.J. Acl and meniscal injuries increase the risk of primary total knee replacement for osteoarthritis: A matched case-control study using the clinical practice research datalink (CPRD). Br. J. Sports Med. 2019, 53, 965-968. [CrossRef] [PubMed]

239. Bittersohl, B.; Hosalkar, H.S.; Miese, F.R.; Schibensky, J.; Konig, D.P.; Herten, M.; Antoch, G.; Krauspe, R.; Zilkens, C. Zonal t2* and $\mathrm{t} 1 \mathrm{gd}$ assessment of knee joint cartilage in various histological grades of cartilage degeneration: An observational in vitro study. BMJ Open 2015, 5, e006895. [CrossRef]

240. Tschaikowsky, M.; Selig, M.; Brander, S.; Balzer, B.N.; Hugel, T.; Rolauffs, B. Proof-of-concept for the detection of early osteoarthritis pathology by clinically applicable endomicroscopy and quantitative ai-supported optical biopsy. Osteoarthr. Cartil. 2020. [CrossRef] [PubMed]

241. Meinhardt, M.; Luck, S.; Martin, P.; Felka, T.; Aicher, W.; Rolauffs, B.; Schmidt, V. Modeling chondrocyte patterns by elliptical cluster processes. J. Struct. Biol. 2012, 177, 447-458. [CrossRef]

242. Millerand, M.; Berenbaum, F.; Jacques, C. Danger signals and inflammaging in osteoarthritis. Clin. Exp. Rheumatol. 2019, 37 (Suppl. 120), 48-56. [PubMed]

243. Minguzzi, M.; Cetrullo, S.; D’Adamo, S.; Silvestri, Y.; Flamigni, F.; Borzi, R.M. Emerging players at the intersection of chondrocyte loss of maturational arrest, oxidative stress, senescence and low-grade inflammation in osteoarthritis. Oxid. Med. Cell Longev. 2018, 2018, 3075293. [CrossRef]

244. Ershler, W.B. Interleukin-6: A cytokine for gerontologists. J. Am. Geriatr. Soc. 1993, 41, 176-181. [CrossRef]

245. Maggio, M.; Guralnik, J.M.; Longo, D.L.; Ferrucci, L. Interleukin-6 in aging and chronic disease: A magnificent pathway. J. Gerontol. A Biol. Sci. Med. Sci. 2006, 61, 575-584. [CrossRef] [PubMed]

246. Franceschi, C.; Bonafe, M.; Valensin, S.; Olivieri, F.; De Luca, M.; Ottaviani, E.; De Benedictis, G. Inflamm-aging. An evolutionary perspective on immunosenescence. Ann. N. Y. Acad. Sci. 2000, 908, 244-254. [CrossRef] [PubMed]

247. Franceschi, C.; Campisi, J. Chronic inflammation (inflammaging) and its potential contribution to age-associated diseases. J. Gerontol. A Biol. Sci. Med. Sci. 2014, 69 (Suppl. 1), S4-S9. [CrossRef]

248. Rezus, E.; Cardoneanu, A.; Burlui, A.; Luca, A.; Codreanu, C.; Tamba, B.I.; Stanciu, G.D.; Dima, N.; Badescu, C.; Rezus, C. The link between inflammaging and degenerative joint diseases. Int. J. Mol. Sci. 2019, 20, 614. [CrossRef]

249. Whittaker, J.L.; Woodhouse, L.J.; Nettel-Aguirre, A.; Emery, C.A. Outcomes associated with early post-traumatic osteoarthritis and other negative health consequences 3-10 years following knee joint injury in youth sport. Osteoarthr. Cartil. 2015, 23, 1122-1129. [CrossRef] [PubMed]

250. Roos, E.M. Joint injury causes knee osteoarthritis in young adults. Curr. Opin. Rheumatol. 2005, 17, 195-200. [CrossRef] [PubMed] 
251. Lees, S.; Golub, S.B.; Last, K.; Zeng, W.; Jackson, D.C.; Sutton, P.; Fosang, A.J. Bioactivity in an aggrecan 32-mer fragment is mediated via toll-like receptor 2. Arthritis Rheumatol. 2015, 67, 1240-1249. [CrossRef] [PubMed]

252. Miller, R.E.; Ishihara, S.; Tran, P.B.; Golub, S.B.; Last, K.; Miller, R.J.; Fosang, A.J.; Malfait, A.M. An aggrecan fragment drives osteoarthritis pain through toll-like receptor 2. JCI Insight 2018, 3, e95704. [CrossRef]

253. Han, B.; Li, Q.; Wang, C.; Patel, P.; Adams, S.M.; Doyran, B.; Nia, H.T.; Oftadeh, R.; Zhou, S.; Li, C.Y.; et al. Decorin regulates the aggrecan network integrity and biomechanical functions of cartilage extracellular matrix. ACS Nano 2019, 13, 11320-11333. [CrossRef] [PubMed]

254. Moreth, K.; Iozzo, R.V.; Schaefer, L. Small leucine-rich proteoglycans orchestrate receptor crosstalk during inflammation. Cell Cycle 2012, 11, 2084-2091. [CrossRef] [PubMed]

255. Ding, L.; Buckwalter, J.A.; Martin, J.A. Damps synergize with cytokines or fibronectin fragment on inducing chondrolysis but lose effect when acting alone. Mediat. Inflamm. 2017, 2017, 2642549. [CrossRef]

256. Ding, L.; Guo, D.; Homandberg, G.A.; Buckwalter, J.A.; Martin, J.A. A single blunt impact on cartilage promotes fibronectin fragmentation and upregulates cartilage degrading stromelysin-1/matrix metalloproteinase-3 in a bovine ex vivo model. J. Orthop. Res. 2014, 32, 811-818. [CrossRef]

257. Fujihara, Y.; Abe, T.; Asawa, Y.; Nishizawa, S.; Saijo, H.; Hikita, A.; Hoshi, K. Influence of damage-associated molecular patterns from chondrocytes in tissue-engineered cartilage. Tissue Eng. Part A 2020. [CrossRef]

258. Aulin, C.; Lassacher, T.; Palmblad, K.; Erlandsson Harris, H. Early stage blockade of the alarmin hmgb1 reduces cartilage destruction in experimental OA. Osteoarthr. Cartil. 2020, 28, 698-707. [CrossRef]

259. Wenzhao, L.; Jiangdong, N.; Deye, S.; Muliang, D.; Junjie, W.; Xianzhe, H.; Mingming, Y.; Jun, H. Dual regulatory roles of hmgb1 in inflammatory reaction of chondrocyte cells and mice. Cell Cycle 2019, 18, 2268-2280. [CrossRef]

260. Rosenberg, J.H.; Rai, V.; Dilisio, M.F.; Sekundiak, T.D.; Agrawal, D.K. Increased expression of damage-associated molecular patterns (DAMPS) in osteoarthritis of human knee joint compared to hip joint. Mol. Cell. Biochem. 2017, 436, 59-69. [CrossRef]

261. Xu, M.; Bradley, E.W.; Weivoda, M.M.; Hwang, S.M.; Pirtskhalava, T.; Decklever, T.; Curran, G.L.; Ogrodnik, M.; Jurk, D.; Johnson, K.O.; et al. Transplanted senescent cells induce an osteoarthritis-like condition in mice. J. Gerontol. A Biol. Sci. Med. Sci. 2017, 72, 780-785. [CrossRef]

262. Peilin, W.; Songsong, T.; Chengyu, Z.; Zhi, C.; Chunhui, M.; Yinxian, Y.; Lei, Z.; Min, M.; Zongyi, W.; Mengkai, Y.; et al. Directed elimination of senescent cells attenuates development of osteoarthritis by inhibition of c-iap and xiap. Biochim. Biophys. Acta Mol. Basis Dis. 2019, 1865, 2618-2632. [CrossRef]

263. Vinatier, C.; Dominguez, E.; Guicheux, J.; Carames, B. Role of the inflammation-autophagy-senescence integrative network in osteoarthritis. Front. Physiol. 2018, 9, 706. [CrossRef]

264. Jeon, O.H.; Kim, C.; Laberge, R.M.; Demaria, M.; Rathod, S.; Vasserot, A.P.; Chung, J.W.; Kim, D.H.; Poon, Y.; David, N.; et al. Local clearance of senescent cells attenuates the development of post-traumatic osteoarthritis and creates a pro-regenerative environment. Nat. Med. 2017, 23, 775-781. [CrossRef]

265. Jeon, O.H.; David, N.; Campisi, J.; Elisseeff, J.H. Senescent cells and osteoarthritis: A painful connection. J. Clin. Investig. 2018, 128, 1229-1237. [CrossRef]

266. Martin, J.A.; Brown, T.; Heiner, A.; Buckwalter, J.A. Post-traumatic osteoarthritis: The role of accelerated chondrocyte senescence. Biorheology 2004, 41, 479-491. [PubMed]

267. Philipot, D.; Guerit, D.; Platano, D.; Chuchana, P.; Olivotto, E.; Espinoza, F.; Dorandeu, A.; Pers, Y.M.; Piette, J.; Borzi, R.M.; et al. P16ink4a and its regulator mir-24 link senescence and chondrocyte terminal differentiation-associated matrix remodeling in osteoarthritis. Arthritis Res. Ther. 2014, 16, R58. [CrossRef]

268. Jun, J.I.; Lau, L.F. Cellular senescence controls fibrosis in wound healing. Aging 2010, 2, 627-631. [CrossRef]

269. Demaria, M.; Ohtani, N.; Youssef, S.A.; Rodier, F.; Toussaint, W.; Mitchell, J.R.; Laberge, R.M.; Vijg, J.; Van Steeg, H.; Dolle, M.E.; et al. An essential role for senescent cells in optimal wound healing through secretion of pdgf-aa. Dev. Cell 2014, 31, 722-733. [CrossRef] [PubMed]

270. Jeon, O.H.; Wilson, D.R.; Clement, C.C.; Rathod, S.; Cherry, C.; Powell, B.; Lee, Z.; Khalil, A.M.; Green, J.J.; Campisi, J.; et al. Senescence cell-associated extracellular vesicles serve as osteoarthritis disease and therapeutic markers. JCI Insight 2019, 4. [CrossRef] [PubMed]

271. McCulloch, K.; Litherland, G.J.; Rai, T.S. Cellular senescence in osteoarthritis pathology. Aging Cell 2017, 16, 210-218. [CrossRef]

272. Eskelinen, A.S.A.; Tanska, P.; Florea, C.; Orozco, G.A.; Julkunen, P.; Grodzinsky, A.J.; Korhonen, R.K. Mechanobiological model for simulation of injured cartilage degradation via pro-inflammatory cytokines and mechanical stimulus. PLoS Comput. Biol. 2020, 16, e1007998. [CrossRef]

273. Heijink, A.; Gomoll, A.H.; Madry, H.; Drobnic, M.; Filardo, G.; Espregueira-Mendes, J.; Van Dijk, C.N. Biomechanical considerations in the pathogenesis of osteoarthritis of the knee. Knee Surg. Sports Traumatol. Arthrosc. 2012, 20, 423-435. [CrossRef]

274. Griffin, T.M.; Guilak, F. The role of mechanical loading in the onset and progression of osteoarthritis. Exerc. Sport. Sci. Rev. 2005, 33, 195-200. [CrossRef]

275. Perruccio, A.V.; Chandran, V.; Power, J.D.; Kapoor, M.; Mahomed, N.N.; Gandhi, R. Systemic inflammation and painful joint burden in osteoarthritis: A matter of sex? Osteoarthr. Cartil. 2017, 25, 53-59. [CrossRef] [PubMed]

276. Schwarz, S.; Mrosewski, I.; Silawal, S.; Schulze-Tanzil, G. The interrelation of osteoarthritis and diabetes mellitus: Considering the potential role of interleukin-10 and in vitro models for further analysis. Inflamm. Res. 2018, 67, 285-300. [CrossRef] 
277. Courties, A.; Sellam, J. Osteoarthritis and type 2 diabetes mellitus: What are the links? Diabetes Res. Clin. Pract. 2016, 122, 198-206. [CrossRef]

278. Louati, K.; Vidal, C.; Berenbaum, F.; Sellam, J. Association between diabetes mellitus and osteoarthritis: Systematic literature review and meta-analysis. RMD Open 2015, 1, e000077. [CrossRef] [PubMed]

279. Zeggini, E.; Panoutsopoulou, K.; Southam, L.; Rayner, N.W.; Day-Williams, A.G.; Lopes, M.C.; Boraska, V.; Esko, T.; Evangelou, E.; Hoffman, A.; et al. Identification of new susceptibility loci for osteoarthritis (arcogen): A genome-wide association study. Lancet 2012, 380, 815-823. [PubMed]

280. Reynard, L.N.; Barter, M.J. Osteoarthritis year in review 2019: Genetics, genomics and epigenetics. Osteoarthr. Cartil. 2020, 28, 275-284. [CrossRef] [PubMed]

281. Lauer, J.C.; Selig, M.; Hart, M.L.; Kurz, B.; Rolauffs, B. Articular chondrocyte phenotype regulation through the cytoskeleton and the signaling processes that originate from or converge on the cytoskeleton: Towards a novel understanding of the intersection between actin dynamics and chondrogenic function. Int. J. Mol. Sci. 2021. submitted. 